\title{
Brokk Eduration
}

A Journal of Edurational

\section{Resparth \& Pratiog}

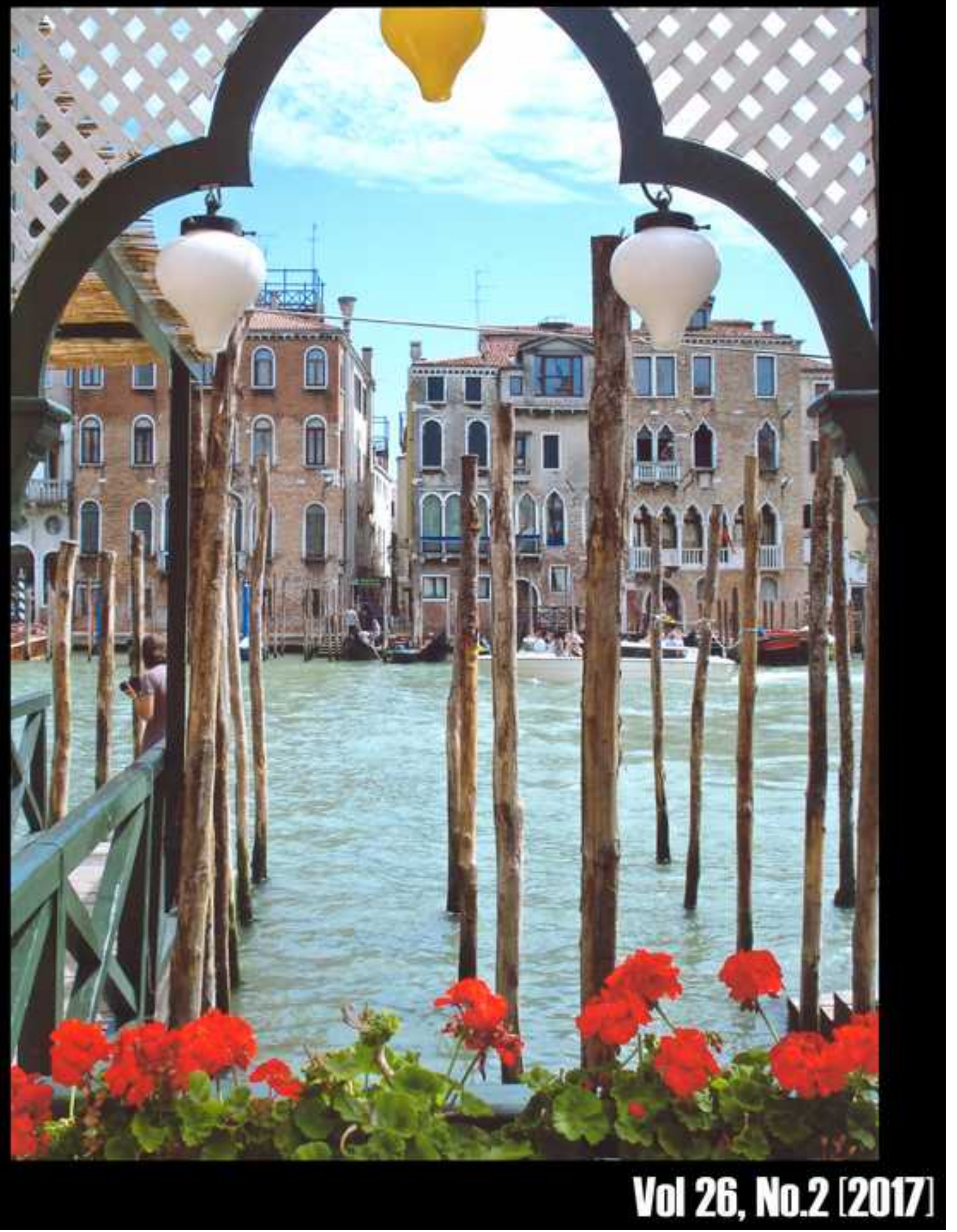




\section{Table of Contents}

Brock Education Journal, 26(2), 2017

Editorial: Research Inquiry for Whom and for What Purpose?

Dolana Mogadime.

p. $1-3$

A Family Affair: Caring in Teaching and Implications for Teacher and Researcher Preparation James A. Bernauer, Mary Pat Bernauer, McCarthy, Patrick J. Bernauer...... p. 4 - 15

A Communities of Practice Approach to Field Experiences in Teacher Education

Connor Kirwan Warner and Heidi L. Hallman.

p. $16-33$

Non-Indigenous Women Teaching Indigenous education: A Duoethnographic Exploration of Untold Stories

Sarah Burm and Dawn Burleigh

p. $34-46$

What Informs and Inspires the Work of Equity Minded Teachers

Stephanie Tuters

p. $47-61$

Teacher Stress and Social Support Usage

Kristen Ferguson, Colin Mang, and Lorraine Frost.

p. $62-86$

The Impact of Use of Manipulatives on the Math Scores of Grade 2 Students

Robert Scott Liggett.

p. $87-101$

THE DIAGNOSIS DILEMMA: DYSLEXIA AND VISUAL-SPATIAL ABILITY

Donna Kotsopoulos, Joanna Zambrzycka; Samantha Makosz, Emma Asdrubolini, Jovana Babic, Olivia Best , Tara Bines, Samantha Cook, Natalie Farrell, Victoria Gisondi, Meghan Scott, Christina Siderius, Dyoni Smith p. $102-110$ 
Exploring Native and Non-Native EFL Teachers' Oral Corrective Feedback Practices: An Observational Study

Yusuf Demir and Kemal Sinan Özmen........................................................................ p. 111-129

Book Review: Ipsative Assessment: Motivation Through Marking Progress

Jeff Irvine............................................................................................................ p. $130-133$ 


\section{Editorial:}

\section{Research Inquiry for Whom and for What Purpose?}

\section{Dolana Mogadime}

Editor-in-chief

Brock University

What drives research inquiry? Why do researchers formulate an inquiry as they do? How do we support the development of improved human relationships through research? These are a set of questions uniquely answered by James A. Bernauer, Mary Pat Bernauer and Patrick Bernauer (2017) in their coauthored collaborative article featured in this issue entitled, "A Family Affair: Caring in Teaching and Implications for Teacher and Researcher Preparation." The Bernauers' family inquiry sets the stage for a better understanding about the role of care in education. Of interest, are recommendations the authors advance with reference to improving teacher education. Connor Kirwan Warner and Heidi L. Hallman's (2017) article entitled, "A Communities of Practice Approach to Field Experiences in Teacher Education," delves into questions about how inquiry can enrich and improve the practicum experience for teacher candidates. They argue for the incorporation of Community of Practice $(\mathrm{CoP})$ as a shared goal for both teacher educators and the school based teachers who mentor student teachers. Using two case studies drawn from a larger set of interviews with 17 teacher candidates, the authors provide a "Continuum of Participation in Community of Practice" (p. 21). Locating the case studies on this continuum facilitates an angle through which to better understand and articulate how and why a given student is located differentially. The study's recommendations suggest a stronger partnership and collaboration between universities and schools. Further, such as suggestion corroborates with directives from both the Accord on Initial Teacher Education (ACDE, 2016) in Canada as it does the Council for the Accreditation of Educator Preparation (CAEP) in the United States.

Sarah Burm and Dawn Burleigh's (2017) inquiry, "Non-Indigenous Women Teaching Indigenous education: A Duoethnographic Exploration of Untold Stories about their teaching practices," invites the reader into their parallel journey into becoming, living and sustaining authenticity within their dual roles as non-Indigenous educators teaching about Indigenous education. Imploring the duoethnographic inquiry approach, allows the authors to engage in critical self-reflection on their teaching positions with the view to become personally accountable to living allyship. Put simply, they challenge one another to walk the talk, through delving into their 'untold stories.' Burm and Burleigh utilize what they term as 'four conversational sites.' These are places and spaces in which they socially interact as scholars, educators and people, daily. The significance of this work is that the duoethnographic inquiry read with the authenticity in which it is written holds potential to challenge the reader educator to undergo a similar journey toward a better understanding about our multiple roles in learning, supporting and responding to the call to Indigenize Canadian universities. Stephanie Tuters' (2017) inquiry entitled, "What Informs and Inspires the Work of Equity Minded Teachers, " focuses on questions about what encourages and motivates teachers to engage in equity based approaches in teaching. The inquiry draws from interviews with 15 teachers, located in three different school boards. Tuter's 
contribution is important within the current milieu, particularly in Ontario, with the equity and inclusive strategy on one hand and lack of research data on the personal contexts for why teachers become interested in doing equity work. Her argument about 'equity minded' educators' unearths the inner terrain of the teacher to arrive at how critical incidents in their life stories inform their interest in equity. Furthermore, this knowledge has implications for teacher education and teachers in the field. Tuter points out that her research findings can be used as a baseline for further investigations into what informs teachers decisions to become aligned with equity based approaches. As well, it may encourage educators to take-up an interest in becoming equity minded teachers. Kristen Ferguson, Colin Mang and Lorraine Frost's (2017) inquiry about "Teacher stress and support usage" suggests strategies to attain work life balance need greater attention. The researchers used 264 surveys from teachers in northern Ontario to examine "the impact of social supports based on the frequency with which teachers spoke to others about stress" (p. 63). The study is significant because teacher attrition is becoming an area of concern as increasing research reports identify that improved supports could reduce attrition. The implications of the study make known the role that teacher education programs can play in instilling the importance of stress management and well-being as an integral part of the professional learning. Further, they argue that the focus on well-being needs to begin in teacher education but continue throughout teachers' careers via ongoing professional learning contexts.

Robert Scott Liggett's (2017) inquiry, "The Impact of Use of Manipulatives on the Math Scores of Grade 2 Students." is contextualized within "the pressure on schools, teachers, and students to improve test scores" (p. 87). This is made evident in media coverage highlighting the need for improvement among Saskatchewan students' performance in math. Liggett's contribution advances discussion and consideration for the possibility of using mathematical manipulatives to support improved math test scores as well as students attitude toward math. Forty-three Grade 2 students participated in the study. Liggett's review of the literature accounts for decade-long debates regarding mathematics pedagogy in relation to the uses of manipulates. Liggett focuses the reader on the goals of his research within such debates when he states,

School professionals are constantly looking for methods to improve student learning. Achieving this will require effort and the use of multiple strategies or methods. The goal of this quasi-experimental study was to provide information about the value of manipulatives as another tool that is available to assist educators in the endeavor of improving student learning. (Liggett, 2017, p. 88-89)

Liggett argues that given we find ourselves within an era that demands both school boards and teachers improve test results, the uses of manipulatives should be taken as a serious and viable solution, particularly when backed by research inquiry. Educators and school boards will be better served by having knowledge of the debates and how Liggett's experiential research fits within the larger discussion of solutions. Donna Kotsopoulos et al., (2017) in their coauthored article entitled, "The Diagnosis Dilemma: Dyslexia and Visual-Spatial Ability," provide an inquiry that makes an important point regarding research participants, research designs and equity. The final section of the article is both intriguing and provides scope for new research emerging, as a result of the inquiry. While this article is primarily a commentary appended to the beginnings of a research report that took a different turn, it makes a contribution and provides an interesting set of questions in need of further investigation by the field. 
Coauthors, Yusuf Demir and Kemal Sinan Özmen (2017) in "Exploring Native and Non-Native EFL Teachers' Oral Corrective Feedback Practices: An Observational Study,” draw from Demir's doctoral research study in Turkey, based on classroom observations and interviews conducted with seven native and non-native English-speaking teachers NESTs and seven NNESTs. While the coauthors argue that "oral corrective feedback (OCF) is an interactional classroom phenomenon which frequently occurs in foreign language classes and has gained growing momentum in Second Language Acquisition (SLA) research in recent years," (p. 111) Demir and Özmen's inquiry questions the fact that the role of the teacher as a variable in facilitating OCF has become underresearched and marginalized. The authors make known the limitations in professional knowledge when they point out that teacher education provides limited opportunities for student teachers to develop Second Language pedagogies. Their research therefore attempts to fill this gap. All the inquiries featured in the current issue, based in Canada, the United States, and Turkey, unanimously call for teacher education programs as well as stakeholders to oversee ongoing professional learning for teachers, to provide new and improved content to ameliorate the concerns, issues and problems raised in their studies. As such, they provide research results that are of interest to both teacher education institutions as well as school-based partners vested with supporting ongoing professional learning among teachers.

\section{References}

Association of Canadian Deans of Education (ACED) (2016). Accord on initial teacher education. Retrieved from http://www.csse-scee.ca/docs/acde/ACDE_Accord_on_Initial_Teacher_Education.pdf

Bernauer, J. A., Bernauer, M. P., \& Bernauer, P. (2017). A Family Affair: Caring in Teaching and Implications for Teacher and Researcher Preparation. Brock Education: A Journal of Educational Research and Practice, 26(2), 4-15.

Burm, S., \& Burleigh, D. (2017). Non-Indigenous Women Teaching Indigenous education: A Duoethnographic Exploration of Untold Stories about their teaching practices. Brock Education: A Journal of Educational Research and Practice, 26(2), $34-46$.

Council for the Accreditation of Educator Preparation (CAEP). (2015). Standard 2: Clinical partnerships and practice. Retrieved from http://caepnet.org/standards/standard-2

Demir, Y., \& Özmen, K. S. (2017). Exploring Native and Non-Native EFL Teachers' Oral Corrective Feedback Practices: An Observational Study. Brock Education: A Journal of Educational Research and Practice, 26(2), 111-129.

Ferguson, K., Mang, C., \& Frost, L. (2017). Teacher stress and support usage. Brock Education: A Journal of Educational Research and Practice, 26(2), 62 - 86.

Kotsopoulos, D. et al., (2017). The Diagnosis Dilemma: Dyslexia and Visual-Spatial Ability. Brock Education: A Journal of Educational Research and Practice, 26(2), $102-110$.

Liggett, R. S. (2017) The Impact of Use of Manipulatives on the Math Scores of Grade 2 Students. Brock Education: A Journal of Educational Research and Practice, 26(2), 87 - 101.

Tuters, S. (2017). What Informs and Inspires the Work of Equity Minded Teachers. Brock Education: $A$ Journal of Educational Research and Practice, 26(2), 47 - 61.

Warner, C. K., \& Hallman, H. L. (2017). A Communities of Practice Approach to Field Experiences in Teacher Education. Brock Education: A Journal of Educational Research and Practice, 26(2), 16 33. 


\title{
A Family Affair: Caring in Teaching and Implications for Teacher and Researcher Preparation
}

\author{
James A. Bernauer \\ Robert Morris University \\ Mary Pat Bernauer \\ McCarthy Training and Consulting \\ Patrick J. Bernauer \\ University of Dayton
}

\begin{abstract}
The purpose of this study was to explore how perceptions of remembered instances of teacher caring in K-College impacted the motivation of a college student. Implications for teacher preparation programs and educational research were then drawn from these perceptions. The first part of the title "A Family Affair" stems from the fact that the authors are members of the same family - Father, Mother, and Son. Both the father and mother had prior knowledge of some (not all) of the instances of caring and non-caring described by their son and thus shared a privileged insider position that offered unique insights while cooperative peer checking was used both during and after the interview to help promote the trustworthiness of findings. It was found that the degree of caring shown by teachers had a profound influence on the participant's willingness to put forth effort especially in those courses that were not his favorite subjects which suggests that a strong connection exists between caring and student motivation. An important implication of this study is that teachers and those responsible for teacher preparation programs would benefit by being aware of the impact of caring on students' engagement and attitude toward learning. If the ultimate purpose of educational research is to contribute to effective teaching, then the "soft variable" of caring should be considered an important component of researcher preparation. It is hoped that readers will find this study to be transferable to the degree that it resonates with their own experience as teachers, students, and parents, and which we refer to as "experiential validity".
\end{abstract}

Keywords: Caring, experiential validity, oral coding, perceptual realities, qualitative tradition, quantitative tradition

James A. Bernauer is a Professor of Education at Robert Morris University in Pittsburgh, PA. (USA) where he teaches educational psychology, qualitative methodology, and quantitative methodology.

Bernauer@rmu.edu

Mary Pat Bernauer is the owner of McCarthy Training and Consulting in Pittsburgh, PA where she trains individuals and corporations on Microsoft and other specialty software.

mpmccarthy@pobox.com

Patrick J. Bernauer is a senior at the University of Dayton in Dayton, $\mathrm{OH}$ where he is majoring in Digital Media and journalism.

Bernauerp1@udayton.edu

Brock Education Journal, 26(2), 2017 
"I wish I could care what you do or where you go but I can't... My dear, I don't give a damn." (Gone With The Wind, 1939)

"For I don't care too much for money, for money can't buy me love" (Can't Buy Me Love, The Beatles, 1964)

"The longer we consider and examine the present day methods of education, the more clearly we recognise that children lack the care and consideration which would be in accord with their present and future needs, a care which considers equally the child's mental and physical needs and capacities. We notice that if children are not given the care which takes their stage of human development into consideration, they will lack the foundation for the task ahead in school and for their later lives in general." (Friedrich Froebel, Founder of Kindergarten, 17821852; Moore, 1991)

“They don't care what we know until they know that we care." (Madeline Hunter, 1982)

The above array of quotes (where care and caring have been emphasized) convey some of the meanings and nuances that can be used to define these terms. In this article, the concept of caring in education was investigated from the perspective of a SonResearcher (SR) and further elucidated by the Mother-Researcher (MR). SR was the primary focus in this study since he was asked by the Father-Researcher (FR) to share his experiences and perspectives related to remembered instances of caring and non-caring during his elementary, high school, and college years during a group interview.

The following Research Questions guided data collection:

$R Q 1$. What instances of caring and non-caring does $S R$ readily recall from elementary and high school and to what extent are these recalled instances perceived by $S R$ as having a continuing impact on motivation to do well in college?

$R Q 2$. What instances of caring and non-caring does $S R$ readily recall from college during his Freshman and Sophomore years and to what extent are these recalled instances perceived by $S$ as having a continuing impact on his motivation to do well in college?

RQ3. Based on recalled instances of caring and non-caring in elementary school, high school, and college, what suggestions would SR make to help teachers and professors make a stronger impact on their students in terms of their motivation to do well in school and to pursue their career aspirations?

RQ4: What perspectives are offered by $M R$ in relation to $R Q 1$ to $R Q 3$ ?

FR envisioned these questions as a fertile field for transforming data via "description, analysis, and interpretation" (Wolcott, 1994) including both tacit and propositional knowledge (Polanyi, 1962) in order to understand the role of caring in relation to 
teaching, learning, and research. It was anticipated that themes would emerge from intrafamily dialogue where the interactions among MR, SR, and FR were seen as positive contributions toward understanding the influence of caring on learning and motivation rather than as a source of "bias". FR used dialogue coupled with empathetic understanding and reflection as a type of "member checking" to promote the trustworthiness of data and to integrate tacit knowledge including emotion, intuition, and body language with propositional knowledge that was conveyed via straight-forward language captured in the oral responses. The ultimate aim was to get to the heart of the matter regarding the impact of caring on students and therefore its potential role in both teacher and researcher preparation programs.

\section{The Qualitative and Quantitative Traditions}

Is it not sometimes the case that we qualitative researchers believe that our quantitatively-oriented colleagues do not care as much as we do about participants and that these colleagues think that qualitative research is inferior to quantitative research? One older and one more recent source may weaken this belief. Bauswell (1994) introduces his book Conducting Meaningful Experiments: 40 Steps to Becoming a Scientist by first saying that "meaningfulness" can be defined in different ways by different people but that "I happen to define a meaningful research study as one that has the potential of actually helping people and improving the human condition" (p. 1). Pilcher and Cortazzi (2016) interviewed 17 researchers who leaned quantitatively and found that most of them not only did not deprecate qualitative approaches but found these approaches to be valuable to scientific inquiry. So, even if we differ with our quantitatively-oriented colleagues in terms of epistemology and methods, it might be beneficial to remind ourselves once in awhile that we are all on the same team and we hope that this article is received in this same spirit!

\section{Purpose of Education}

Purpose is behind everything that we do. In the case of education, aspiring teachers are typically required to arrive at their own "philosophy of education" that captures their values and beliefs. Here is our suggested statement of educational purpose --

The purpose of education is help students grow artistically, cognitively, emotionally, morally, and socially within a safe, encouraging, and caring environment, leave as lifetime adventurers who are ever ready to question and learn about themselves, others, and their world, and to meaningfully contribute to the interrelated welfare of self, others, and world throughout their lives.

Purpose is described here in terms of growth and caring in relation to five inborn capacities and provided a context for both data collection and data analysis in this study. We additionally suggest that this purpose statement can provide a sound basis for developing and improving teacher and researcher preparation programs.

\section{Framework and Methods}

A group interview was conducted on August 4, 2016 and FR tried to keep the stated 
educational purpose firmly in mind during this interview. Based on the process of Oral Coding (2015a), both analysis and interpretation were refined in the weeks that followed. Oral Coding was used to analyze interview data because it relies on an aural-oral approach for making sense of data. FR introduced the process of Oral Coding in a study that focused on higher education (Bernauer, Semich, Klentzin, \& Holdan, 2013) where one of his co-authors used phenomenological coding while FR used Oral Coding to analyze data that were collected during focus group sessions. It was found that there was substantial agreement across findings and interpretations. FR then used Oral Coding in a study that explored the remembrances of graduates of Catholic schools over several decades and found that Oral Coding helped to preserve the unique voices of participants as he went about transforming raw data into written text (Bernauer, 2015b). Finally, FR attempted to codify Oral Coding more explicitly into seven steps (Bernauer, 2015a).

While analyzing data for this current study, FR found that, while he adhered to the spirit of the seven steps, that he drifted from them especially in the way that the three technologies of GarageBand on the Mac laptop that was used to initially record the interview, QuickVoice Pro on the IPhone that served as the secondary recording device, and Dragon Dictate on the Mac that was used to transcribe from voice to text in Microsoft Word overlapped and intersected. Consequently, it would be difficult to describe the exact sequence of using these technologies because FR found himself "jumping around" among them and would be hard-pressed to try and present a linear account of a very non-linear process. Nonetheless, FR intends to continue experimenting with this method of transforming data that will hopefully serve to generate useful information to those who are interested in using this method in their own work.

In addition to the foundational role of educational purpose, Cooper and Garner (2012) stress that the sequence of Relationships-Relevance-Rigor is critical since developing relationships with students lays the necessary prerequisite for the other two components of effective teaching. In addition both Noddings (2005) and Heshusius (1996) provide persuasive arguments for positioning caring into any discussion of teaching and learning. FR also tried to follow Wolcott's (1994) suggestion to transform qualitative data into a written account through description - analysis - interpretation while recognizing that in the actual practice of making sense of data, that these processes often overlap. FR also tried to incorporate the ideas related to critical thinking in qualitative data analysis (Bernauer, Lichtman, Jacobs, \& Robertson, 2013). These sources offer a framework for making sense of qualitative data and it was within this framework that FR utilized "Oral Coding" to analyze and interpret data in relation to the question of caring in education using a multi-phase process using voice recordings to transform data into a written account rather than using verbatim transcriptions of oral data. Finally, while there was only one primary informant (SR) and two secondary informants (MR and FR), it is hoped that readers will identify their own points of connection based on their personal experiences as teachers, students, and/or parents. We refer to these connections as exemplifying experiential validity and offer this concept in lieu of "external generalizability" under the quantitative tradition.

\section{Description, Analysis, and Interpretation}

SR was a first semester junior in college at the time of the interview and although major psychological and emotional changes occur as a result of "going away to college", 
the interview was only about two years removed from when SR graduated from high school so the memories of caring and non-caring from his high school days were still relatively fresh. Probably more importantly, if we subscribe to the notion that "we may forget what people say but we will never forget how they made us feel" then remembrances that had an emotional impact on us (for good or ill) are still readily available to us even if these remembered instances were from our younger years. It is within this context that the responses from SR should be understood.

What follows are first the conversation prompts derived from the purpose of this study followed by description, analysis, and interpretation of the data that SR provided in response to these prompts. It should also be pointed out that while both SR and MR knew that the purpose of this group interview was to recall instances of caring and non-caring in school and to tease out impacts on motivation and learning, no specific examples were discussed in advance. Rather, the construct of caring was allowed to emerge as SR reflected upon these conversation prompts.

Prompt 1.1: Thinking about your days in elementary and high school, what instances of teacher caring or non-caring do you recall that had an effect on your motivation to do well in school?

Unfortunately, SR immediately related negative perceptions about his religion teacher in high school (SR attended a Catholic school). He said that during a typical 45 minute class, the teacher talked for 30 minutes about his own opinions and took no questions. SR also said that when a student got a question wrong on a test and asked about this question that the teacher's response was simply that "the answer was wrong and there was no more discussion or explanation." SR went on to say that this was probably the worst class that he ever had because it was simply "somebody standing up there telling students what he thought."

SR then related another instance of non-caring in high school when he described his English teacher from his junior (third) year. He said that whereas the religion teacher suffered from too much "self dialogue", his English teacher was almost the opposite. He described a typical class as one where students took turns reciting sections of literature by going up and down the rows. SR indicated that he felt like students were still being treated like they were in elementary school instead of individuals who were now capable of independent thinking. According to SR, this teacher sat at her desk, presumably listening to students read, while she did other work and then assigned homework for them to do at the end of the class.

As SR harkened back to elementary school, he recalled his fourth grade teacher as another example of non-caring similar to his examples from high school but he added that "at least we had a recess in elementary school whereas we did not in high school!" This elementary teacher was described not so much in terms of classroom practice but rather her demeanor and behavior in general. As noted above, SR indicated that unlike high school where he had to sit through long boring classes with no break, recess was a regular feature in elementary school. However, he said that when recess had to be held in the classroom because of bad weather, that the teacher would sit outside the door to the hallway and if any student's foot inadvertently would go beyond the threshold of the door that the student was immediately given a detention. SR indicated that "this type of 
teaching whether in elementary school, high school, or college results in students feeling like the teacher really does not care about them as individuals and so very little learning results."

In addition, SR referred to a "lack of respect" as being the major feeling he experienced during these times when caring was not demonstrated. It seems, based on these perceptions, that the personal characteristics of the teacher and the teacher's relationship to students were inextricably connected to student learning. Consequently, it may very well be that if teachers are not perceived as caring then their instructional methods may also be perceived as inadequate.

When encouraged to recall positive instances of caring in elementary school and high school, SR immediately said that "Mr. A" (a teacher in $8^{\text {th }}$ grade) is probably the most effective teacher I have had through my sophomore year of college." He described effectiveness in terms of the way that Mr. A interacted with him and his classmates and the respect that he showed towards their ideas and perspectives. SR described this interaction as one where Mr. A. did not place himself in a position of authority but rather where students felt like he listened to them as if "he was talking to another adult". SR said that consequently he and his classmates felt more "grown up" with this teacher and also felt like they mattered to him as individuals. He also identified "Mrs. D." who taught math in high school as a positive influence. SR confessed that he is not a "math person" but that Mrs. D. not only took the time to explain concepts to him that were unclear but did so on her own personal time such as before and after school or during lunch.

Prompt 1.2: To what extent do any of these instances of caring and non-caring continue to have an effect on you in terms of your motivation to do well in college?

Both of the instances of caring from high school described above regarding Mr. A. and Mrs. D. were not only deeply felt by SR but he said that they continue to have a positive impact on his learning in college. SR then abruptly posed this question "how can teachers in large lecture halls connect with their students?" and related this barrier to his negative elementary and high school experiences. The question about large lecture halls was actually the only connection to non-caring that the participant offered. He then went on to talk about three instances of caring that he has experienced as a college freshman and sophomore described next under Prompt 2. This was a welcome change from his predominant focus on instances of non-caring in elementary and high school.

Prompt 2: What instances of teacher caring or non-caring do you recall from your experiences thus far in college that have had a strong effect on your motivation to do well during the remainder of your college years and on your career aspirations?

The first instance described by the participant offered a great counterpoint to the negative experiences he described in high school. SR said that his college instructor for philosophy and theology, rather than lecture about his own thoughts and experiences like his high school teacher, so engaged him in the content "that it didn't matter how much time and work was needed -- I was motivated to learn because this teacher was very much interested in what he was teaching and also his students". SR went on to say that because of the obvious enthusiasm of the instructor and his concern for students that he 
was motivated to learn a subject that previously held little interest for him. During the interview he said that even though he was not Catholic (which was news to his parents) that he experienced valuable learning in this college class related to a deeper meaning of religion and that what he learned in grade school and high school was a sham. [both FR and MR tried to console themselves by classifying his response as a normal part of rebellion against all things parental]. He reiterated that while there was a lot of work required in this college class, he didn't care because he stressed that his college professor is the only religion teacher he ever liked because he cared and wanted them to learn.

The second instance of caring in college described by SR related to his Spanish teacher who required that assignments given every Monday, Wednesday, and Friday had to be submitted at the following class session. Regarding these assignments, he said that "while they were hard he gladly did them because he knew that the teacher really cared that he learned Spanish." He contrasted this positive experience with his negative high school English experience described earlier - "It was a lot different than doing mindless work at the end of the day in order to assign a grade."

He also cited high teacher expectations (for both his religion and Spanish teachers) as something that had a very positive effect on him although these expectations presented formidable challenges. However, he went on to say that the "personal care that these two teachers exhibited dwarfed the challenge of the work". He concluded his evaluation of these two teachers by saying that they were passionate about what they taught and passionate about their students. [At this point, FR engaged in some "private speech" about the "Three R's" (Relationships-Relevance-Rigor) as the necessary sequence for creating a "learning classroom" where students" engagement in learning is the primary focus (Cooper \& Garner, 2012)]. When asked about negative instances of caring in colleges his immediate response (again) was "lecture halls don't work" but he added that in college "you almost are treated as an adult" [this elicited a discrete smile from both MR and FR!].

SR then recalled a third instance of caring during college that did not involve a college instructor per se but rather the owner of a café named the "Spirited Goat" located near his college. SR identified this individual as a person who had a very positive impact on him because of the respect and caring he felt as well as the wisdom he shared. He went on to relate an experience he had where he had such a great conversation with the owner that he forgot to pay him and the owner also forgot to ask him to pay. SR related that he was so moved by the genuine caring shown by the owner "that I went out of my way to go back to the shop to pay what I owed". Although this instance was not "academic" in the sense of formal schooling, it reinforced the construct of caring and also demonstrates that valuable learning experiences should be recognized as extending "beyond the walls" of the school.

SR characterized all three of these individuals (religion, Spanish teacher, and café owner) by saying that "all three of them had a balance of relationships, professorship, and setting expectations and who took the time to form a relationship that formed the basis for my learning." SR also said that he wasn't sure where he picked up the following quote -- "they don't care what you know until they know that you care" but he said that it epitomized these three teachers. [FR knew that the quote was from Madeline Hunter that he must have shared earlier - kids really do listen sometimes!]. 
Prompt 3. Based on all of the examples you provided from Elementary, High School, and College, what would you suggest to teachers so that they could have a stronger positive effect on their students in terms of their wanting to do well in school and to pursue their career aspirations?

When asked this question SR immediately responded with "don't get comfortable". He then went on to say that his current experience working part time as a supervisor for a nutrition company taught him that he needs to "talk to the new person in the room" because everyone is learning something new including him and that both teachers and students should consider themselves as "perpetual students". He then said that teachers and professors should teach as if the labels of "teacher" and "student" are removed in order to create an environment where teachers are seen as fellow learners. He added that when he presents to a group of people that it's like he is "teaching and learning for the first time. When asked about the concept of caring, he connected it to the idea of us all being perpetual students "because teachers are human beings just like their students and that by learning right along with their students it comes across as genuine caring." The final research question applies to the Mother Researcher (MR) in terms of her reactions to the responses of SR.

Prompt 4. Based on what you have heard during this interview what reactions do you have?

While MR intentionally did not interject during the interview (except for saying that she really did not know how deeply negative experiences had affected SR), she now joined SR in discussing the ill effects of large lecture halls in college. She especially resonated with his feeling that he felt like he was treated like a number and that many students are lost both physically and mentally in such a large classroom environment. Because MR had experienced the same kind of environment in college, she commiserated with SR about this experience. In addition, because she owns her own company to educate adult students to use computer software, she was especially sensitive to the load on the teacher in such a large classroom since it prevents the teacher from developing any kind of relationship with students. She also agreed with SR that the workload for a teacher with such a large number of students would be quite overwhelming and again would prevent personal relationships and communication. This conversation between SR and MR ended the interview.

\section{Implications of Caring for Researcher and Teacher Preparation: FR's Reflections}

What is disturbing about SR's elementary and high school remembrances is not only the perceived lack of caring, but that these instances were foremost in the memory of SR rather than more positive experiences. It is also important to note the close connection between the teaching process and the impact on student perceptions of teachers caring about their students including their views and perspectives. In addition, what became most apparent during this interview was that SR automatically linked his interest and commitment to put forth effort in a subject matter, regardless of his prior interest, to the passion of teachers for their subject and the concern that they evidenced for their 
students. Hopefully someday positive remembrances will overshadow the negative instances in his mind.

I recognize that our more quantitatively-inclined colleagues would point out that there is too much "noise" or confounding of variables to be able to deem findings valid and therefore quite problematic for generalizing beyond this admittedly small sample size of $\mathrm{n}=1$. On the first count of noise and confounding of variables I plead "guilty" and happily so because I don't think that the complexity of human beings, including learning and teaching, is amenable to partitioning of variables. As for the second charge of findings not being valid, I also admit that, judged by the quantitative criteria of validity or even by the criteria of credibility put forward by some qualitative researchers, that the findings from this study would not be considered trustworthy especially since they are based on data obtained from just one primary participant. However, I appeal to readers to evaluate the findings of this study, not based on the traditional criteria of internal or external validity, but rather to draw upon their own life's experiences in order to come to their own conclusions about trustworthiness - we refer to this as experiential validity.

To carry this idea of experiential validity a bit further, I ask you to think back to those teachers who made a real difference in the way that you felt about a subject, yourself, or your future. Was it not those teachers who you perceived as caring about you as an individual who you still remember as having a positive impact on your life even if the particular way that it was expressed may have varied among these teachers? Whenever we find ourselves nodding in agreement as we think back to our own experiences throughout our lives, aren't we giving silent assent to the validity of what we hear now? In fact, whenever two or more individuals really agree on a perspective based on their own history and interpretation of this history, does this not constitute a type of validity because of a shared perceptual understanding of phenomena? And, while this shared understanding cannot be shown to be statistically generalizable, I venture to hypothesize that this generalizability could be confirmed through large-scale interviews.

So if our solitary participant does in fact speak for many of us then what might schools of education that prepare future teachers and those departments that prepare researchers take from these findings? I would suggest that caring, although not a variable that is typically used in prediction equations, is critically important in helping students to grow and achieve academically, emotionally, and socially. One of the things that I believe must happen is that education must shed the paradigm where scores on achievement tests, that are concerned primarily with right and wrong answers, serve as the primary indicators of student, teacher, or school success (Cooley \& Bernauer, 1991; Powell, Bernauer, \& Agnihorti, 2011). Rather, if we begin with the belief that every student has unique interests, motivations, capabilities, potential, and ability to learn, should we not first discover what motivates our students to learn and then adapt our teaching approaches based on this recognition?

If schools of education should include "soft" concepts such as caring in their preparation programs, what about programs that prepare students to conduct research in schools? While I was trained to become an educational researcher it was strictly in line with the quantitative paradigm where the search was on for "variables" that could be used to help "explain and predict" student cognitive achievement (as measured on tests) using techniques such as regression analysis and factor analysis. It is the ability to compartmentalize in order to arrive at cause-effect statements and then to generalize 
these statements that is at the heart of the quantitative paradigm. It seems that it would be both problematic and unwise to somehow transform the construct of caring into a variable that could be analyzed quantitatively. On the other hand, the qualitative paradigm can readily admit soft variables such as "caring" into its methodologies since it's ontology is not anchored in a stable reality that can be parceled into variables but rather is embedded in multiple perceptual realities.

A solution to this apparent problem may be for teacher preparation and educational research programs to not only talk about "mixed methods" but to also recognize that when it comes to the complexity of teaching and learning, that while quantitative methodologies can be used to investigate the impact of some aspects of the educational system (such as SES, expenditures, school size, etc.), that they are of limited usefulness when investigating the intimacy of teaching and learning. Rather, it is those very things that promote student motivation and interest in learning such as caring and high expectations that more than likely hold the real key to doing well academically. On the other hand, when it comes to assessing the impact of social and economic factors on schools, the sophisticated techniques employed by quantitative researchers admirably fit the bill. It is therefore suggested, based on the findings of this study and this researcher's own sense of "experiential validity", that educational research should start with the learner and then move outward to those influences that are more peripheral to teaching and learning. I am quite sure that there is a place for every type of educational inquiry as we search for ways to create a more caring and effective educational environment.

Looking to literature as another manifestation of experiential validity, Thomas Mann (1952) in his novel The Magic Mountain, speaks through his characters thus....

One day all the world would realize that our system, which had developed out of the cloister school of the Middle Ages, was a ridiculous bureaucracy and anachronism, that nobody in the world any longer owes his education to his schooling, and that a free and public instruction through lectures, exhibitions, cinematographs, and so forth was vastly to be preferred to any school course (p. 519).

Although dated both historically and geographically, I wonder how many of us might agree with this position when viewed through the lens of experiential validity; that is when we as adults look inward and backward to discover what really mattered in our cognitive, emotional, moral, and social growth is it not those teachers who demonstrated caring as well as those individuals who, while not a part of the formal school system such as the owner of the "Spirited Goat" café, who have had a lasting positive impact on us as learners?

Noddings (2005) writes persuasively that the primary purpose of education is not cognitive but rather moral and that caring and growth should be of primary concern rather than a focus on achievement. This thesis matches well to the purpose statement offered earlier. However, she "complicates" the issue of caring when she notes that even if teachers try to be caring that these efforts must be perceived as such in order to have a positive impact on students. In fact, it could very well be the case that some of the teachers that SR perceived as non-caring may have been well-intentioned. However, perceptions can become quite complex within the swirl of the school milieu where power differences intermix with the ever-changing chemistry of peer relations and "growth 
pains". Again, this suggests that the traditional way of conducting educational research is not well-suited for identifying and appreciating these complexities.

Heshusius (1996) begins her article by describing her experiences as a graduate student in special education with a somewhat humorous (but mostly sad) account of her first course in an American university. She was late for her "Learning Theories for Educators" course and thought that when she heard the professor talk about rats that she was in the wrong classroom. However, she discovered that she was indeed in the right classroom and then adds "needless to say, at the end of the course we were still talking about rats and pigeons doing very strange and silly things to get a pellet of food into their half-starved bodies" (p. 50). The fact that this anecdote revolves around behavioral learning theory is no coincidence since the tenets of behavioral theory with its focus on measurable performances fits perfectly with the quantitative paradigm. Again, it would appear to be a very difficult task to see how the attributes of caring in the classroom fits into this educational paradigm.

The question also arises how we would gain any important information by quantifying something that is important in its own right and which would lose its essence if we tried to quantify it. It seems that trying to do so would be similar to trying to quantify the characteristics of poetry, drama, or art. Because the experience that Heshusius (1996) described was to help prepare aspiring teachers to work with students with learning differences, makes it especially depressing since it treats these students not as individuals with unique emotional, social, and moral needs but only as students who need "fixed" so that they can function in the real world. And, if teachers go into classrooms steeped in this mindset, then the construct of caring must indeed "take a backseat" to the more quantifiable and measurable aspects of learning. We should not let this happen. 


\section{References}

Bauswell, R.B. (1994). Conducting meaningful experiments: 40 steps to becoming a scientist. Thousand Oaks, CA: Sage.

Bernauer, J. A., Lichtman, M., Jacobs, C., \& Robertson, S. (2013). Blending the old and the new: Qualitative data analysis as critical thinking and using Nvivo with a generic approach. The Qualitative Report, 18, 1-10. Retrieved from http://www.nova.edu/ssss/QR/QR18/bernauer2.pdf

Bernauer, J. A., Semich, G., Klentzin, J. C., \& Holdan, E. G. (2013). Themes of tension surrounding research methodologies education in an accelerated, cohort-based doctoral program. International Journal of Doctoral Studies, 8, 173-193. Retrieved from http://ijds.org/V olume8/IJDSv8p173-193Bernauer0397.pdf

Bernauer, J. A. (2015a). Opening the ears that science closed: Transforming qualitative data using oral coding. The Qualitative Report, 20(4), 406-415. Retrieved from http://www.nova.edu/ssss/QR/QR20/4/bernauer1.pdf

Bernauer, J. A. (2015b). Reflections on Catholic education in the USA: A dialogue across generations from the 1950s to the 2000s. International Studies in Catholic Education, 7(1), 74-93. doi: 10.1080/19422539.2014.998500

Cooley, W. W. \& Bernauer, J.A. (1991). School Comparisons in statewide testing programs. In R. Stake (Ed.), Advances in program evaluation (Volume 1, pp. 159-170). London: JAI Press Inc.

Cooper, N. \& Garner, B.K. (2012). Developing a learning classroom: Moving beyond management through relationships, relevance, and rigor. Thousand Oaks, CA: Corwin.

Fleming, V. (Producer), \& Cukor, G. (Director). (1939). Gone with the wind. United States: Selznick International Pictures.

Heshusius, L. (1996). Of life real and unreal. In Lous Heshusius and Keith Ballard (Eds.),From positivism to interpretivism and beyond (pp. 50-55). New York, NY. Teachers College Press.

Hunter, M. (1982). Mastery teaching. El Segundo, CA: TIP Publications.

Mann, T. (1981). The magic mountain. New York, NY: Alfred A. Knopf, Inc.

Moore, M.R. (2001). An American's journey to kindergarten's birthplace. Childhood Education 79 (1), 15-20.

Noddings, N. (2005). The challenge to care in schools: An alternative approach to education ( $2^{\text {nd }}$ ed.). New York, NY: Teachers College Press.

Pilcher, N. \& Cortazzi, M. (2016). Dialogues: QUANT research on QUAL methods. The Qualitative Report, 21(3), 450-473.

Polanyi, M. (1958). Personal knowledge. Chicago, IL: The University of Chicago Press.

Powell, J. C., Bernauer, J. A., \& Agnihorti, V. (2011). Chapter 18: Learning from incorrect answers on multiple-choice tests: Implications for a new teaching paradigm. In Isaias, P. et al., Towards learning and instruction in web 3.0 advances in cognition and educational psychology. (pp. 265-287). New York, NY: Springer. ISBN: 978-972-893927-4

McCartney, P. (1964). Can't buy me love. [ The Beatles] Paris, France: Capitol Records.

Wolcott, H.F. (1994). Transforming qualitative data: Description, analysis, interpretation. Thousand Oaks, CA: Sage. 


\title{
A Communities of Practice Approach to Field Experiences in Teacher Education
}

\author{
Connor Kirwan Warner \\ University of Missouri-Kansas City
}

\section{Heidi L. Hallman}

University of Kansas

\begin{abstract}
This article argues that prospective teachers who have the most productive experiences within pre-student teaching field experiences are those whose field sites allow them to become members of communities of practice, the conditions of which, according to Wenger (1998) include joint enterprise, mutual engagement, and shared repertoire. Employing interviews and content analysis of documents, the researchers explored the experiences of a cohort of teacher candidates in a pre-student teaching practicum to better understand elements of field experience that might influence identity development. We highlight the cases of two prospective teachers as illustrative and contrasting experiences of the cohort as a whole. We conclude by offering recommendations for how teacher education programs might assist prospective teachers with negotiating for conditions within field sites that allow for productive participation and growth.
\end{abstract}

Keywords: Teacher education, field experience. community of practice. practicum

Connor Kirwan Warner, Ph.D., is an Assistant Professor of Teacher Education \& Curriculum Studies at the University of Missouri-Kansas City. A former high school English and social studies teacher, his primary research agenda centers on the interplay of teacher education policy, curriculum, and assessment, while his secondary research interests include issues of curriculum and representation in English and social science education.

E-mail: warnerck@umkc.edu

Heidi L. Hallman, Ph.D., is an Associate Professor of Curriculum \& Teaching at the University of Kansas. A former high school English teacher, her research interests include studying "at risk" students' literacy learning as well as how prospective English teachers are prepared to teach in diverse school contexts.

E-mail:hhallman@ku.edu 
Fostering possibilities for teacher candidates to succeed and learn from successes within field experiences promotes growth and understanding of the teaching act. In this article, we complement existing literature on field experiences in teacher education by bringing Wenger's (1998) communities of practice to bear. We argue that teacher candidates who have the most productive pre-student teaching field experiences are those whose sites allow them to become members of communities of practice, the conditions of which, according to Wenger (1998) include joint enterprise, mutual engagement, and shared repertoire. Employing phenomenological interviews and content analysis of documents, we explored the experiences of a cohort of teacher candidates in a pre-student teaching field experience to better understand elements of field experience that influence teacher identity development. We conclude by recommending ways that teacher education programs might assist teacher candidates with negotiating for conditions within field sites to allow for productive participation and growth.

\section{Conceptual Framework and Literature Review}

Identity, as a component of teachers' development, has been theorized as fluid and complex, as well as inherently 'social' (Alsup, 2006). Holland, Lachicotte, Skinner, and Cain (1998) discuss the premise that "identities, the imaginings of self in worlds of action, [are]...lived in and through activity and so must be conceptualized as they develop in social practice" (p. 5). Alongside other scholars who study teacher identity (e.g., Alsup, 2006; Zembylas, 2008), this article understands that teachers are produced as "particular types of professionals" (Zembylas, 2008, p. 124, italics in the original), and take up their identity as teachers through a project of continuous "becoming" (Gomez et al., 2007). Furthermore, teachers mediate their stories of self with the cultural and institutional expectations of what it means to be teachers. Identity is always in relationship with the contexts in which it is fostered, and teacher identity has been considered central to teacher development (Alsup, 2006; Britzman, 1991). We wish to further expand upon how teacher identity exists in relation to the complex sociocultural contexts that shape both the work and the people doing that work (Lavadenz \& Hollins, 2015). In referencing these sociocultural contexts, Gomez et al. (2007) state, "in such communities of prospective teachers...zones of contact in which the ideological positions that preservice teachers bring to teacher education are made visible and prominent" (p. 2133).

To explore the dynamics within field experiences, we look to Wenger's (1998) communities of practice. We see the community of practice framework as explicitly tying teacher identity to the sociocultural contexts in which identity is shaped. Communities of practice are "groups of people informally bound together by shared expertise and passion for a joint enterprise" (Wenger \& Snyder, 2000, p. 139). Within such groups, "each participant in a community of practice finds a unique place and gains a unique identity" (Wenger, 1998, p. 76). Scholars who have explored how communities of practice can be harnessed in the context of teaching have illustrated such communities as professional development for veteran teachers (Hollins, McIntyre, DeBose, Hollins, \& Towner, 2004; Lotter, Yow, \& Peters, 2014), as support for retention of novice teachers (Cuddapah \& Clayton, 2011), as bridges between disciplines (Spalding \& Wilson, 2006), as means for connecting research and practice (Friedrichsen, Munford, \& Orgill, 2006; Wesley, 2003), and as frames for understanding educational leadership (Margolin, 2012). In teacher education, Kaschak and Letwinsky (2015) discuss how the emergence of a community of practice within their methods course, a result of a collaborative service-learning project, encouraged prospective teacher confidence and self-efficacy. Likewise, Daniel, Auhl, and Hastings (2013) found that 
development of a community of practice for teacher candidates in their first professional semester helped participants develop the confidence to engage in productive critique. Collectively, these studies generally concur that there are positive impacts of both deliberate and serendipitous communities of practice within prospective teacher preparation coursework. Yet, less has been written about the function of communities of practice within teacher education field experiences.

Friedrichsen et al. (2006) has argued that field experiences serve as the intersection of two communities of practice, represented by the mentor teacher/pre-service teacher dyad. The success of the field experience, according to Friedrichsen et al. (2006) depends upon the ability of the prospective teacher to broker, or make connections (Wenger, 1998), across the two communities. Like Friedrichsen et al. (2006), our work sees the concept of communities of practice as especially pertinent to understanding prospective teachers' work in field experiences. First, though, we begin by defining the characteristics of communities of practice, according to Wenger (1998). These characteristics include: joint enterprise, mutual engagement, and shared repertoire.

\section{Joint Enterprise}

In order for a community of practice to exist, the people in a community must work together to develop a "complex, collectively negotiated response to what they understand to be their situation" (Wenger, 1998, p. 78). The key element in a joint enterprise is not that all participants agree fully on all aspects of the practice, but that they work together to negotiate ways in which their individual understandings can coexist and coordinate in service of common goals.

\section{Mutual Engagement}

The negotiation of the joint enterprise can only happen if participants are mutually engaged in practice. Mutual engagement refers to the development of "interpersonal relationships" (Wenger, 1998 , p. 76) within a particular practice. At its root, mutual engagement means "[b]eing included in what matters." (p. 74). Not every member of a community of practice must be engaged in the same way, but for a community of practice to exist, all members must feel that they hold a stake within the joint enterprise of the practice, and must feel a sense of agency in shaping the shared repertoire of that practice.

\section{Shared Repertoire}

The shared repertoire of a community of practice refers to the observable actions of a practice, as well as the concrete artifacts used during those actions. Examples include: "routines, words, tools, ways of doing things, stories, gestures, symbols, genres, actions or concepts that the community has produced or adopted" (Wenger, 1998, p. 83). This shared repertoire helps participants to concretely define their joint enterprise and to facilitate their mutual engagement in that joint enterprise. 


\section{Field Experiences in Teacher Education}

The primary entry points of teacher candidates into the community of practice of professional teaching are the experiences embedded within their teacher preparation programs that place them within pK-12 schools. Commonly referred to as practica or practicum experiences in international teacher education literature and as field experiences or clinical experiences in the United States, this component of teacher education is consistently rated by teacher candidates as among the most valuable parts of their preparation (White \& Forgasz, 2016). This is despite the fact that "Often, the clinical side of teacher education has been fairly haphazard, depending on the idiosyncrasies of loosely selected placements with little guidance about what happens in them and little connection to university work" (Darling-Hammond, 2006, p. 308). Given this concurrent value and variance, we undertook this study to develop a deeper understanding of conditions that might lead to more productive field experiences.

We situate our inquiry as examining a particular phase of field experience, which we refer to as an intermediate field experience (See Figure 1 below). These intermediate field experiences serve as a bridges between theory and practice, and are often the contexts in which new teachers begin developing personal teaching competence (Smith \& Lev-Ari, 2005). Field experiences occurring prior to student teaching, referred to commonly as early field experiences, are generally underresearched (Capraro, Capraro, \& Helfeldt, 2010; Heafner \& Plaisance, 2012; Huling, 1998). While intermediate field experiences are sometimes categorized as 'early' field experiences because they occur before the student teaching semester, we see them as qualitatively different from the passive observation that characterizes many teacher candidates' initial entry into pK-12 settings (Heafner \& Plaisance, 2012), and, like Capraro et al. (2010), argue that more research is needed concerning the unique role that such experiences have in teacher education programs. The program on which this paper is based included a series of field experiences that increased in time and candidate participation over the four semesters before the culminating semester, the student teaching semester.

\begin{tabular}{|c|c|c|}
\hline Early Field Experiences & Intermediate Field Experiences & Student Teaching/Internship \\
\hline $\begin{array}{l}\text { Occurring near the } \\
\text { beginning of, or even } \\
\text { before formal admission to, } \\
\text { a teacher preparation } \\
\text { program }\end{array}$ & $\begin{array}{l}\text { Occurring in the middle of } \\
\text { a teacher preparation } \\
\text { program } \\
\text { Intended to help candidates } \\
\text { develop particular } \\
\text { competencies, bridge } \\
\text { theory to practice, and } \\
\text { transition into professional } \\
\text { teaching practice } \\
\text { - Widely varying in character }\end{array}$ & $\begin{array}{l}\text { - Occurring in the final year } \\
\text { or semester of a teacher } \\
\text { education program } \\
\text { - Intended to provide } \\
\text { candidates with the } \\
\text { opportunity to achieve and } \\
\text { demonstrate competence in } \\
\text { all aspects of the teaching } \\
\text { role } \\
\text { Characterized by full-time } \\
\text { placement in a school with } \\
\text { eventual assumption of the } \\
\text { majority of duties of a full- } \\
\text { time teacher }\end{array}$ \\
\hline
\end{tabular}

Figure 1. Levels of field experience/practica 
Given our interest teacher candidate identity development and how it might be made more visible to candidates through intermediate field experiences, this paper asks the following questions:

1. How do teacher candidates negotiate and make visible their teacher identity through participation in an intermediate field experience? How can a community of practice framework assist in understanding this negotiation?

2. How might teacher education programs foster communities of practice within intermediate field experiences?

\section{Methods}

We have described this inquiry as phenomenological in the sense articulated by Seidman (2013), as we are primarily interested in the "experiences of participants and the meaning they make of that experience" (p. 16). We wanted to know how our participants understood and negotiated the tensions inherent in their field experience contexts, and we wanted "to come as close as possible to understanding the true 'is' of our participants' experience from their subjective point of view" (p. 17). This recognition of the subjective, yet still formative and powerful, nature of lived experience shaped our data collection, analysis, and reporting methods, leading us, as much as possible, to foreground the voices and interpretations of our participants themselves.

\section{Context and Participants}

The site of our inquiry is an intermediate field experience situated in the fall of teacher candidates' final year of teacher education coursework. This experience occurs before candidates' student teaching semester, yet comes after initial experiences that could be characterized as 'observations' of classrooms (Hollins, 2015). The larger study on which this paper is based focused on the experiences of 14 English teacher candidates from a large university in the Midwest United States. Participant selection for this study was based upon the concept of purposeful sampling (Lincoln \& Guba, 1985), and the intent of the study was to gain in-depth understanding of the holistic experiences of an entire cohort of prospective English teachers.

\section{Data Collection}

The primary data collection methods included group interviews and in-depth individual interviews, insights from which were then triangulated through the analysis of documents produced within field experience contexts (Lincoln \& Guba, 1985; Marshall \& Rossman, 2006; Merriam, 2009; Patton, 2002; Seidman, 2013). Participants were interviewed at several points. These interviews were semi-structured, with researchers asking open-ended questions to allow the participants to emphasize aspects of experience that they found essential for making meaning (Seidman, 2013). Initially, participants were divided into small groups based upon the location and grade level of their field experience. After group interviews, participants were also interviewed individually. Emerging themes from interviews were triangulated with data drawn from artifacts (e.g., Blackboard discussion posts and reflection papers).

Connor served as the university supervisor of the teacher candidates who participated in the study and Heidi was an instructor for the methods class in English teaching within the teacher education program. During the time of data collection, the researcher responsible for grading the 
participants was not the researcher collecting data; this minimized the tendency that participants might feel compelled to take part in the study.

\section{Data Analysis}

As data was collected, it was inductively analyzed and thematically coded using constant comparison (Strauss \& Corbin, 1994). This process generated a list of codes that were organized into categories, and, eventually, into emergent themes (Lincoln \& Guba, 1985; Merriam, 2009). These emergent themes were then deductively analyzed using Wenger's (1998) communities of practice as a lens (Patton, 2002). Specifically, we compared our emergent themes to the three definitive elements of communities of practice detailed previously-joint enterprise, mutual engagement, and shared repertoire-finding that the majority of our themes fit easily into at least one of these three categories.

Inductive and deductive coding helped the researchers see across cases, and though the experiences of all participants contributed to and corroborated our understanding of the ability of communities of practice to influence growth and identity development, we choose, in this article, to highlight the cases (Stake, 1995) of two participants, referred to as Tom Martin and Andrea Adams. The richness of their stories, as told to us, as well as the fact that their cases presented contrasting experiences, position these two participants as "telling" cases (Ellen, 1984), highlighting particular issues and themes that recurred across the broad spectrum of participants. The experiences of Tom and Andrea can be viewed as existing on opposing sides of a continuum of involvement, ranging from full immersion in a robust community of practice to outside observation of a setting without establishing any real belonging (see Figure 1 below). The experiences of other participants in the larger study would be positioned in between these two cases.

Full Immersion in (CoP)

Outside Observation

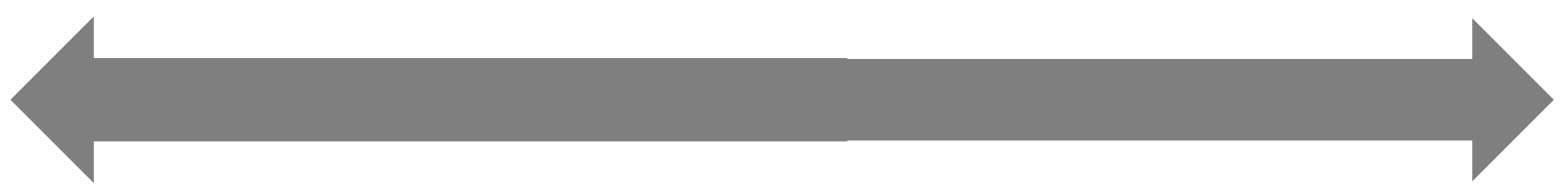

Figure 2. Continuum of participation in community of practice $(\mathrm{CoP})$

To aid in illustrating this argument, the three primary descriptors identified by Wenger (1998) as defining individual communities of practice - joint enterprise, mutual engagement, and shared repertoire - are seen as deductive codes framing the two cases. They are used throughout the findings section to discuss Tom and Andrea's experiences. 


\section{Findings}

\section{Tom Martin}

Tom's experience working at North Middle School exemplifies what engaging in a productive community of practice for teaching and learning to teach looked like in the field experience. Tom was a white male who grew up in a suburban town on the outskirts of a Midwestern U.S. city. Tom's field experience took place in an eighth grade language arts classroom at a middle school, hereafter referred to as North Middle School, in the same small city that houses Midwest University. His cooperating teacher, a white female who we refer to as Ms. Faber, had been teaching at North for over a decade, and had previously supervised a number of teacher candidates in all three levels of field experience described in Figure 1. She was a confident teacher who served as the lead eighth grade language arts instructor at the middle school.

Tom experienced positive professional identity development and indicated a strong sense of satisfaction and personal growth as a result of his field experience. When asked at the end of his experience what he would have done differently if given the opportunity, he answered, "I love being there [so] much...if I could go back, I'd have prioritized everything else in my life to give my students more time." Tom and Ms. Faber were able to mutually engage in the joint enterprise of teaching eighth graders at North Middle School and as well as work on expanding Tom's professional knowledge and skills. Their engagement was built upon a fundamental mutual respect for each other's skills and knowledge. Tom described it this way:

[Ms. Faber]'s been teaching a while, you know, she's been at this, teaching for a long time, and her training was more than a decade ago, so I know some things that she doesn't. But we have a mutual respect, I think because I first respected her, and I showed excitement and gratitude for being in her classroom, and I think that first impression made a big difference. I mean, I showed up like this was a new job and I was getting on-the-job training, and I wasn't going to let myself be discouraged when I couldn't do things exactly my way. Teaching is a profession, and in every profession you have to work your way up and learn on the go.

Such mutual respect allowed Tom and Ms. Faber to construct Tom's learning experience throughout the semester in a manner congruent to both their understandings of how best to learn to teach. Tom explained: "I was teaching something of my own design the very first week. Ms. Faber said the best way to introduce you is to just have you do it, which is a philosophy that I personally agree with." Their complimentary understandings of the joint enterprise in which they were engaged helped Tom to mutually engage in professional practice. Tom described the first time that felt he had made a significant transition from student to teacher, noting,

I guess it was probably during my first mini-lesson on 6 traits. I didn't really want to teach that, but I wanted to teach, so I taught it. I was struggling a little with management, and I made a joke with a reference to a video game, and they laughed and got it and the students started to interact with me without her mediating. I had command and authority because they gave it to me. I think I was able to do that so early because I was able to develop a close relationship with my cooperating teacher, and she fosters a good relationship with her students.

Despite holding a different view on the value a particular element of the curriculum, Tom was still able to productively engage in the community of practice within that classroom.

Contributing to that community of practice was the shared repertoire of procedures and artifacts

Brock Education Journal, 26(2), 2017 
that Tom and Ms. Faber were able to construct. Lesson plans and curriculum documents are some of the most common artifacts in the practice of teaching, and, along with developing systems of classroom management, understanding lesson planning is often one of the most common concerns of the novice teacher. Ms. Faber's planning process, while hardly concrete, resonated with Tom. He noted the following:

I think the biggest way that I relate to my teacher is that she says all the time..."I don't have my curriculum planned out [because] I've been doing it for a long time," which is something I relate to. I want to have things I want to cover, but I don't want to have those planned to the day, and that goes along with her kind of organic storytelling type deal that she only has the next couple weeks planned out but still gets through everything she wants to cover. She'll be the first to tell you that her students do the best on the test of the eighth grade English teachers in the area. She says she's glad that I'm like that because some of her students in the past had a hard time.

Ms. Faber noted that some of the teacher candidates she had worked with in the past held a different understanding of the importance of concrete long-term planning than she did, and so struggled to grow within her classroom. Tom, on the other hand, who held similar beliefs to his cooperating teacher, thrived in that environment. Because of the community Tom and Ms. Faber were able to build, any negotiations resulted in significant learning as positive professional identity development for Tom.

\section{Andrea Adams}

Andrea's case exemplifies the tensions we observed for participants who were unable to engage in a productive community of practice for teaching and learning to teach within their intermediate field experiences. Andrea was a white female who grew up in a different suburban town on the outskirts of the same Midwestern U.S. city as Tom. Andrea's field experience took place in a high school, hereafter referred to as West High School, in the same district as North Middle School. Her cooperating teacher, who we refer to as Mr. Higgins, was a white male who had worked at West High for over 15 years and was the chair of the English department. Though he had supervised numerous teacher candidates in the past, at the time of the study it had been several years since he had hosted any in his classroom. He was a commanding and demanding teacher who believed above all else in the primacy of content knowledge and intellectual rigor.

Andrea's experience is representative of those participants whose field placements did not provide them the opportunity to enter communities of practice, and who, therefore, experienced negative or stagnant professional identity development and indicated dissatisfaction with their experiences. Andrea felt constrained in a variety of ways, as though she were an outsider to the very experience in which she was involved. She also expressed some concern about her future career, given the struggles she found in the classroom in which she was placed. She noted, "I realize that teaching is a very challenging career, consisting of a lot of extra time, energy, and work... I'm more concerned that the students won't want to at least meet me halfway."

Unfortunately, unlike Tom, Andrea never felt able to mutually engage with Mr. Higgins in the practice of teaching during her field experience. This was at least partially due to the very different understandings of the teaching enterprise held by Andrea and Mr. Higgins and their inability to negotiate those differences. When asked about her experience, Andrea said, "I feel intimidated by [Mr. Higgins] as a new teacher. I don't want to deviate from his lesson plans, his ways of doing things, even though he tells me I can. I feel like I have to do lectures because that's what he does, 
so obviously he thinks it's the best way to go." Even though Mr. Higgins indicated on his formal evaluations of Andrea that he was willing to let her experiment with different methods and pedagogies, she did not feel comfortable doing so.

The unequal power dynamic that existed between Andrea and Mr. Higgins seemed to play a considerable part in an inability to mutually engage. While Tom and Ms. Faber were able to develop a respectful relationship in which both were willing to learn from each other, despite the fact that Ms. Faber was ultimately the authority in the classroom, Andrea and Mr. Higgins were unable to do so. This was likely at least partially due to Mr. Higgins' own status within West High School; Andrea noted that, "he's the department chair, in charge of hiring, so if I wanted to work here I need him on my side." The radically unbalanced dynamic meant that Andrea never felt that she was a legitimate participant in teaching practice while in the presence of Mr. Higgins. She noted that the only time she really felt like a teacher during her field experience was the day that Mr. Higgins was absent, and, though the district hired a substitute teacher, Andrea led the class. She described her feeling of strength and legitimacy, noting, "I was in control and I was the 'go to' person. When [Mr. Higgins] is in the room, no matter what, he's the 'go to."'

Due to their conflicting conceptions of the work of teaching and their inability to mutually engage in the field experience setting, Andrea and Mr. Higgins were unable to develop a shared repertoire of teaching practices and artifacts. One of the earliest manifestations of this lack of shared repertoire involved the instructional planning process. Unlike Tom, Andrea struggled to understand the lesson planning process of her cooperating teacher and did not feel able to engage in a mutual negotiation of a process that would work for her. From her perspective, Mr. Higgins simply,

doesn't plan a lot... [maybe because] he's been doing it for so long [that] he [just] knows what he wants to say or what he wants to do. [When I'm watching] It seems to me like it's just off the top of his head, but then he starts talking, and it seems so well-planned out...it's just hard for me to see the angles of things or...even the progression of the unit or the day...He does a great job of conveying [the material, but]...it's hard for me to sit in there and have a clear view of what's going on and what the goals are.

Her observations of Mr. Higgins contrasted sharply with her own construction of planning for instruction. She described herself as,

a planner, I plan everything out... Which doesn't always parallel with my teacher's style...it works for him, but it just doesn't feel right to me.

Unlike Tom and Ms. Faber, Andrea and Mr. Higgins were never successful in developing a shared repertoire of planning processes and tools. Lack of shared repertoire was also apparent in Andrea and Mr. Higgins' differing perspectives regarding teaching methods. For Andrea, a defining characteristic of good teaching was social interaction. She described her frustration with Mr. Higgins' class, noting:

I'd like to be doing discussion and there's none of that... [students] won't even raise their hands to answer...it's like, they've been conditioned to sit there and listen and be passive learners and do the work, and I think that there's a lot to be learned from discussion.... and if it were my class, I would really push for the kids to open up to each other and comfortable sharing their ideas. It's frustrating...

From Andrea's viewpoint, social interaction defined both the goal and method of teaching. Mr. Higgins, however, seemed to understand teaching more in terms of content than social interaction, and so his teaching methods reflected this understanding. In his final evaluation of Andrea, he recommended that Midwest University require "more content knowledge and less educational 
theory" of their prospective teachers. Andrea described Mr. Higgins as, very college-like. He does a lot of lecturing...He doesn't think there is anything wrong with a teacher talking "at" students if the teacher has valid knowledge to convey...My cooperating teaching has a lot to offer. He knows the material forward and backward...

Andrea could appreciate some value in this approach, and certainly admired her cooperating teacher's deep-seated knowledge. However, she still felt that the essence of the enterprise of teaching, in her estimation, was lacking. She explained,

It's good for students to be able to sit and listen, since this is what the expectation will be in college, but I think these students are missing out on a key component of educationdiscussion. The students are never given time to discuss their opinions, argue topics, or really even ask questions. The kids are like robots, and it's not an atmosphere I feel comfortable with. I'm a very open person, who likes conversation [and] active learning.

When Andrea attempted to implement such a mode of teaching, she "got shot down" because Mr. Higgins said he "didn't see it working." Their lack of a common construction of teaching left Andrea feeling like an outsider, disengaged with the classroom, and not able to do what she felt she needed to do in order to learn what she felt she needed to learn. As she put it, "I see other teachers teaching the same level and same content as he does, but they do all kinds of different activities and cooperative learning, so I know it can be done. I just don't feel comfortable doing it here." In effect, the lack of a joint enterprise between Mr. Higgins and Andrea led directly to an inability to develop a shared repertoire of teaching methods, and, therefore, to a lack of mutual engagement in the work of teaching. The net result of all these tensions and disconnects was the inability to form a community of practice in which Andrea could productively learn to teach and develop her own professional identity.

In her methods class, Andrea was often quiet in discussions about her field experience. While others shared positive ways they were interacting with both the students in the classroom and their cooperating teacher, Andrea referred often to her experience with Mr. Higgins as "fine, but we have different philosophies." The idea of differing teaching philosophies is often a way for teacher candidates, like Andrea, to cope with an experience that does not lead to growth as a teacher and, in the next section, we explore how teacher education programs can go beyond a claim of a mismatch of teaching philosophies to help students like Andrea.

\section{Discussion}

We stress that participation in communities of practice resides on a continuum (see Figure 1). Because we place Tom's experience closer to full immersion in a community of practice and see Andrea's experience as closer to residing in an "outsider" position, we were led to consider the second question that frames our inquiry: How might teacher education programs help foster communities of practice within the pre-student teaching field experience?

We see this work as resting on assisting teacher candidates to develop what Wenger (1998) calls legitimate peripheral participation. Since field experiences are intended to allow teacher candidates to both practice teaching and to learn the practice of teaching, in order to learn within practice, participants "must be granted enough legitimacy to be treated as potential members" (Wenger, 1998, p. 101) and at least "an approximation of full participation that gives exposure to actual practice" (p. 100). Tom and Ms. Faber, though not necessarily deliberately, worked these elements out. Andrea and Mr. Higgins did not. Perhaps the most important finding was that whether or not the field experience resulted in positive growth and development for the teacher 
candidates involved seemed to be dependent not upon systems put in place by the teacher education program at Midwest University or even by the schools in which the teacher candidates were placed, but upon interconnected factors including personal theories of teaching and learning to teach, institutional and social power dynamics, and personality characteristics - none of which were deliberately analyzed, mediated, or deconstructed by the teacher education program. The following section is organized into a discussion of two explicit lessons that we believe teacher education programs can take away from the experiences of Tom and Andrea.

\section{Lesson 1: Develop a Shared Understanding of Teaching Itself}

First, the experiences of our participants indicate that incompatible understandings of the work of teaching and, as a corollary, what it means to be a teacher, can derail an intermediate field experience. Jackson (1986) noted that "despite the ubiquity of teaching as an activity, there is no uniformity of opinion about it...Teachers, it turns out, often disagree among themselves about teaching and what its demands are in the way of knowledge" (pp. 2-3). Such disagreement is salient, given that a wide variety of scholars have demonstrated the ways in which beliefs about and understandings of teaching shape the actual actions of teachers in practice (Darling-Hammond \& Bransford, 2005; Korthagen, 2004; White \& Forgasz, 2016). Most understandings of teaching include beliefs relating to curriculum content and planning, the value/effectiveness of particular pedagogies, the function and format of assessment (Hollins, 2015; Jackson, 1986; Joyce, Weil, \& Calhoun, 2014). Undergirding these understandings are differing theories about the way people learn and differing beliefs about the overarching goals of educational experiences and the nature of knowledge itself (Jackson, 1986; Labaree, 1997; Warner, 2016).

To address this issue, teacher education programs might emphasize the development of teaching as shared repertoire. According to Wenger (1998), developing repertoire, styles, and discourses means re-negotiating the meaning of various elements. It also means "producing or adopting tools, artifacts, representations; recording and retelling events; inventing new terms and redefining or abandoning old ones; telling and retelling stories; creating and breaking routines" (p. 95). Again, Andrea and Mr. Higgins simply did not have a shared repertoire of teaching strategies, procedures, experiences, or routines. Andrea chaffed at Mr. Higgins' emphasis on lecture and content and could not reconcile it with her own belief in personal relationships and social interaction. It was not that Andrea felt she did not have access to the artifacts of Mr. Higgins' practice. It was that, from her perspective, his practice did not seem to produce any artifacts other than students who mechanically took notes like "robots." As such, there was certainly no space for the two of them to work together to reify their practice into a shared repertoire of artifacts and routines.

On the other hand, Tom and Ms. Faber, by establishing a concrete schedule and negotiating a shared understanding of the meanings of observation, co-teaching, and teaching, and the routines and procedures that they would both employ to bring meaning to those activities, were able to share in a repertoire for both teaching and learning to teach. While cooperating teachers, as experts in their craft, may not think to make transparent the varied sophisticated decisions, routines, and artifacts that define their practice, a phenomenon that Darling-Hammond and Bransford (2005) called expert blind spots, teacher education programs could facilitate conversations between cooperating teachers and teacher candidates early in the experience to help underscore important elements of their practice such as lesson planning, classroom management, learning activities, teaching strategies, assessment development, and data use. These are the conversations and outcomes that Tom and Ms. Faber had, and that Andrea and Mr. Higgins did not. 


\section{Lesson 2: Develop a Shared Understanding of Learning Teaching}

Second, Tom and Andrea's experience highlight the essentiality that stakeholders in an intermediate field experience hold a shared understanding of how an individual learns teaching. If a cooperating teacher believes that a teacher candidate is going to learn teaching by observing and replicating his or her behavior, and the teacher candidate believes he or she is going to learn teaching through joint inquiry into learners and learning environments, then both are likely to be stymied in their efforts and dissatisfied with the experience. As the institution tasked with recommending candidates for licensure, it is incumbent upon the teacher education program to develop a clear, coherent conceptualization of learning teaching, and to ensure that the cooperating teachers who partner with the program and the teacher candidates it sends out into the field share that common understanding.

Wenger (1998) argued that members of the community of practice must be constantly involved in understanding and tuning their enterprise. This means that members must be willing to learn and hold each other accountable to their enterprise as well as reconcile conflicting interpretations of what the enterprise is about. For this to happen, teacher education programs might emphasize with prospective teachers the importance of learning to teach in new ways. In contrast to how field experiences have been conceptualized-as spaces for teacher candidates to observe master teachers and attempt to replicate their behaviors in a process that Hollins (2015) referred to as "representation and approximation" (p. 18) - a reconceptualization would stress field experiences as sites for examining the benefits and drawbacks of particular classroom practices. In such a framework, teaching is viewed not as a set of competencies or an act driven by a singular theory (Smith \& Lev-Ari, 2005); as a result, each teaching context requires different theories in practice. In this way, learning to teach becomes an interpretive process (Hollins, 2015) dependent upon analysis of learners and contexts.

In order to foster Wenger's tenet of mutual engagement in the teaching act, cooperating teacher and prospective teacher must be invested in each other's competence and how such competence evolves over time. Mutual engagement, according to Wenger (1998) "involves not only our competence, but also the competence of others" (p. 76). Teacher education programs might pay particular attention to what Wenger viewed as evolving forms of mutual engagement, including "discovering how to engage, what helps and what hinders; developing mutual relationships; defining identities, establishing who is who, who is good at what, who knows what, who is easy or hard to get along with" (p. 95).

Referencing the case of Andrea Adams, we can see that mutual engagement appears fundamental to successful and fulfilling field experiences. Andrea summed up the lack of mutual engagement in her field experience, stating in the introduction to one of her reflection papers, "I have taught several lessons, but unfortunately, due to [a variety of factors], I cannot be involved in the lesson planning and teaching every day." Tom, on the other hand, described the specific ways in which he and his cooperating teacher worked out ways for them to mutually engage in the joint enterprise of teaching the students at North Middle School. Tom spent approximately one hour per day, five days per week at his field site, and Tom described the way he and his co-teacher divided that time in the following way:

On average, I'm...observing and talking to the teacher about strategies for three days of the week. One day is co-teaching... and one day is full on teaching...I'm preparing to start a large unit of my own design, something I feel really lucky to take part in. 
Andrea, on the other hand, because of limitations in her own course schedule and because of her cooperating teacher's administrative duties, was unable to be in the classroom every day, and, instead, came in for several hours at a time, a couple of days per week. Those days tended to change from week to week, depending upon the availability of her cooperating teacher to meet and plan with her, since he frequently needed to use his non-teaching time to attend to department chair business.

\section{Implementing the Lessons}

If teacher education programs are to truly learn from these lessons, most will need to make substantial changes to the ways in which intermediate field experiences are designed, introduced, and supported, which will require addressing challenges of logistics, buy-in, and resources. Programs' recasting of field experiences, especially intermediate experiences, as professional development for both teacher candidates and cooperating teachers would emphasize the centrality of communication and the importance of all parties involved looking at the relationship as a site for learning (McQuirter, Scott, Dortmans, Rath, Meeussen, \& Boin, 2015: Roland, 2010). FeimanNemser \& Buchmann (1987) concluded their study of factors necessary for student teaching to serve as meaningful teacher education by arguing the following:

Becoming a mentor involves making a transition from classroom teacher to teacher educator. Classroom teachers need time and commitment to develop the necessary understandings, skills, and orientations, and schools must broaden the scope of teachers' roles and rewards to include teacher education. (273)

We concur, but would add that university teacher preparation programs will need to provide the structure, expertise, and experience necessary to help classroom teachers develop competence as teacher educators.

One approach that might allow teacher education programs to establish field experiences as mutual professional development is structured dialogue (Hollins, 2006). Structured dialogue is a problem-solving approach to teacher professional development pioneered by Hollins (2006) to improve literacy instruction and student achievement in urban schools in Dayton, $\mathrm{OH}$. The teachers involved in Hollins' study engaged in weekly dialogues in which they (1) jointly identified problems of practice, (2) identified possible solutions, and (3) developed plans to implement those solutions. Over the three-year course of the study, Hollins found that the approach led to productive changes in teacher habits of mind and school culture, which in turn led to increased student achievement. Hollins (2006) argued that "structured dialogue can bring about a learning community in which teachers transform their schools' beliefs, values, and instructional practices" (p. 52). We posit that such a powerful intervention could be harnessed within intermediate field experiences as well in order to establish the communities of practice for which we have advocated in this article.

We recommend that teacher education programs consider requiring not just hours of observation and practice teaching, but also hours of structured dialogue as part of the intermediate field experience. In such an approach, candidates and cooperating teachers would schedule a significant time, at least an hour per week, in which to engage in structured dialogue about teaching practice. Both parties would bring problems of practice to the dialogue, and both would be responsible for generating solutions, and considering the means of implementing those solutions. In an ideal context, multiple teacher candidates and cooperating teachers in the same school or department would meet within this structured dialogue group to maximize the generative nature of dialogue. 


\section{Limitations}

We have chosen to highlight two distinct cases throughout this article; however, we realize that by contrasting these cases, there is risk in presenting one "successful" case and one "unsuccessful" case rather than fully illuminating the continuum of experience that we observed. Some teacher candidates may experience truly immersive intermediate field experiences that would place them even further left along the continuum than Tom, while others (unfortunately, in our view), may be forced to the right of Andrea on Figure 2, and positioned as outsiders looking in. Yet, by outlining how tenets of communities of practice are present in this particular setting, we hope that teacher educators can be more expert in understanding the range of prospective teachers' experiences in field experiences through a more nuanced lens.

We are also left to postulate how teacher education programs might design intermediate field experiences that allowed teacher candidates to move further left on the continuum, even closer to full immersion in robust communities of practice. It is possible that a tipping point exists where teacher candidates in pre-student teaching field experiences might be immersed too quickly in a community of practice, bypassing, or passing too quickly through legitimate peripheral participation and being thrust directly into full participation. Such an experience, where teacher candidates would be asked to practice teaching before they had learned teaching might be as detrimental to their emerging professional identities as experiences on the far right of the continuum. Next, we move to place our work in the broader context of reform in North American teacher education.

\section{Conclusion and Implications}

Adopting a communities of practice approach to pre-student teaching field experience in teacher education would take a degree of cooperation and partnership with teachers and PK-12 schools that has not traditionally existed, despite a significant base of scholarly literature indicating the positive outcomes of such partnerships (Bier et al., 2012; Kenny, 2012; Margolin, 2012; Stairs, 2010; Trent \& Lim, 2010). However, the call for such partnerships is growing louder. For example, in Canada, the Accord on Initial Teacher Education (2016), which provides guiding, but not binding, principles for teacher education, argues that

An effective initial teacher education program involves partnerships between the university and schools, interweaving theory, research, and practice and providing opportunities for teacher candidates to collaborate with teachers to develop effective teaching practices. (p. 3)

In the United States, the Council for the Accreditation of Educator Preparation (CAEP), the national accrediting body for teacher preparation, has placed substantive emphasis on partnerships between teacher preparation programs and PK-12 schools as one of its core standards for program evaluation (CAEP, 2015). Hollins (2015) argued that, in developing such partnerships, teacher preparation programs should look to develop field experiences that function as "guided practice within a professional community...a type of apprenticeship that is significantly different from traditional conceptualizations of student teaching" (p. x).

Many teacher educators (e.g., Cochran-Smith, 1995; Gay, 2003) have asserted that what is needed in teacher education programs is space and opportunity for teacher candidates to work in contexts that will broaden their belief systems and assist in constructing more sophisticated 
understandings of students as learners. As this article suggests, the intermediate field experience, an often ignored feature of teacher education programs, can be a potential site for undertaking such work. A communities of practice approach, in theoretically framing such field experiences, could offer a robust framing of the field experiences that are intended to serve as transition points into professional teaching practice. As the field of teacher education reiterates a commitment to prepare teachers to teach diverse groups of students, it is important that this move beyond rhetoric and into the spatial and temporal contexts in which we live. 


\section{References}

Alsup, J. (2006). Teacher identity discourses: Negotiating personal and professional spaces. Urbana, Illinois: National Council of Teachers of English.

Association of Canadian Deans of Education. (2016). Accord on initial teacher education.

Retrieved from http://www.csse-scee.ca/docs/acde/ACDE_Accord_on_Initial_Teacher_Education.pdf

Bier, M. L., Horn, I., Campbell, S. S., Kazemi, E., Hintz, A., Kelley-Petersen, M., \& Peck, C. (2012). Designs for simultaneous renewal in university-public school partnerships. Teacher Education Quarterly(Summer), 127-142.

Britzman, D. P. (1991). Practice makes practice: A critical study of learning to teach. Albany, NY: State University of New York Press.

Capraro, M. M., Capraro, R. M., \& Helfeldt, J. (2010). Do differing types of field experiences make a difference in teacher candidates' perceived level of competence? Teacher Education Quarterly(Winter), 131-155.

Cochran-Smith, M. (1995). Color blindness and basket making are not the answers: Confronting the dilemmas of race, culture, and language diversity in teacher education. American Educational Research Journal, 32, 493-522.

Council for the Accreditation of Educator Preparation (CAEP). (2015). Standard 2: Clinical partnerships and practice. Retrieved on December 13, 2015, from http://caepnet.org/standards/standards/standard2/

Cuddapah, J. L., \& Clayton, C. D. (2011). Using Wenger's communities of practice to explore a new teacher cohort. Journal of Teacher Education, 62(1), 62-75.

Daniel, G. R., Auhl, G., \& Hastings, W. (2013). Collaborative feedback and reflection for professional growth: Preparing first-year pre-service teachers for participation in the community of practice. Asia-Pacific Journal of Teacher Education, 41(2), 159-172.

Darling-Hammond, L. (2006). Constructing 21st-century teacher education. Journal of Teacher Education, 57(3), 300-314.

Darling-Hammond, L., \& Bransford, J. (2005). Preparing teachers for a changing world: What teachers should learn and be able to do. San Francisco: Jossey-Bass.

Ellen, R. F. (1984). Ethnographic research: A guide to general conduct. New York: Academic Press.

Feiman-Nemser, S., \& Buchmann, M. (1987). When is student teaching teacher education? Teaching and Teacher Education, 3(2), 255-273.

Friedrichsen, P. M., Munford, D., \& Orgill, M. (2006). Brokering at the boundary: A prospective science teacher engages students in inquiry. Science Education, 90(3), 522-543.

Gay, G. (Ed.) (2003). Becoming multicultural educators: Personal journeys toward professional agency. San Francisco: Jossey-Bass.

Gomez, M.L., Black, R.W. \& Allen, A. (2007). "Becoming" a teacher. Teachers College Record, 109(9), 2107-2135.

Heafner, T., \& Plaisance, M. (2012). Shared viewing as an approach to transforming early field experiences. Contemporary Issues in Technology and Teacher Education, 12(4), 423437.

Huling, L. (1998). Early field experiences in teacher education. ERIC Clearinghouse on Teaching and Teacher Education. Washington, DC: ERIC Clearinghouse on Teaching and Teacher Education.,

Holland, D. Lachicotte, W., Skinner, D. \& Cain, C. (1998). Identity and agency in cultural 
worlds. Cambridge, MA: Harvard University Press.

Hollins, E.R. (2015). Rethinking field experiences in preservice teacher preparation. New York: Routledge.

Hollins, E. R. (2006). Transforming practice: Structured dialogue spurred educators at two underachieving schools to fuel their own professional growth. Educational Leadership (March), 48-52.

Hollins, E. R., McIntyre, L. R., DeBose, C., Hollins, K. S., \& Towner, A. (2004). Promoting a self-sustaining learning community: investigating an internal model for teacher development. International Journal of Qualitative Studies in Education, 17(2), 247-264.

Jackson, P. (1986). The practice of teaching. New York: Teachers College Press.

Joyce, B., Weil, M., \& Calhoun, E. (2014). Models of teaching (9th ed.). Upper Saddle River, NJ: Pearson.

Kaschak, J. C., \& Letwinsky, K. M. (2015). Service-learning and emergent communities of practice: A teacher education case study. The Clearing House: A Journal of Educational Strategies, Issues and Ideas, 88(5), 150-154.

Kenny, J. D. (2012). University-school partnerships: Pre-service and in-service teachers working together to teach primary science. Australian Journal of Teacher Education, 37(3).

Korthagen, F. (2004). In search of the essence of a good teacher: towards a more holistic approach in teacher education. Teaching and Teacher Education, 20(1), 77-97.

Labaree, D. (1997). Public goods, private goods: The American struggle over educational goals. American Educational Research Journal, 34(1), 39-81.

Lavadenz, M. \& Hollins, E.R. (2015). Urban schools as a context for learning teaching. In E. Hollins (Ed.), Rethinking field experiences in preservice teacher preparation. New York: Routledge.

Lincoln, Y. S., \& Guba, E. G. (1985). Naturalistic inquiry. Beverly Hills, CA: Sage.

Lotter, C., Yow, J. A., \& Peters, T. T. (2014). Building a community of practice around inquiry instruction through a professional development program. International Journal of Science and Mathematics Education, 12(1), 1-23.

Margolin, I. (2012). A coterminous collaborative learning model: Interconnectivity of leadership and learning. Brock Education Journal, 21(2), 70-87.

Marshall, C., \& Rossman, G. B. (2006). Designing qualitative research (4th ed.). Thousand Oaks, CA: Sage.

McQuirter Scott, R., Dortmans, D., Rath, C., Meeussen, N., \& Boin, J. (2015). Collaborative teacher inquiry into Ipad use in grade 3 classrooms: Mobilizing knowledge through a longterm school-university partnership. Brock Education Journal, 25(1), 73-90.

Merriam, S. B. (2009). Qualitative research: A guide to design and implementation. San Franscisco: Jossey-Bass.

Patton, M. Q. (2002). Qualitative research \& evaluation methods (3rd ed.). Thousand Oaks, CA: Sage.

Roland, K. (2010). Associate teacher perspectives of the triumvirate relationship in teacher education: The role of faculty advisors. Brock Education Journal, 19(2), 36-47.

Seidman, I. (2013). Interviewing as qualitative research: A guide for researchers in education and the social sciences $\left(4^{\text {th }}\right.$ ed.). New York: Teachers College Press.

Smith, K. \& Lev-Ari, L. (2005). The place of the practicum in pre-service teacher education: The voice of the students. Asia-Pacific Journal of Teacher Education, 33(3), 289-302.

Spalding, E., \& Wilson, A. H. (2006). Bowling together: Cultivating communities of practice in 
English and social studies teacher education. English Education, 38(2), 102-122.

Stairs, A. J. (2010). Becoming a professional educator in an urban school-university partnership: A case study analysis of preservice teacher learning. Teacher Education Quarterly, 37(3), 45-62.

Stake, R. (1995). The art of case study research. Thousand Oaks, CA: Sage Publications.

Strauss, A., \& Corbin, J. (1994). Grounded theory methodology: an overview. In N. K. Denzin \& Y. Lincoln (Eds.), Handbook of Qualitative Research (p. 273-285). London: Sage.

Trent, J., \& Lim, J. (2010). Teacher identity construction in school-university partnerships: Discourse and practice. Teaching and Teacher Education, 26(8), 1609-1618.

Warner, C.K. (2016). Contested definitions of excellent teaching: An analysis of the discourse of quality. Journal of Thought, 50(1), 20-36.

Wenger, E. (1998). Communities of practice. Learning, meaning, and identity. New York: Cambridge University Press.

Wenger, E. C., \& Snyder, W. M. (2000). Communities of practice: The organizational frontier. Harvard business review, 78(1), 139-146.

Wesley, P. W. (2003). Communities of practice: Connecting what we know. Exceptional Children, 69(3), 263-277.

White, S., \& Forgasz, R. (2016). The practicum: The place of experience? In J. Loughran $\&$ M. L. Hamilton (Eds.), International handbook of teacher education (pp. 231266). Singapore: Springer.

Zembylas, M. (2008). Interrogating 'teacher identity': Emotion, resistance and self formation. Educational Theory, 58(1), 107-127. 


\title{
Non-Indigenous Women Teaching Indigenous Education: A Duoethnographic Exploration of Untold Stories
}

\author{
Sarah Burm \\ Western University \\ Dawn Burleigh \\ The University of Lethbridge
}

\begin{abstract}
Identifying as non-Indigenous, we are often left considering our positionality and identity in Indigenous education, how we have come to be invested in this area of research, and what we see as our contribution. In conversation with one another, we realized we choose to share certain stories and not others about our experiences working in Indigenous education, but were less familiar with why, after working in the field for a sustainable period of time, we felt the need to censor our stories. What did we fear might happen if we divulged these 'untold' stories? What follows is a duoethnographic inquiry that seeks to attend to this question. We have chosen to dialogically document, analyze, and probe our experiences as teacher-educators in Indigenous education to unpack why we refrain from sharing certain experiences we have encountered since becoming involved in teacher education. By responding to this question through duoethnographic writing we hope to broaden how we come to understand and extract meaning from our experiences working in the area of Indigenous education.
\end{abstract}

Keywords: Indigenous education, duoethnography, teacher education, dialogic reflection

Sarah Burm, Ph.D., is a Research Education Innovation Specialist at the Centre for Education Research \& Innovation (CERI) at Western University. She is also an Ontario certified teacher with experience teaching at the K-12 level as well as at the post-secondary level.

Email: sarah.burm@schulich.uwo.ca

Dawn Burleigh, Ph.D., is an Assistant Professor in the Faculty of Education at the University of Lethbridge. Her research and teaching interests include, Indigenous teacher education and the work of teachers in Northern and remote communities.

Email: dawn.burleigh@uleth.ca 
It was while living and teaching in a remote First Nations community in northern Ontario where we shared with one another our experiences, insights, and reflections concerning schooling for Canada's First Nations, Metis, and Inuit (FNMI) students and our position as non-Indigenous people involved in this work. Looking back, we spent a lot of time talking about our teaching experiences, remembering the students who walked through our classroom doors. Over lunch, after school, at a weekend potluck or on the phone with family and friends, we would recall an incident that occurred at school; our response, student reactions, and lessons learned. Some stories were told with pride or laughter while others brought out our individual insecurities and at times, even feelings of negativity and hopelessness.

Those conversations did not end when we boarded the airplane for summer holidays at the end of each school year. Nor did they stop when we finally left the community where we started our teaching careers. And they especially did not end when we each made the decision to pursue graduate studies in Indigenous education. Our conversations continued, intensifying. However, what was different now was our position within the story. We were no longer situated within the story. Rather, we gazed retrospectively back at ourselves, as though we were watching our experiences, ourselves from a bird's eye view. We developed an awareness of the stories we told and began to attend to what our experiences, our stories taught us.

\section{Arriving at the Inquiry}

The negotiation of our roles was explored thoroughly in a paper titled Unpacking our White Privilege: Reflecting on our Teaching Practice (Burleigh \& Burm, 2013). In that paper we respond to the question "What is it like to teach in a remote First Nations community?" This initial inquiry was fueled by our desire to further preservice teachers' understandings of teaching Indigenous students. During that inquiry we realized we choose to share certain stories and not others when asked about our continued involvement within Indigenous education. What did we fear might happen if we divulged these 'untold' stories? What follows is a duoethnography (Norris, Sawyer, \& Lund, 2012) that attends to this critical question. We have chosen to dialogically document, analyze, and probe our experiences as teacher-educators in Indigenous education to unpack why we refrain from sharing certain experiences, challenges, and dilemmas we have encountered since becoming involved in teacher education.

\section{Encountering the Problem}

While designing a conceptual framework for this paper, we realized we told different versions of the same story depending on who asked and in what context. This became especially apparent when we each taught an Indigenous education course within a mid-size university in southwestern Ontario. This course, offered as an elective to teacher education candidates, was designed to help pre-service teachers examine the social, political, and historical impacts of Indigenous education in Canada. Throughout the course, teacher education candidates were encouraged to engage in ongoing, critical reflection around what they knew about teaching Indigenous students, and how their own assumptions and understandings about Indigenous communities, issues, and perspectives informed their development as professional educators. Students critically engaged in discussions on such topics as the intergenerational impact of the residential school system, decolonization, white privilege, and power, all while considering their own positions and perspectives in relation to these topics. This can be heavy, emotional work, and often these topics were abstract and difficult for some students to grasp. It was not uncommon for us to share certain stories from our 
teaching and research practice as a means to mitigate student resistance or anxiety. Our stories served as a gateway to introduce issues sensitive in nature.

Students listening to our stories reacted to them, participating in a sense, in the action of the narratives we told. As they began understanding the many barriers to education that impact Indigenous learners (Battiste, 2013; Cannon, 2012; Gordon \& White, 2014; Hare, 2011; Paquette \& Fallon, 2008), they wondered why we continued dedicating time and effort to this work. Others were curious to learn more about our experiences as non-Indigenous women working in this field, the impact it has had on how we come to understand ourselves and our role in the conversation concerning Indigenous education in Canada. Similar interactions would occur in the presence of our colleagues, or our families and friends. Anytime issues concerning Indigenous Peoples were raised or the question "What do you do?" was posed, we found ourselves emphasizing, modifying, or even omitting certain people, places, and events from our responses, careful not to divulge too much information. Other times we remained silent, unsure what the appropriate response might be given the milieu we found ourselves in.

\section{Utilizing Duoethnography}

\section{Methodology}

We turn to duoethnography (Norris, 2008; Sawyer \& Norris, 2013) in our efforts to critically examine our tendency to share certain stories over others when asked about our continued involvement in Indigenous education. A relatively new research genre, duoethnography is a collaborative research methodology whereby a team of researchers utilize storytelling to simultaneously generate, interpret, and articulate data in order to co-engage in meaning making around a particular phenomenon (Norris, Sawyer, \& Lund 2012; Sawyer \& Norris, 2013). The authors voices are made explicit as readers witness them in conversation with one another. The approach is deeply personal and introspective; each researcher pushing the other to engage critically and reconceptualise their perceptions around the topic at hand (Norris, Sawyer, \& Lund 2012). Given the dialogic nature of this mode of inquiry and the conducting of research 'with' and not 'on' another (Kovach, 2009), it was important for us to enter into this research endeavour with someone where a relationship of trust and respect was firmly established. As teacher-educators, we have more than 10 years' experience working in the field of Indigenous education. Collaborating on a self-study exploring how we broach the subject of our cultural identities as nonIndigenous people felt almost necessary if we expected students to do the same. (Nicol \& Korteweg, 2010). Our draw to duoethnography was the opportunity it afforded to confront the "multiplicity of perspective" (Sawyer \& Norris, 2016, p. 8) flowing throughout our entangled story. Engaging in dialogic reflection was an opportunity to interrogate our cultural assumptions, and revisit those pivotal 'untold' stories we purposely abstained from sharing with others.

\section{Collecting Data}

Data collected focused on our involvement in Indigenous education since entering the university context as doctoral students to the transition to early career teacher-educators. These data included discussions we had with one another spanning five years which, within that time, we each started and finished doctorates in Indigenous education, taught a preservice course, and developed relationships with Indigenous organizations and community members within our 
respective communities. We also drew on individual journal entries kept during this time whereby we began to articulate our perceptions, ask questions, and make connections to one another's insights and interpretations of encounters we had both in and out of academic, encounters that left us questioning how we position ourselves and our stories in the context of the work we do. The culmination of these experiences and critical conversations are comprised here into four stories, each in a different setting: the academic, the social, the insider (the stories we share with each other) and, self (the stories we tell ourselves). We utilize these stories to unpack and delve deeper into the potential fears and reasons we reshape and reframe the stories we tell.

We casted ourselves as the main characters in each of the four stories and generated dialogues to make explicit how our stories over the years have varied depending on who we are speaking to and in what context. We created a series of composite characters representing individuals with whom these stories involve. Italicized text indicates our internal dialogue, what we are thinking and not saying in interactions with others. Rather than artificially disassociating the analysis from our autobiographical stories, we have chosen to integrate the discussion and analysis throughout the remainder of the paper. We conclude by outlining three teaching approaches that have helped us move beyond the limitations we found in ourselves and in our stories.

\section{The Academic}

\section{Telling Our Stories}

Dialogue. At conferences, in the hallways, and during committee meetings we are often confronted with questions about our teaching practice. What follows is a dialogue representative of the many interactions we have had both individually and together that highlight some of the tensions we encounter as new scholars in the field of Indigenous education. After a particularly challenging class where students appeared resistant to explore their own privilege and positionality, Sarah sets off down the hall and as she turns the corner, sees Beth, another Faculty member in Education:

Beth: Hello Sarah. How are you doing? How are your classes going this term? I am hearing really good things about your Indigenous Education class from some of our teacher candidates.

I knew I should have went the other way! She caught me off guard and I am melting into the walls, in hopes that I disappear and that she will just keep walking.... I'll just wait a few seconds .... nope she is still talking to me. Ok, time to formulate a response.

Sarah: "Hello Beth. How are you? Yes, the classes seem to be off to a good start. The students appear to be engaged and are asking a lot of great questions. I am really enjoying teaching this class so far."

Thank goodness she can't hear what is going on inside my mind. I would much rather respond with something like, "Well Beth, my students seem particularly resistant to exploring their own privilege and how that might impact their positionality as teachers. My students can't process their privilege and it is so frustrating to watch. However, I am not sure that's a conversation you are interested in having right now."

Beth: So how has it been for you teaching the Indigenous students in the class seeing as you are not Indigenous? 
Really, I can't believe she is asking me this. Perhaps now is not an appropriate time to get into the politics and optics of who the Indigenous students are in our Faculty of Education. Let's not get into the politics of self-identification right now in the hallway. And this course isn't JUST for the students who self-identify as Indigenous is it? What about the non-Indigenous students and increasing their levels of cultural awareness and sensitivity? I am reminded yet again of the lack of cultural sensitivity this Faculty carries. I wish I could say all of what I am thinking aloud rather than letting these thoughts ruminate in my head, but that wouldn't be professional of me now would it? So after a few head nods and a short pause to signal that I am thoughtfully crafting a response I answer with:

Sarah: It's been a great opportunity to model for students how a non-Indigenous person can and should be engaged in this field of education. One of the real goals of the course is to increase students' confidence and comfort levels so that they see themselves doing this work.

Beth: That's great Sarah. You are doing fine work.

Sarah's self-reflection. I always hold my breath slightly when I am at a faculty meeting, a staff luncheon, or beginning a new class term and I am asked the question, "What do you do?" I never know where I am supposed to begin. How far back do I go? How much do people really want to hear? Do I tell them I am doing research in the field of Indigenous education? Usually this information leads to a curious look on people's faces. They stare harder, their eyes burning into me trying to figure out why someone non-Indigenous is involved in such work. Do I tell them I once taught in a First Nations community? Revealing this information usually causes the dumbfounded look on people's faces to fade. Depending on the venue I either propel forward with this fact or I hold onto it for a moment, slipping it into my pocket for when I need to prove my legitimacy. I introduce myself as non-Indigenous but I find some discomfort in the non-piece. I feel it excludes, divides me, perhaps even distancing me from the work that I do. I am easily made uncomfortable by other's questions. How do I both present my legitimacy, my motivation for working in Indigenous education while being honest with myself and others that I am still very much a learner alongside them?

\section{The Social}

Dialogue. We both have had various school and professional experiences, and as a result of those we have created lasting and important friendships. Tibby represents a culmination of our experiences and conversations with friends in social situations. Over lunch the usual conversation about family and social updates has been taken care of and the focus turns to work. Tibby, an ever caring and invested friend begins to inquire about how Dawn's work is coming along.

Tibby: How are things going with your work Dawn? What's new?

Dawn: Things are good. Busy with work and school as usual. Sarah and I are writing a paper right now and we are focussing on how we respond in different ways to different people when asked questions related to our field of study. It has been really interesting. It is nice because it provides us with an opportunity to really look at how our writing and thinking remains colonial in some 
ways. We always struggle with our roles in Indigenous education as non-Indigenous people you know?

Tibby: Oh right - so we are saying Indigenous now and not Native or Aboriginal - I cannot keep up with what they prefer to be called. I am not even sure what some of those words mean - hahaha - that's good you are writing with Sarah because you need that for publishing right - so how is Sarah doing? I saw on Facebook that she had been on a road trip and done some hiking?

Dawn: She is good. Busy with school and stuff too but she has been doing lots of travelling. We are going to a conference in a few weeks so we might do some shopping when we are there. It should be fun.

I am going to completely avoid any details about what I am specifically working on at this time. Would Tibby want to know or understand the anti-colonial position of teacher retention in First Nation communities, or the funding gaps and achievement gap that dictate the literature I have been reading? Probably not. So rather than expand, I deflect all questions about my research and work and move on to more neutral territory - shopping.

Dawn's self-reflection. At BBQ's, birthdays, and basically any social gathering I attend I am often asked, "So how is work going?" I consider how I might reply. Constructing this reply requires a quick but deep analysis of who is asking and what they really want to know. At this point I hope my phone will ring, that someone reaches for me or joins the conversation and changes the subject. Avoidance, delay and outright redirection are usually my initial responses to this question.

It is often difficult to respond in a meaningful way for a number of reasons. First, I dread that a comment or statement will be made that deeply offends me and could potentially compromise the relationship I have with that person. What would I do if a close friend of 25 years made a racist comment? Rather than explore the possible outcomes of that scenario I avoid it all together. Do you need help with those dishes? I can help! Do you need a hand preparing dinner? I can help! I will help with anything rather than detail my experiences. I assume whoever asks doesn't really want to know. I assume they are just trying to engage me, humor me, or entertain me to be polite. I assume they don't care. I assume if I really talked about what I was working on or thinking that they would grow uncomfortable because what I talk about might require them to assess their own privilege, question the stereotypes they hold and seek to understand rather than be understood. It is clear that my perception in social interactions are riddled with assumptions: I don't want to inconvenience others, or disrupt the status quo but then I leave feeling like a fake, like I am perpetuating the status quo. Why in these social situations am I so careful not to disrupt?

\section{The Insider (The Stories we Tell Each Other)}

Dialogue. We have been friends, colleagues, and co-authors for several years and as a result, phone calls are often blended conversations between personal and professional stories. Teaching similar courses across the country have made for some interesting conversations about the parallels and differences between provincial politics and the needs of students and school communities. Below is a phone call that details a common teaching experience. 
Dawn phones Sarah:

Dawn: Hey. So I was teaching today and the whole idea about not doing Indigenous work because I don't have Indigenous students in my class came up yet again.

Sarah: Oh dear. What happened?

Dawn: Basically I have a group of about 20 students, some are First Nations and Metis but most are non-Indigenous and we were talking about how to incorporate Indigenous perspectives and content into the curriculum. Specifically, we were talking about using story books by Indigenous authors at the elementary level and a few of the students seemed really disengaged. So I went up to them and tried to get a dialogue going and they were saying, "I will be teaching here in town. I won't have any Indigenous students in my class so I would not need to use these types of books." Ugh it is so annoying.

Sarah: This issue keeps coming up. I have had the same discussion in my class and I can't help but feel slightly defeated when this question is asked. Like all of the work we have done in class up to this point has gone over their head. Anyway, how did you respond?

Dawn: Yeah, I hear you. We spent the first four or five weeks of class talking about positionality, assumptions in education, and white privilege and that was a challenge enough. The students were initially resistant because they had to think through some difficult and uncomfortable things. But, at some point I felt like we had made progress. When we talked about settler Canadians and the role of treaties, I felt like I had made the case for why incorporating Indigenous perspectives, content, and resources is needed.

Sarah: Yes, but Dawn, both you and I know that talking about white privilege and examining white privilege are two different things. And we have to acknowledge that by teaching courses such as this we hold a certain position of power as teachers and as non-Indigenous people that cannot be taken for granted.

Dawn: I had my students read The Invisible Backpack by Peggy Mcintosh and we did an activity called Cross the Line where if students had experienced one of the items on Macintosh's list, they would cross the line. It made a very clear case that some students in the class had certain privileges and others didn't, specifically related to race. I saw students who were white step over the line and look back at the Indigenous students and other non-white students in the class who didn't step over the line. There was a clear distinction. I think they can understand it theoretically but when it comes to how it looks in the classroom they, and I, hit a roadblock.

Sarah: It is like we are having to almost persuade our students that white privilege is real, all while working within a system that unfortunately operates through a colonial, Eurocentric framework. We are trying to decolonize our class but the influence of conflicting messages continues to push back against our best efforts. At times like this I think we both need to take a step back and remind ourselves what brought us to this work in the first place. Why is doing Indigenous education important to us? Why does this matter to us? We wouldn't keep returning to this topic if it didn't matter to us in some way. 
Dawn: True. I think I realized that for me now, the reason I still do this is not only because of my past teaching experience up North but because I want students here in the Faculty of Education to carry this work on. I had a moment in my class this term that was very different than any other class I have taught. I was teaching in a curriculum and instruction class and all my students had majors in Native American Studies (NAS) so they came to me with a really good grasp of Indigenous issues so we had a different starting point. One day we had an Elder come to class and he talked about their experiences in school. We invited another class who were not NAS majors to join the discussion. The debrief conversation was amazing! At one point a student asked the same question we are talking about right now. The student basically said, "Why would I need to do any of this if I don't have Indigenous students in my class? I teach science so there isn't really room for Indigenous perspectives to be incorporated." There was a moment of silence in the room and I hoped someone would respond to this student. Slowly I saw a student raise her hand. A typically quiet student, she actually stood up and addressed the question. She basically said, "You not only have a responsibility to incorporate Indigenous perspectives, because it is provincially required and it is in the curriculum, but you also have a responsibility as a settler Canadian. You have a stake in treaties as do all of our students. It's not about having Indigenous students or not. In fact non-Indigenous students might need to know this more." Wow. I was blown away. The NAS students were able to respond to the questions of the other non NAS students really well. It was one of the rare times where I felt like I was standing amongst allies and didn't have to convince anyone about why this work is necessary and important.

Sarah: That's incredible that your student felt comfortable enough to stand up in class and make such a strong statement. And it is true. We all have a stake, an obligation to do this work but unless our preservice students have those one on one interactions with people where personal stories are shared, they won't understand why this work is so important and needed. In class I often feel like I have hooked them, like they have seen the light, so to speak, but I am always worried that their responses to me are just lip service. Do they say they get it just so that I get off their back? What happens when they walk out those classroom doors?

Dawn: I think about the sustainability of it too. What will students do in a year, three years or even five years? It's hard to know what impact has been made if any. I think strategically, the strongest way to have an impact is to ensure the actual curriculum is more inclusive of Indigenous issues and perspectives. And of course create more understanding within Faculties of Education so the message is somewhat consistent across programming.

Sarah: Yes, I agree. I tell myself that maybe what we discuss in class may not matter to my students now, but some day, in some interaction they have, be it in a classroom or in the checkout line at the grocery store, they will reflect back and draw some sort of connection and hopefully be more empathetic towards others, not believe everything they hear and just learn to listen more.

Dawn: I hope so too. I am sure we will continue to talk about this again. I teach in 10 minutes so maybe I will call you after class with a new story. Talk to you soon.

Sarah: There is always something to talk about isn't there? Have a good class.

Dawn: Always. Talk to you soon. Bye 
Dawn: Oh shoot - I only have 10 minutes. I need to grab chart paper and markers and all the lesson plan assignments that need to be handed back. Off I go. Hopefully the students are feeling good today. I know they were a bit down last week with all the tensions around white privilege. I will need to get them engaged again. Sarah asked why this was important to me, and why we keep doing this work. I don't know if I stop enough to really think through what my own response to these questions are. What is my response to myself? It should be the most important but I think it's the response I think about the least.

Sarah: I hang up the phone with Dawn and despite having a hundred things to get done by the end of day, my thoughts go back to our phone conversation and the questions I posed. What brought us to this work in the first place? Why does this matter to us? Why does this matter to me? I think about these questions a lot and often it is difficult to put into words why this work matters, why I am involved in this work. Just as my students are working through these difficult questions so am $I$.

\section{The Self (The Stories we Tell Ourselves)}

Dawn: The story I tell myself is quite possibly the simplest of all. I am invested in Indigenous education because when I was a high school teacher I felt the challenges my students experienced and somewhere inside of me I knew it wasn't fair. Inequitable funding, oppression, loss of language and culture, assimilation - all through the education system. I saw the impacts on my students and how it shaped their experiences of school. I realized that as a teacher I was implicated within this system. I needed to understand more and I am still doing that many years later.

My response to how I feel about doing this work as a non-Indigenous person is not simple at all. The intention may be clear and simple but the carry through is wrought with complexities about place, space, identity, legitimacy, and allyship. I know this is a path for me and every day I move along that path sometimes being redirected by different people or my own reflections. I remind myself to be patient and be ready for what I need to know when I will most need to know it. I realize now I model this journey for my students and try to make it explicit, often inviting students to join me. Everyday poses new challenges and new opportunities and with those I will continue to think about why this is important to me. This is only a partial response, one that might not ever be complete, but it is the beginning that will grow with time and for now I remain comfortable with the uncomfortability of it all.

Sarah: I look back at the person I was in those first couple years teaching in northern Ontario and I don't recognize her. I am amazed at how little she knew and wonder what impact her ignorance and complacency might have had on her young students. Other times I am angry, appalled that she didn't know more. Even now I am continuously in awe at how little people know about Canada's Indigenous peoples, at how unaware or apathetic people are to another's experience of inequity because of who they are and where they come from. How do people turn and simply look the other way? She is/I am not able to look away anymore.

Now that I teach new teachers who are just beginning their careers I am more sympathetic toward her, knowing that she and I are a product of a system that privileges certain ways of knowing over others. The hesitation, the fear of making a mistake, the desire to learn more but unsure of when enough is enough--these are the questions and comments I hear constantly from my students. I tell them I understand, that I have heard her/myself respond in the same way. I tell them their good intentions will go a long way, that people will be there to help guide them, 
encourage them, that people will be kind to them. Providing these words of comfort and encouragement puts my students at ease; it gives them hope. They need to hear these words. There are times however when hearing such words is not enough. A positive sentiment can't take away the heaviness that weighs on my shoulders and heart after hearing another's story of trauma and abuse. Hearing students confide to me that they don't feel safe in school because of their cultural background nearly brings me to tears. There is no knife sharp enough to cut through the tension that has filled the rooms of meetings I have attended between Indigenous and non-Indigenous people around what Indigenous education is, what it can be, why it is important. It is often tiring, emotional work. I have days where I grow frustrated with how slowly things seem to change. Yet, I know too that this journey is lifelong. That where I am today is different from where I was yesterday and where I will be tomorrow. There is an ebb and flow to the work that requires me to trust others and myself and I will continue on this journey.

\section{Discussion}

\section{Unpacking our Stories}

Through our writing, we realized the stories we shared previously were ones where we felt most comfortable; those where a happy ending was always guaranteed and where our audience was left feeling hopeful about the future. We avoided the embarrassing, awkward, and upsetting stories but were less clear as to why we censored ourselves. We have brought forward one perspective of those uncomfortable stories here. We face the avoidance and censoring and acknowledge the constraining boundaries.

\section{Avoiding and Censoring}

Avoidance was a strong tactic used in our academic and social interactions. We were not engaging in dialogue or conversation with our colleagues or friends but rather avoiding one. In fact, we utilized exit strategies to disengage and remove ourselves from the spaces where these conversations occurred. These strategies were enacted most often when we sensed possible conflict or disagreement.

In these interactions we often censored what we said and how we said it when the conversation turned to our involvement in Indigenous education. One strategy of censorship we utilized was pre-determining at what point to begin a conversation. Our pre-determinations were based on a number of assumptions about the person we were conversing with. How much do they already know? What positions do they hold? What were their beliefs? What were their intentions and what was their purpose in beginning a conversation with us in the first place? And most importantly, what was our existing relationship with this person? We were more consciously aware of this behaviour in our interactions with friends and family but less so when interacting with colleagues. For example, in the social story, Dawn quickly averted the conversation with Tibby when Dawn perceived tensions around terminology. This was not only an avoidance tactic but a strong indication of censorship to the degree of silencing ourselves. We noticed these behaviours most often in our social interactions where long-standing, valuable relationships could be compromised. These themes are limiting to our position as instructors in Indigenous education and as allies to Indigenous agendas. We need to see social and academic interactions as proactive opportunities and invitations rather than reactive exits and endings. 


\section{Constraining Boundaries}

We feel empowered in our teaching practices and in conversation with one another but why does empowerment not extend to the hallway conversation with Beth or the informal conversations with Tibby? We found deeply rooted connections with our own educational experiences as students and then as teachers all in predominantly western institutions. We learned early on in our own schooling experiences that the work of teachers takes place in classrooms and schools. So, when our work as teachers and researchers extended beyond classroom walls, we often felt unsure about how to proceed and as a result, we avoided and censored. The classroom environment became a safe space and site for engagement and ongoing professional development. Unfortunately this engagement and empowerment is often limited to the classroom versus the hallways or out for coffee with friends because those spaces are traditionally not perceived as sites for learning. Institutional norms also impact how we see our role. The university measures what counts and what matters in course units and in instructional hours. We see now that there are amazing teaching and learning opportunities that extend beyond the classroom. Rather than seeing these spontaneous encounters as something to avoid, we need to push beyond the institutional constraints and our conceptions of where and when teaching and learning can occur.

\section{Conclusion}

We began this inquiry by asking what we feared might happen if we divulge our untold stories. In order to critically engage with the stories we tell, we utilized four conversational sites in which we regularly interact: the academic, the social, insider, and self. In the academic and social interactions, censorship and avoidance were tactics we employed to prevent potential conflict or misunderstanding. Through listening and sharing these stories with one another, we found what we fear most is compromising relationships, including our relationship with ourselves. A greater fear lies in compromising our integrity, and silencing ourselves to the point where we are unable to embody allyship in Indigenous education. This implores us to seek new strategies beyond censorship and avoidance.

\section{Recommendations}

With an increased focus on national reconciliation efforts, (Truth and Reconciliation Commission of Canada, 2015), faculties of education are being called on to improve their programming and better attend to Indigenous perspectives. This effort, out of necessity, must include both Indigenous and non-Indigenous students and educators. Hansen and Antsanen (2016), emphasize the connection between the inclusion of Indigenous perspectives in education and the ongoing colonial experience. They recommend:

expanding Indigenous teachings devoted to raising awareness of social and cultural issues to the non- Indigenous community who could also benefit from a non-Eurocentric Indigenous education curricula. Without these governmental supports, Indigenous people will continue to experience racial stereotyping, social exclusion, and marginalization in the wider society. (p.15)

Moving beyond censorship and avoidance is necessary, not only to improve our practice as teachers, but to better attend to and engage in reconciliation efforts. In our own teaching, we raise 
students' and our own consciousness utilizing three general strategies; low-risk role play, community integrated involvement, and partnerships.

Low-risk role play strategies create experiential opportunities for students to explore sensitive but important concepts like oppression and privilege. The blanket exercise (Kairos Canada, 2017) is an excellent low-risk teaching tool where students interactively build understanding about our shared history as Indigenous and non-Indigenous peoples in Canada. Community integrated involvement is another approach which shifts the locus of knowledge to members of the local community. Inviting guest speakers into your class or arranging visits to significant local sites are all opportunities for students to experience the specificity of various Indigenous contexts. These experiential learning opportunities are essential for disrupting any preconceived assumptions or stereotypes held by students. Lastly, early engagement with Indigenous leaders and communities, both within and beyond the academy is the foundation that will set the tone for long term sustainability. These relationships must reside on a sincere commit to trust and learn from one another. Only then will we be better able to engage our students and empower ourselves to move beyond the avoidance and censorship that has so often dictated the stories we tell. 


\section{References}

Battiste, M. (2013). Decolonizing education: Nourishing the learning spirit. Vancouver, BC: Purich Publishing Ltd.

Burleigh, D., \& Burm, S. (2013). Unpacking our white privilege: Reflecting on our teaching practice. In Education, 19(2), 107-119.

Cannon, M. J. (2012). Changing the subject in teacher education: Centering Indigenous, diasporic, and settler colonial relations. Cultural and Pedagogical Inquiry, 4(2), 21-37.

Gordon, C. E. \& White, J. P. (2014). Indigenous educational attainment in Canada. The International Indigenous Policy Journal, 5(3), 1-28.

Hansen, J. G. \& Antsanen, R. (2016). Elders' teachings about resilience and its implications for education in Dene and Cree communities. International Indigenous Policy Journal, 7(1), $1-17$.

Hare, J. (2011). The way of the warrior: Indigenous youth navigating the challenges of schooling. Canadian Journal of Native Education, 34(2), 93-111.

Kairos Canada. (2017). What is the blanket exercise? Retrieved from https://www.kairosblanketexercise.org/

Kovach, M. (2009). Indigenous methodologies: Characteristics, conversations, and contexts. Toronto, ON: University of Toronto Press.

Norris, J. (2008). Duoethnography. In L. M. Given (Ed.), The SAGE encyclopedia of qualitative research methods (pp. 233-236). Los Angeles, CA: SAGE.

Norris, J., Sawyer, R. D., \& Lund, D. (Eds.). (2012). Duoethnography: Dialogic methods for social, health, and educational research. New York: Routledge.

Nicol, C., \& Korteweg, L. (2010). Braiding teacher lives into relation: The steps and dilemmas of culturally responsive teacher education in Canada. In A. Heinz (Ed.), The eighth international conference on self-study of teacher education practices (pp. 183-187). Provo, Utah: Brigham Young University.

Paquette, J. \& Fallon, G. (2008). First Nations education and the law: Issues and challenges. Education Law Journal, 17(3), 347-378.

Sawyer, R. D., \& Norris, J. (2013). Duoethnography. New York, NY: Oxford University Press.

Sawyer, R. D., \& Norris, J. (2016). Dialogic interdisciplinary self-study through the practice of duoethnography. In R. D. Sawyer \& J. Norris (Eds.), Interdisciplinary reflective practice though duoethnography: Examples for educators (pp. 1-14). New York: Palgrave Macmillan.

Truth and Reconciliation Commission of Canada. (2015). Honouring the truth, reconciling for the future: Summary of the final report of the truth and reconciliation commission of Canada. Retrieved from http://nctr.ca/assets/reports/Final\%20Reports/Executive_Summary_English_Web.pdf 


\title{
What Informs and Inspires the Work of Equity Minded Teachers
}

\author{
Stephanie Tuters \\ OISE/UT \& Niagara University
}

\begin{abstract}
This article explores teachers' reasons for engaging in equity work. Although multiple bodies of literature discuss teaching for equity from different perspectives, little empirical data exists about what informs or motivates people to teach for equity. This study aims to help fill that gap in existing research with the purpose of informing professional development and training for practicing teachers hoping to or attempting to engage in equity work, and for encouraging and motivating other educators in beginning to engage in equity work. Data was gathered through interviews with 15 teachers from three large school boards in Southern Ontario. Findings illustrate that participants were motivated to engage in equity work because of personal experiences with inequity, witnessing other people experience inequities, and learning about inequities in school. Three key findings stand out with regards to their utility for professional development and training: all participants spoke of critical incidents which compelled them to do equity work; emotional struggles were associated with their work, yet they remained hopeful in the possibility of change regardless of what they had experienced; finally, the nature of the equity work that participants chose to undertake was directly related to the nature of their experience with in/equity.
\end{abstract}

Keywords: Teachers, motivations, equity work, experiences of inequity, witnessing inequity, learning about inequity

Stephanie Tuters, Ph.D., is currently a Lecturer at the Ontario Institute for the Studies in Education (OISE) of the University of Toronto, and Niagara University. Her doctoral thesis, supported by Ontario Graduate Scholarships and University of Toronto Scholarships, explored how teachers understand, experience, and respond to inequities in elementary schools. Stephanie has presented research relating to leadership and teaching for social justice at both academic and practitioner conferences; this work can also be found in both academic and practitioner publications.

\section{Email: stephanie.tuters@mail.utoronto.ca}


This article describes a study exploring teachers' reasons for engaging in equity work. The study is in response to the growing diversity in the student population in Ontario, and the increasing need for teachers who are able to respond to that diversity in an equitable fashion (Brown, Wiggins, and Secord, 2009; Gerin - Lajoie, 2008; Solomon, Singer, Campbell, Allen, $\&$ Portelli, 2011). Ontario is an increasingly diverse province. For example, Ontario receives around $40 \%$ of all immigrants to Canada on a yearly basis with a large portion of those immigrants settling in the Greater Toronto Area (GTA) (Ontario Ministry of Finance, 2011a). It is projected that by 2036 net migration will account for $68 \%$ of the population growth in the province (Ontario Ministry of Finance, 2011b). Regrettably, although there are many positives associated with diversity, and Ontario as a province celebrates diversity, differences in academic achievement exist which are related to characteristics of diversity such as socioeconomic status, and ethnicity. For example, "recent estimates from the Toronto District School Board (TDSB) indicate that as many as 40 per cent of Caribbean-born students and 32 per cent of those born in Eastern Africa, and 28 per cent of students from Western Africa dropped out of high school" (Brown, 2006 as cited in Sweet, Anisef, Brown, Walters \& Phythian, 2010, p. 10). Further, the Thames Valley District School Board (TVDSB) in London Ontario had a five-year high school graduation rate of $77 \%$ in 2014 while the Halton District School Board (HDSB) had a five-year graduation rate of $88 \%$ (Ontario Ministry of Education, 2015). The director of the TVDSB was quick to point out that their students experience great challenges in their academic pursuits, particularly relating to family income. The students in the TVDSB experience higher levels of poverty than students at other school boards such as the HDSB (Dubinski, 2015).

School boards such as the Toronto District School Board have acknowledged that achievement gaps exist which are directly related to race which they state they "must continue to work on" (Malloy, 2016). As a result, they have set up programming such as the Inner City Schools program, and the Afrocentric School, to help eliminate such achievement gaps, along with a comprehensive Inclusive and Special Education Plan to "ensure that every student, every day, in every school is welcomed and included within the most enabling learning environment" (Toronto District School Board, 2014). These policies and programs relate to the Provincial mandate which is focused on increasing equity and inclusion in Ontario public schools, and is described in the Ontario Ministry of Education Equity and Inclusive Education Strategy (2008). The ministry of Kathleen Wynne acknowledged in the Equity and Inclusive Education Strategy (2008), that barriers to inclusion exist in Ontario schools, and that they need to be addressed and removed (p. 2). Teachers doing equity work is one way in which these barriers to inclusion can be overcome.

Few scholars have investigated the understandings and beliefs held by teachers who choose to engage in this work. Those who have researched this topic note that the lives of equity minded educators informs their practice, yet their voices of critical educators are unfortunately uncommon in existing literature and need to be uncovered (Mogadime, 2011, 2012; Mogadime \& Smith, 2007). Researchers also note that many teachers unfortunately hold deficit conceptions of students, even those educators who claim to be engaging in equity and social justice work, and that this issue should be addressed in training and education (Sleeter et al., 2004); and that teacher candidates are often resistant to overcoming these deficit conceptions and adopting an equity lens to inform their practice (Brown, Wiggins, \& Secord, 2009). Data from this study can be used to inform professional development, education, and further research, by uncovering what encourages people to teach for equity. In particular, data can be used to support existing equity minded educators in developing their craft in the form of

Brock Education Journal, 26(2), 2017 
professional development and training, and for encouraging others to engage in work that contributes to the creation of more equitable and inclusive schools.

\section{What is Equity/Inequity?}

Equity is popularly discussed in education, yet it is a complicated term with multiple meanings. For some, equity means that everyone should receive the same things (Jencks, 1988, p. 519). For others, equity means more should be given to those in need (Jencks, 1988). For others still, equity includes calculations of merit based on fair or meritocratic competition (Jencks, 1988). Determining who should get what and how is not an easy task and it is highly dependent on context and the distribution of political power (Stone, 2012). Those with more voice and political power will have a greater influence over the distribution of all other assets. Broadly speaking, for this article the term equity is used to describe processes where individuals are working to achieve fair and equal opportunities for all students, based on their individual needs, it "does not necessarily entail equal treatment" (Solomon et al., 2011, p. 15). In this case, the work that equity minded educators are doing will be specifically targeted towards helping students to overcome barriers to achievement such as discrimination and oppression based group membership and identity characteristics, and other barriers associated with things such as socio economic status and access to high quality educational programming and opportunities (Banks \& Banks, 1995; Ryan 2012).

\section{What is Equity Work?}

Equity work can take many forms, including but not limited to: differentiating instruction and materials based on student needs (Delpit, 1995); encouraging participation in schooling from all stakeholders (parents, community organizations etc.) about what education should be like (Athanases \& De Oliveira, 2008; Ladson-Billings, 1995; Smith, Wohlstetter, Kuzin \& De Pedro, 2011); ensuring students can see themselves, their backgrounds, and their beliefs reflected in their education (Dei et al., 2003; Ladson-Billings, 1995; Rios \& Montecinos, 1999); ensuring all students have the resources and opportunities to achieve success, broadly defined as respecting the multiple and differing beliefs and values of students and community members (Banks \& Banks, 1995; Ladson-Billings, 1995; Nieto, 2004); helping students to develop agency to change their situations (Picower, 2007); and providing an academically rigorous environment that is supportive of the development of critical thinking (Freire, 2000; Jay, 2003; Nieto, 2004). The question that this study explores is why educators engage in these types of activities, and what informs their understanding, beliefs, and actions regarding equity.

\section{Why do Equity Minded Teachers do Equity Work?}

It has long been said that past experiences and beliefs inform teachers' actions (Irvine, 2003; Villegas, 2007). It has also been stated that it is problematic that the majority of teachers in North America are white when many of their students are of diverse backgrounds (Brown, Wiggins, \& Secord, 2009; Ryan, Pollock, \& Atonelli, 2009), as white teachers have often not experienced inequity and may be less capable of understanding the experiences of their students, particularly in comparison to their colleagues who have experienced discrimination and oppression (Howard, 1999; Sleeter, Torres, \& Laughlin, 2004). In research articles focusing on equity, comments are made about how people have different kinds of 
understandings of things like equity and diversity (Howard, 1999; Sleeter et al., 2004), yet very few scholars have investigated the understandings and beliefs held by teachers before attempting to change them (see for example Sleeter et al., 2004). Research regarding teachers' understandings and beliefs regarding equity and inclusion, in particular - why they choose to engage inequity work, is scant. Mogadime (2011) investigated the experiences of two critical educators, and how their identity informs their attempts to engage in antiracist and critical multicultural work in their schools, and found that the teachers' previous experiences and knowledge were highly informative for their equity practices. This study is therefore informed by the work of Mogadime (2011) as well as research on this topic in relation to the experiences of educational leaders as it is more developed (Griffiths, 2010; Singh, 2010; Theoharis, 2007).

Educational leaders who engage in equity work are described as being able to recognize that society and societal institutions marginalize certain groups and work to decrease inequities through their work (Theoharis, 2007). They are portrayed as deriving their motivation to do equity work from: previous experiences with marginalization or oppression, what they learned from these experiences, and what they would like to see changed as a result (Griffiths, 2010; Singh, 2010; Theoharis, 2007). Church or religious upbringing is often integral to the development of this responsibility to help others and community (Singh, 2010; Theoharis, 2007). Administrators often cite family and other close relationships, such as with mentors, as a source of influence; they refer to their parents as having shown them how education can be the route to a better life or a better world and helping to motivate them to contribute to equitable changes (Griffiths, 2010; Singh, 2010; Theoharis, 2007). Finally, geography or context is often influential. This could include living in an area where marginalization and oppression are commonly experienced, or in a particular time period - having grown up in an era such as the 1960s or 1970s when social justice and activism were common (Griffiths, 2010; Singh, 2010; Theoharis, 2007).

\section{The Cost and Complications Associated with Equity Work}

There are costs and complications associated with engaging in equity work, it is no easy task. Those who choose to engage in equity work often experience conflict with stakeholders such as colleagues, superiors, and parents (Ryan, 2012). Engaging in equity work can also associated with a lack of promotion and retention, isolation, and emotional distress related to engaging in processes such as retrospective meaning making to change and challenge ones thinking (Bell, Love, Washington, \& Weinstein, 2007; Boler \& Zembylas, 2003; Picower, 2011). Even those who believe strongly in the value of equity work and are committed to creating positive change are often ill equipped to deal with the challenges of this work (Tatar, \& Horenczyk, 2003) and can be subsequently pressured to make an early exit from teaching (Picower, 2007). Those who work with aspiring and practicing educators, attempting to encourage and support them in engaging in equity work experience challenges such as deficit thinking (Lipsitz, 2006; McIntosh, 1990) and resistance to change (Brown, Wiggins, Secord, 2009; Merryfield, 2000; Milner, 2010; Picower, 2011). One way of helping to mediate the effects of this environment, to contribute to the sustainment of existing equity work, and to encourage the development of new equity workers, is to learn more about the reasons current educators have for teaching for equity, and what they think attributed to their development as equity minded individuals. This data can be used to inform professional development, education, and further research, with the goal of supporting existing equity minded educators in developing their craft, and encouraging others to engage in work that contributes to the

Brock Education Journal, 26(2), 2017 
creation of more equitable and inclusive schools.

\section{Theoretical Framework}

This study is informed by theories of equity and social justice mentioned above and is guided by a critical lens, with the goal of problematizing things such as disparate achievement levels in education to help bring about positive changes and decrease inequities. Aspects of critical theory which inform this study include: the belief that everything is political, including lack of action; what teachers and administrators choose to do, and choose not to do indicate a political perspective or inclination; the belief that people (students) are unique fountains of knowledge; students are not empty vessels to be filled with information (Freire, 2000; 2001). Along with this comes the importance of incorporating the individual knowledge and experiences of teachers and students into education, and a belief in positive change or as Kincheloe (2004) and Freire (2000; 2001) might call it - radical love which leads to action and therefore positive change. A critical approach to educational research: "seeks to emancipate the disempowered, to redress inequality and to promote individual freedoms within a democratic society" (Cohen, Manion \& Morrison, 2007, p. 26). A fundamental goal of this study is to assist in making education more equitable and inclusive through examining and uncovering why equity-minded educators choose to engage in equity work.

\section{Methods}

The central question guiding the data analysis was - what informed, influenced, or motivated educators to attempt to decrease inequities through their actions as teachers and how did these experiences influence their practice? Data was collected using qualitative research methods (Merriam, 1998), as they are uniquely equipped to explore topics of which little is known. Designed to gather baseline information regarding teacher motivations, this study is primarily descriptive and exploratory. One on one, face to face interviews with teachers were used to gather data. Interviews were chosen as the method of data collection for their capacity to gather rich in depth information about a previously understudied topic. They also allow for flexibility in questioning (Merriam, 1998).

The style of the interview was relatively informal, much like a "conversation with a purpose" (Mason, 2006, p. 62), where the purpose was to get a narrative like account of teachers' viewpoints. Interviews started with a general discussion to familiarize the participants with the purpose of the study and help relax them before any of the questions were asked. The interview was more structured at the beginning, asking the participants to answer simple questions about age, gender, years of teaching experience, and current occupation, which provide a context for the discussion. As the interview progressed questions were less specific, providing greater opportunities for the participant to share narrative like accounts of experiences and thoughts on the topics.

The goal was to have the interview be co-constructed by the interviewer and interviewee, rather than a static process with a power imbalance which favours the interviewer (Rapley, 2001). Interviews varied in length, from half an hour to three hours, with the average length of the interviews being one and a half hours. For the most part, the length of the interviews related to the amount of years of experience the educators had been engaging in equity work. Some of the participants had more to say than others as they had more experiences engaging in equity work. At the end of the interview each of the participants was given the option of reviewing

Brock Education Journal, 26(2), 2017 
the transcripts and making and changes or additions.

Elementary school teachers from Ontario who self-identified as actively engaging in equity work in their schools were invited to participate in the study through a network of educators located at the Ontario Institute for Studies in Education entitled the Centre for Leadership and Diversity (CLD). A recruitment email was sent out to members of the CLD, members were asked to consider participating as well as forwarding on the email to their colleagues that might be interested in participating. Participants included those who held formal leadership roles within their schools, such as the leaders of the equity clubs or teams, as well as those who engaged in equity work in their every-day classroom work yet perhaps did not hold a formal title or belong to an equity group.

The participant group was comprised of teachers from three large school boards in Southern Ontario. The three school boards represent large diverse urban areas. An effort was also made to include a diverse participant group. Eight of the participants were female, seven were male. Many of the participants self-identified as being part of a marginalized group: one of the participants was a lesbian, one was gay, one was transgendered, two were black, two were immigrants, and two of them mentioned being second generation Canadian and having witnessed their parents being marginalized for not being considered to be Canadian. Participants were given pseudonyms that were similar in style to their original names but provided them with anonymity. The pseudonyms used were: Alana, Inta, Joana, Melony, Kurtis, Remi, Sarah, Kent, Sidney, Matt, Lesley, Mitch, Kristen, Bud, and Kelsey. An effort was made to exclude any information from the results that would allow the participants to be identified by a reader as much of the information that was shared by participants was of a deeply personal and sensitive nature.

Interviews were recorded using a voice recorder and transcribed at a later date. Notes were taken in a journal during and after the interviews and during the data analysis process. Interviews were transcribed into a word document. These word files were read to uncover initial themes that were informed by the literature review regarding educational leaders' reasons for engaging in equity work, and then uploaded into Nvivo and coded using these themes while still remaining open to new themes that emerged through repeated re-reading of the transcripts, using grounded theory (Creswell, 2015). The main themes that were uncovered using grounded theory included: having personally experienced inequity, having witnessed other people experiencing inequity, having learned about inequity through their education.

\section{Findings: Participants Reasons for Engaging in Equity Work}

Participants identified three main sources of motivation that included personally experiencing inequities, witnessing others experience marginalization, and being exposed to education about inequities and diversity either through their upbringing or their formal schooling.

\section{Personally Experiencing Inequities}

The most common reason participants gave for why they do equity work was having personally experienced inequities. Six participants described their personal experiences with inequities, and how they were influenced by them. These participants spoke of experiences they had in school settings, times when they had felt powerless, without a voice, and treated like an outsider or other and lacking agency. Inta described her experience as an immigrant

Brock Education Journal, 26(2), 2017 
and how it instilled in her a passion to teach for equity. She and her family immigrated to Canada from Eastern Europe when she was a young girl. She had many wonderful memories of her childhood home that were not reflected in the education she received in Canada. Misinformation and misinterpretation led to her home country and her people being vilified during the class lessons regarding World War 1. Inta said:

When I was in high school there was a textbook written about the war in XXXX, which is the country that I immigrated from. It talked about how the XXXX people were these evil people that started the First World War, and that wasn't my reality. And that was my first experience with that, it was a jarring experience and I remember shutting down in that class whenever conversation around that happened and it wasn't an environment where I felt comfortable to challenge that and say to my teacher - I don't agree with that.

Inta's educational experiences in Canada began with her being marginalized and misunderstood by her peers because of the way her teachers taught them about world events involving her home country. She felt ashamed and hurt about the way her home country was portrayed and like she wanted to change the system so other children would not have the same experiences as her.

Inta described how it was not until she became a teacher, was given a position of power, and accepted by "the system", that she began to feel accepted and Canadian. With this acceptance came an even greater desire to change things for the better. Inta was encouraged by her experiences to try to engage in equity work in her school. She identified two goals of her equity work, to help her students develop critical literacy skills and to help create an educated electorate, with the overarching goal of contributing to the creation of a more equitable society. She stated her belief that doing equity work is a "moral imperative". She concentrates her efforts around helping her students to be smart consumers of knowledge and learning the tools they need to think understand and think critically about the world, their place in it, and to make their own contribution to the creation of a more equitable world.

\section{Witnessing Inequities}

For five of the participants it was witnessing other people experience inequities or seeing their families and friends participating in inequitable behaviours that influenced and informed their equity work. Participant Melony's experiences travelling and living abroad as a child, because of her fathers' job, had initiated her development as an activist and critical thinker. A few events really stood out to her as critical moments. One was a trip to a local market with her parents:

For me, the image in my mind is always this little girl that I saw in Thailand, she had had her feet slashed for begging. We were at this market, so my parents were looking at fake alligator shirts, the Lacoste shirts, and they were haggling over how much for a dozen. And this girl was sitting right there and she was about the same age as I was. And because she was sitting there she wasn't learning how to develop a water filtration system that would help her own village. Or she wasn't able to get excited about painting or whatever it was that would be her thing to do. And all around her people were not seeing her, they were walking around and engaging in the superficial commerce.

One of the things that stood out to her the most about this situation was that her parents seemed oblivious to what was happening. When Melony looked around in astonishment, assuming

Brock Education Journal, 26(2), 2017 
someone would assist this girl, she was struck by that fact that this inequitable situation was somehow normalized and acceptable to those around her. She felt her parents and the other shoppers at the market were more concerned with their purchases than they were about the feelings and situations of others. Melony described her parents as nice people, of whom she was quite fond. However, she also described them as unaware and possibly disinterested in the fact that inequities existed and the fact that they might be contributing to the inequitable situations of others through their actions and inactions. Coming to this realizing was a difficult emotional process.

These feelings and questions resulting from Melony's experiences inspired her work as an educator and her beliefs about what people could and should learn. Melony had learned through her travels that people who enjoyed powers and privileges such as herself could choose to acknowledge the reality of their existence and the roles they played in contributing to inequitable situations, and they could become aware and interested in making positive changes. As a result of her experiences Melony had decided to help her students and colleagues develop critical consciousness, to incorporate multiple and global perspectives in her classroom, and to be transparent and educative of the different power relationships existing in schools. She attempted to get students to question where they fit in the formal and informal hierarchies of society and how they could express agency to create changes. Melony was also influenced to do this work in an affluent school as a result of her experiences. She felt it was very important to try to reach students who currently occupied positions of relative power, and would likely occupy positions of even more power in their adulthood.

\section{Learning About Inequity Through Education}

The third main reason participants gave for doing equity work was their education. Participants described how they had learned about equity and inequity, and felt compelled to teach for equity, as a result of formal or informal learning. Participant Matt described his motivation for engaging in equity work as beginning in university. He said:

In my masters work I have really had to think about it actually think about how I approach it as a teacher. Because when I think about my own identities and the bias that I bring and the various things that I carry with me and the various things that I portray to others just because of who I am, it carries different weights, different stigmas, and I need to be aware of that to be able to access and reach every single student on a human level.

He credited his formal schooling as helping him develop an awareness and desire to be more equitable. Matt described himself as a middle class White man. Although he had grown up in a very diverse area of a large city, he did not feel like he had really been "forced" to challenge himself and think about who he was in relation to others until he went to university. As a result of what he learned in university, he developed a desire to know more and to make changes. He began to understand that he had a particular identity that shaped how he perceived things and how other people perceived him. His identity also influenced the kinds of access and experiences he had. He therefore desired to learn more about people in general, what they had experienced, what personal biases people might have that could influence how they viewed one another, and the different ways he could get involved in equity work. He used this awakening that happened through his education to help inform his everyday classroom teaching, and in his interactions with his colleagues. He worked hard to be equitable as an educator and encourage his colleagues to do so as well by discussing what he was doing in his

Brock Education Journal, 26(2), 2017 
class and questioning his colleagues about how they could attempt to do similar things in their classes. Though, he highlighted that this was challenging, particularly when working with colleagues who had personally not experienced discrimination.

\section{Discussion}

Whether participants had personally experienced inequities or learned about them in school, commonalities emerged with regards to the kinds of things participants learned as a result of their experience, and how they influenced their equity practice. Three key findings stand out with regards to their utility for professional development and training in terms of assisting those currently engaging in equity work, and those providing professional development and training to aspiring and practicing equity minded educators. The findings are particularly useful in terms of their value for helping equity minded educators overcome challenges associated with engaging in equity work. All participants spoke of critical incidents which compelled them to do equity work. Emotional struggles were associated with their work, yet they remained hopeful in the possibility of change regardless of what they had experienced. Finally, the nature of the equity work that participants chose to undertake was directly related to the nature of their experience with in/equity.

All participants spoke vividly of critical incidents which informed their equity work. For some participants, the incidents took place in university programs, whereas for others they were personal experiences such as when Melony traveled abroad with her family. Studies involving prospective teachers that investigate the effect of service learning on their beliefs regarding things such as equity and diversity demonstrate similar findings with regards to the power of critical incidents. For example, Baldwin, Buchanan, and Rudisil (2007) found that for many of their participants, their service learning experiences were the first time they had experienced student diversity and their experiences were found to be successful at helping them to see things from alternate perspectives. Mogadime (2012) found that "teachers' growing awareness of social inequalities through critical incidents beginning in childhood, adolescence and adulthood" (p. 199). Findings such as these suggest that programs designed with the purpose of enticing educators to become equity minded in their practice could be successful if they incorporated either in service components or educational components that encourage participants to develop the ability to see things from multiple perspectives as well as the impetus for equity work.

Things such as critical reflection could be used with educators working in diverse communities to help unpack their experiences, and the experiences of their students and surrounding communities and how educators could change their thinking and practice to become more equitable. Merryfield (2000) uses the term "retrospective meaning making" to describe a process through which she asked teacher educators reflect on their past experiences and make meaning out of them for their current practice. Milner (2007) endorses the power of reflecting on past experiences for expanding one's knowledge and understanding of how and why to teach for equity, and for improving future teaching practice. Milner also argues that this reflection can be particularly useful for people who might be resistant to this kind of work such as those who occupy positions of power and privilege and have a hard time seeing things from other people's perspectives.

The second key finding is that participants spoke about experiencing challenges associated with their equity work which they described as taking a personal toll on them. Being resistant to engaging in equity work or thinking critically about identity and power are commonly

Brock Education Journal, 26(2), 2017 
researched phenomena (see for example Lipsitz, 2006; McIntosh, 1990). Much less frequently discussed are the emotional challenges experienced by those who willingly engage in equity work. Although the research that does exist suggests that those engaged in equity work are more likely to experience burn-out and leave the profession early (Tatar, \& Horenczyk, 2003; Picower, 2007). The role of emotions in engaging in equity work is scarcely discussed, and when it is, it is largely in relation to the emotional discomfort involved in shifting ones' worldviews (Bell, Love, Washington, \& Weinstein, 2007; Boler \& Zembylas, 2003; Picower, 2011). Ryan and Author (in press) explore the emotional work of educational leaders in Ontario who choose to lead for social justice. They found that there are serious emotional burdens associated with leading for social justice, and that for some, the bulk of their social justice work involves managing (or attempting to manage) the emotions of others (Ryan \& Author, in press). Left unaddressed is the emotional cost associated with engaging in equity work, particularly with regards to the emotional turmoil teachers experience resulting from their students and colleagues resisting work about which teachers feel so passionately. This study lends support to the notion of creating mentorship and support groups for those who choose to engage in equity work, and for those who might be convinced of its value. The participants in this study who mentioned feeling challenged in their attempts to do this work, also often mentioned the support they received from like minded colleagues, and how much they valued this camaraderie in their attempts to do equity work. Communities could therefore be a powerful tool for sustaining equity work in education (Katsarou, Picower and Stovall, 2010; Picower, 2011).

Participants also expressed their belief in positive change regardless of how awful the things were that they had experienced, witnessed, and learned about. Participants believed that they could and should play a role in achieving greater equity and inclusion through their work as educators. This belief in finding and achieving "good" in society is often discussed in equity related literature. Merryfield's (2000) participants espoused similar beliefs about being able to find the good in bad people and situations and enhancing this good through their work as educators. Freire describes this feeling as "radical love". In their work on social justice leadership, Miller, Brown, and Hopson, (2011) suggest that beliefs in radical love and positive change, are more than just niceties, they could represent a complete reframing of educational leadership. With regards to supporting and sustaining teachers' equity work, conceptualizing equity work as coming from a place of love and positivity could be helpful for supporting those currently engaged in equity work and encouraging new teachers to engage in equity work.

Finally, the nature of the equity work which participants chose to undertake in their teaching careers was directly related to the descriptions participants gave of their experiences with in/equity. For example, Inta described how she had experienced marginalization and discrimination related to immigrating to Canada from a country which was in conflict and negatively perceived by society as a result. These experiences led her to develop a critical perspective, especially regarding sources of authority that are often taken for granted such as the government. Later in her interview she went on to describe how one of her fundamental goals as an equitable educator is to teach her children to be critical thinkers. She wanted to teach them to constantly question the world around them and their role. Findings such as this are consistent with the research on this topic by Mogadime (2011), and suggests that targeted placements or educational experiences could be used that relate directly to the experiences of in/equity of the students with which prospective teachers will be working, or for teachers who are currently practicing. 


\section{Conclusion}

The goal of this study was to uncover the ways in which past experiences and learning influenced the development of the teachers involved in this study, what made them decide to become people who teach for equity, and how they incorporate this knowledge into their practice, with the further purpose of informing professional development and training of aspiring and practicing equity minded educators. Participants in this study identified personal experiences with inequities, having witnessed others experiencing inequities, and having learned about inequities in school as encouraging and influencing them to teach for equity. Findings such as this help fill the gap in the small but growing body of research regarding what influences and informs the work of those teaching for equity. Findings also provide baseline information for more in depth investigations into why teachers choose to engage in equity work, for the purpose of supporting those who choose to engage in equity work and encouraging other educators to follow suit. 


\section{References}

Athanases, S. Z., \& De Oliveira, L. C. (2008). Advocacy for equity in classrooms and beyond: New teachers' challenges and responses. Teachers College Record, 110(1), 64-104.

Baldwin, S. C., Buchanan, A. M., \& Rudisill, M. E. (2007). What teacher candidates learned about diversity, social justice, and themselves from service-learning experiences. Journal of Teacher Education, 58(4), 315-327.

Banks, J. A. (2008). Diversity, group identity, and citizenship education in a global age. Educational Researcher, 37(3), 129-139.

Banks, J. A., \& Banks, C. A. M. (1995). Equity pedagogy: An essential component of multicultural education. Theory into Practice, 34(3), 152-168.

Bell, L. A., Love, B., Washington, S., \& Weinstein, G. (2007). Knowing ourselves as social justice educators. In M. Adams, L. A. Bell, \& P. Griffin (Eds.), Teaching for diversity and social justice (2nd ed., pp. 381-393). New York, NY: Routledge. (Original work published 1997)

Boler, M., \& Zembylas, M. (2003). Discomforting truths: The emotional terrain of understanding differences. In P. Tryfonas, (Ed.), Pedagogies of difference: Rethinking education for social justice. New York: Routledge. 110-136.

Brown, N., Wiggins, R., \& Secord, D. (2009). This must be a suburban classroom!: Using photographs to investigate teacher candidates developing professional identities. Brock Education Journal, 18(2), 49-65.

Cohen L., Manion L., Morrison K. (2007). Research methods in Education. New York, NY: Routledge.

Cooper, K., \& White, R. E. (2004). Burning issues: Foundations of education. Oxford, UK: ScarecrowEducation.

Creswell, J. W. (2015). Educational Research: Planning, Conducting, and Evaluating Quantitative and Qualitative Research, Enhanced Pearson eText with Loose-Leaf Version--Access Card Package. Pearson Education, Inc.

Dei, G. J. S., James, I. M., Karumanchery, L. L., James-Wilson, S., \& Zine, J. (2003). Removing the margins: The challenges and possibilities of inclusive schooling. Toronto, Ontario, Canada: Canadian Scholars' Press.

Delpit, L. (1995). What should teachers do? ebonics and culturally responsive instruction. In T. Perry, \& L. Delpit (Eds.), The real ebonics debate (pp. 17-26). Boston, MA: Beacon.

Dubinski, K. (2015, April, 20). Big discrepancies in graduation rates at Ontario school boards. The Toronto Sun. Retrieved from http://www.torontosun.com/2015/04/20/bigdiscrepancies-in-graduation-rates-at-ontario-school-boards

Flores, M. A., \& Day, C. (2006). Contexts which shape and reshape new teachers' identities: a multi- perspective study. Teaching and Teacher Education, 22, 219 -232.

Freire, P. (2001). Pedagogy of Freedom: Ethics, democracy, and civic courage. New York: Rowman \& Littlefield Publishers Inc.

Freire, P. (2000). Pedagogy of the oppressed. New York, NY: The Continuum International Publishing Group.

Gerin-Lajoie, D. (Ed.). (2008). Educators' discourses on student diversity in Canada: Context, Policy, and Practice. Toronto, Ontario, Canada: Canadian Scholars Press.

Griffiths, D. (2010). Urban elementary principals' approaches to inclusion. Unpublished

Brock Education Journal, 26(2), 2017 
doctoral thesis, University of Toronto.

Howard, G. R. (1999). We can't teach what we don't know: White teachers, multiracial schools. New York, New York: Teachers College Press.

Irvine, J. J. (2003). Educating teachers for diversity: Seeing with a cultural eye. New York, New York: Teachers College Press.

Jay, M. (2003). Critical race theory, multicultural education, and the hidden curriculum of hegemony. Multicultural Perspectives, 5(4), 3-9.

Jencks, C. (1998). Whom must we treat equally for educational opportunity to be equal? Ethics, 98 (3), 518-533.

Katsarou, E., Picower, B., \& Stovall, D. (2010). Acts of solidarity: Developing urban social justice educators in the struggle for quality public education. Teacher Education Quarterly, 137-153.

Kissen, R. M. (2002). Getting ready for Benjamin: Preparing teachers for sexual diversity in the classroom. Lanham, MD: Rowman \& Littlefield.

Kincheloe, J. L. (2004). Critical pedagogy. New York, NY: Peter Lang.

Kumashiro, K. (2002). Against repetition: addressing resistance to anti-oppressive change in the practices of learning, teaching, supervising and researching. Harvard Educational Review, 72(1), 67-93.

Ladson-Billings, G. (1995). But that's just good teaching! The case for culturally relevant pedagogy. Theory into Practice, 34(3), 159-165.

Ladson-Billings, G. (2006). From the achievement gap to the education debt: understanding achievement in U.S. schools. Educational Researcher, 35(7), 3-12.

Lipsitz, G. (2006). The possessive investment in whiteness: How white people profit from identity politics. Philadelphia, PA: Temple University Press.

Malloy, J. (2016, July 29). TDSB's plan to tackle racial disparity. The Star. Retrieved from https://www.thestar.com/opinion/commentary/2016/07/29/tdsbs-plan-to-tackle-racialdisparity.html

Mason, J. (2006) (2 $2^{\text {nd }}$ ed.). Qualitative researching. Thousand Oaks, CA: SAGE.

McIntosh, P. (1990). White privilege: Unpacking the invisible knapsack. Independent School, Winter, 31- 36.

McGee Banks, C. A., \& Banks, J. A. (1995). Equity pedagogy: An essential component of multicultural education. Theory into Practice, 34(3), 152-158.

Merriam, S. B. (1998). Qualitative research and case study applications in education: Revised and expanded from case study research in education. San Fransico, CA: Jossey Bass.

Merryfield, M. M. (2000). Why aren't teachers being prepared to teach for diversity, equity, and global connectedness? A study of lived experiences in the making of multicultural and global educators. Teaching and teacher Education, 16, 429-443.

Miller, P. M., Brown, T., \& Hopson, R. (2011). Centering love, hope, and trust in the community transformative urban leadership informed by Paulo Freire. Urban Education, 46(5), 1078-1099.

Milner, H. (2005). Developing a multicultural curriculum in a predominantly white teaching context: Lessons from an African American teacher in a suburban English classroom. Curriculum Inquiry, 35(4), 391-427.

Milner, H. (2007). Race, narrative inquiry, and self-study in curriculum and teacher education. Education and Urban Society, 39(4), 584-609.

Milner, H. (2010). What does teacher education have to do with teaching? Implications for

Brock Education Journal, 26(2), 2017 
diversity studies. Journal of Teacher Education, 61(1-2), 118-131.

Mitchell, L. A. (2009). Becoming culturally responsive teachers in today's diverse classroom. Paper Presented at the 2009 American Educational Research Association Annual Meeting. San Diego, CA. pp. 1-50.

Mogadime, D. (2011). An Ethnography of two teachers' antiracist and critical multicultural Practices. Brock Education Journal, 21(1).

Mogadime, D. (2012) Using interdisciplinary feminist theory to arrive at an understanding of critical educators who put human rights at the center of school curriculum, In Cornelia Roux (Ed.), Safe Spaces: Human Rights Education in Diverse Contexts (193-206). Rotterdam, the Netherlands: Sense Publishers.

Mogadime, D., \& Smith, S. R. (2007). Including Muslim Teachers' Sensibilities into Wider National and International Discussions About Culturally Responsive Pedagogy. International Journal of Diversity in Organisations, Communities \& Nations, 7(4).

Nieto, S. (2004). Affirming diversity: The sociopolitical context of multicultural education (4th ed.). New York, NY: Allyn \& Bacon.

Ololube, N. P. (2006). Teachers job satisfaction and motivation for school effectiveness: An assessment. Retrieved from http://eric.ed.gov.myaccess.library.utoronto.ca/?id=ED496539

Ontario Ministry of Education. (2008). Realizing the promise of diversity: Ontario's equity and inclusive education policy. Toronto, ON: Queens Printer for Ontario.

Ontario Ministry of Education. (2015). 2014 graduation rates across the province. Retrieved from http://news.ontario.ca/edu/en/2015/04/2014-graduation-rates-across-the- province.html

Ontario Ministry of Finance. (2011a). Ontario Demographic Quarterly. Retrieved October 1 from http://www.fin.gov.on.ca/en/economy/demographics/quarterly/dhiq1.pdf

Ontario Ministry of Finance. (2011b). Ontario population projections update. Queens Printer.

Picower, B. (2007). Supporting new educators to teach for social justice: The critical inquiry project model. Penn GSE Perspectives on Urban Education, 5(1), 1-22.

Picower, B. (2011). Resisting compliance: Learning to teach for social justice in a neoliberal context. Teachers College Record, 113(5), 1105-1134.

Rapley, T. (2001). The art(fulness) of open-ended interviewing: Some considerations on analysing interviews. Qualitative Research, 1(3), 303-323.

Ríos, F., \& Montecinos, C. (1999). Advocating social justice and cultural affirmation: Ethnically diverse preservice teachers' perspectives on multicultural education. Equity \& Excellence in Education, 32(3), 66-76.

Ryan, J. (2006). Inclusive leadership. San Francisco, CA: Jossey Bass.

Ryan, J. (2012). Struggling for inclusion: Educational leadership in a neo-Liberal world. Charlotte, NC: Information Age Publishing.

Ryan, J., Pollock, K., \& Antonelli, F. (2009). Teacher diversity in Canada: Leaky pipelines, bottlenecks, and glass ceilings. Canadian Journal of Education, 32(3), 591-617.

Ryan, J \& Author, S. (In Press). Leadership and motions: Promoting social justice. In S. Clarke and T. O’Donoghue (Eds.), Educational Leadership in Diverse Contexts. London, UK: Routledge.

Shanahan, N. (2006). Safe at school: Gay and lesbian issues in the classroom. Our Schools, our Selves, 30-35.

Simpson, A. W., \& Erickson, M. T. (1983). Teachers' verbal and nonverbal communication as patterns as a function of teacher race, student gender, and student race. American Educational Research Journal, 20(2), 183-198.

Singh, H. (2010). Leadership for social justice: From elusive conceptions to arrested

Brock Education Journal, 26(2), 2017 
developments. Unpublished doctoral thesis, University of Toronto.

Sleeter, C. (2008a). Equity, democracy, and neoliberal assaults on teacher education. Teaching and Teacher Education, 24(8), 1947-1957.

Sleeter, C. E. (2008b). Preparing White teachers for diverse students. In M., Cochran-Smith, S., Feiman-Nemser, D. J., McIntyre, \& K. E., Demers (Eds. $3^{\text {rd }}$ ed.). Handbook of research on teacher education: Enduring questions in changing contexts (559-582). New York, NY: Routledge.

Sleeter, C., Torres, M. N., \& Laughlin, P. (2004). Scaffolding conscientization through inquiry in teacher education. Teacher Education Quarterly, 81-96.

Smith, J., Wohlstetter, P., Kuzin, C. A., \& De Pedro, K. (2011). Parent involvement in urban charter schools: New strategies for increasing participation. The School Community Journal, 21(1), 71-94.

Solomon, R. P., Singer, J., Campbell, A., Allen, A., \& Portelli, J. (2011). Brave new teachers: Doing social justice work in Neo-Liberal times. Toronto, ON: Canadian Scholars' Press.

Statistics Canada. (2009). Aboriginal identity population, by province and territory (2006 Census). Retrieved from http://www.statcan.gc.ca/tables-tableaux/sumsom/101/cst01/demo60a-eng.htm

Stone, D. (2012). Policy paradox: The art of political decision making. ( $3^{\text {rd }} \mathrm{ed}$.) New York, NY: Norton and Company.

Sweet, R., Anisef, P., Brown, R., Walters, D., \& Phythian, K. (2010). Post-high school pathways of immigrant youth. Toronto, ON: Higher Education Quality Council of Ontario.

Tatar, M., \& Horenczyk, G. (2003). Diversity-related burnout among teachers. Teaching and Teacher Education, 19(4), 397-408. doi:10.1016/S0742-051X(03)00024-6

Theoharis, G. (2007). Social justice educational leaders and resistance: Toward a theory of social justice leadership. Educational Administration Quarterly, 43(2), 221-258.

Villegas, A. M. (2007). Dispositions in teacher education a look at social justice. Journal of Teacher Education, 58(5), 370-380.

Villegas, A. M., \& Lucas, T. (2002). Educating culturally responsive teachers: A coherent approach. New York, NY: State University of New York Press.

Whipp, J. L. (2013). Developing socially just teachers: The interaction of experiences before, during, and after teacher preparation in beginning urban teachers. Journal of Teacher Education, 64(5), 454-467. doi: 10.1177/0022487113494845. 


\title{
Teacher Stress and Social Support Usage
}

\author{
Kristen Ferguson \\ Colin Mang \\ Lorraine Frost \\ Nipissing University
}

\begin{abstract}
In this paper, we explore how the frequency of utilization of social supports is related to teacher demographics, stress factors, job satisfaction, career intent, career commitment, and the perception of a stigma attached to teacher stress. Using data from self-report questionnaires $(N=264)$ from teachers in northern Ontario, we found that teachers seldom spoke to their health care providers about stress and instead utilized family, friends, fellow teachers, and sometimes their principals. The frequency of which teachers accessed different social support networks did vary depending on stressor (workload, student behaviour, professional relationships, societal attitudes, and employment conditions). Teachers who frequently talked to their friends about stress had a lower sense of career intent and career commitment. Males were less likely to talk to their various social supports about stress. This study adds to the literature by exploring the frequency of contact with and usage of social supports and their impact on teacher stress and perspectives on teaching.
\end{abstract}

Key Words: Teacher stress, social support, job satisfaction, career intent, career commitment

Kristen Ferguson, Ph.D., is an Associate Professor in the Schulich School of Education at Nipissing University. Her research interests include literacy education, literacy coaching, emergent literacy, teacher professional development and stress and coping in teaching. E-mail: kristenf@ nipissingu.ca

Colin Mang, Ph.D., is an Instructor at the Nipissing University School of Business specializing in the economics of education and technology adoption in higher education. Email: colinm@nipissingu.ca.

Lorraine Frost, Ph.D., is an Associate Professor in the Schulich School of Education at Nipissing University. Her research interests include special education, Indigenous education, social justice and equity in education, and issues in inclusive education for diverse populations. E-mail: frost@nipissingu.ca 
There is an established research base indicating that the mental health of employees impacts absenteeism, occupational disability, and early retirement (Baumann \&Muijen, 2010). In the profession of teaching, stress is an important issue for all stakeholders in education. A teacher's performance may suffer owing to high levels of stress and this may impact on student learning (Borg \& Riding, 1991; Brown, Ralph, \& Brember, 2002; Manthei \& Gilmore, 1996). For school administrators, there appears to be a high cost of teacher stress in terms of human resources. The Global Business and Economic Roundtable on Addiction and Mental Health researched data from the Ontario Teachers Insurance Plan and found that the rate of stress-related long-term disability among Ontario teachers is a third higher than in other professions (Harvey, 2004). More recently, in their study of Alberta teachers, Duxbury and Higgens (2013) found that teachers are more likely to report a depressed mood, be less committed to their organization, and have lower job satisfaction than other professional groups. Teacher stress impacts teacher absenteeism and work-related illnesses (Naghieh, Montgomery, Bonell, Thompson, \& Aber, 2015). Stress also contributes to teacher attrition (Clark \& Antonelli, 2009; McIntyre, 2006).

\section{Purpose of the Research}

In our previous research, we examined various aspects related to teacher stress in northern Ontario. We examined the prevalence of stress, the factors that cause stress and the stigma of teacher stress (Ferguson, Frost, Kirkwood, \& Hall, 2007). We have also researched which stress related factors predict two dimensions of teacher stress (anxiety and depression) and teacher job satisfaction (Ferguson, Frost, \& Hall, 2012). We wanted to know more about the possibility of social supports affecting teacher stress and other factors in their professional lives that contribute to stress. In this paper, we extend our analysis from our previous work (Ferguson et al., 2007; Ferguson, Frost, \& Hall, 2012) to explore the impact of social supports based on the frequency with which teachers spoke to others about stress. While other research in the extant literature has mostly explored social supports, teacher stress, and a possible buffering effect (Greenglass, et al.,1994; Greenglass, Fiksenbaum, \& Burke, 1996; Greenglass, Burke \& Konarski, 1997; Qin \& Zhu, 2007), our research is unique in that we are exploring the frequency of contact with social supports and how this contact is related to demographic characteristics, teacher stressors, a perceived stigma of teacher stress, job satisfaction, career intent, and career commitment. This research is significant, as teacher attrition is an area of concern, as some studies suggest that high numbers of teachers are considering leaving teaching (Duxbury \& Higgens, 2013) and that collegial supports could reduce this number (Mäkelä, Hirvensalo, \& Whipp, 2014; Smethem, 2007).

\section{Research Questions}

1. Do certain stressors impact the frequency of utilization of social supports among teachers?

2. Does teacher gender or other demographic characteristics affect the frequency of utilization of use of social supports?

3. Does the perception of a stigma related to teacher stress affect the frequency of utilization of social supports?

4. Does the frequency of utilization of social supports impact teacher job satisfaction, career intent, and career commitment? 


\section{Teacher Stress}

Workplace stress and the stressor-strain relationship has been a popular subject of inquiry since the 1970s (see Bowling Alarcon, Bragg, \& Hartman, 2015) and workplace stress has been associated with illness (Cooper, Dewe, \& O'Driscoll, 2001; Duxbury \& Higgens, 2013; Nixon, Mazzola, Bauer, Krueger, \& Spector, 2011), absenteeism (Duxbury \& Higgens, 2013), negative worker attitudes (Spector \& Jex, 1998), and poor job commitment (Chen \& Spector, 1992). Teacher stress can be defined as "the experience by a teacher of unpleasant, negative emotions, such as anger, anxiety, tension, frustration or depression, resulting from some aspect of their work as a teacher" (Kyriacou, 2001, p. 28).

Reports from Canada demonstrate the issue of teacher stress is an area of concern. In 2001, the Canadian Teachers' Federation reported that six in ten teachers indicated that their job was more stressful than it had been two years earlier. A study by the Ontario College of Teachers of 2001 education graduates found that the second most common reason that graduates were no longer members in good stranding with the Ontario College of Teachers was that the "working conditions were too stressful" (McIntyre, 2006, p. 48). In Newfoundland and Labrador, Dibbon (2004) reports that teachers are experiencing role intensification and its associated stress are negatively impacting both teachers' personal lives and their ability to meet students' needs in the classroom.

The Ontario College of Teachers surveyed teachers in 2006 and reported that $13 \%$ of teachers felt stressed all the time, compared to only $7 \%$ of the general public (Jamieson, 2006). Coulter and Abney (2009) found that Ontario trained teachers working in Canada were more likely to suffer from burnout than their Ontario trained counterparts working abroad in international schools. In their study of Ontario teachers who retired early and/or left the profession, Clark and Antonelli (2009) reported that workload and stress issues were commonly cited reasons why teachers abandoned the profession. Naylor and White (2010) found that two thirds of teachers in BC state that their stress and workload is more than it was five years ago. One fifth of teachers are considering leaving the profession (for reasons other than retirement) and state that the reasons include, "workload, stress and burnout, health conditions aggravated by stress, lack of encouragement, job insecurity, and dissatisfaction with provincial and district governance" (Naylor \& White, 2010, p. v). Naylor and White (2010) also report that of those teachers taking a leave of absence for illness, disability or stress-related, $51.5 \%$ state that workload contributed as a reason for their leave. The Elementary Teachers' Federation of Ontario (2012) stated that $77 \%$ of local union presidents identified workplace mental stress as a great or major concern impacting teachers.

A survey of nearly 1000 teachers by The Saskatchewan Teachers' Federation (STF, 2013) found that Saskatchewan teachers report role intensification and increased time spent on workrelated activities attributed to changes directed by the school divisions and government. This increase of time spent on work encroached on teachers' personal lives and over half of teachers report dissatisfaction with work-life balance (STF, 2013). While the majority of teachers felt that stress was an unavoidable aspect of the profession, 42\% strongly agreed and 33\% moderately agreed that workload was a cause of stress (STF, 2013). Over 8000 Canadian teachers completed a survey distributed by the Canadian Teachers' Federation (CTF) in 2014. CTF (2014) reports $79 \%$ of teachers believe their stress related to work-life imbalance has increased over the last five years and the biggest stressor for teachers was not being able to

Brock Education Journal, 26(2), 2017 
devote enough time to individual students. The Ontario Secondary School Teachers' Federation (Johnston-Gibbens, 2014) found that $41.4 \%$ of secondary schools reported an increase and $30.3 \%$ indicated a significant increase of overall levels of work stress in the past 5 years.

Duxbury \& Higgens (2013) conducted a national study about work-life balance in Canada; over 25000 workers completed the survey, with 2462 identifying as being a member of the Alberta Teachers' Association. Work-life conflict was also found to be significantly high for Alberta teachers when compared to other professions and impacts teacher absenteeism, productivity, and use of employee benefits (Duxbury \& Higgens, 2013). Workload stress is significant for teachers; as Duxbury and Higgens (2013) report, Alberta teachers spend 10 more hours working per week compared to other working professionals in Canada and experience twice the role-overload compared to other professions. This work-life stress is likely due to the lack of flexibility in teaching, with teachers indicting significantly less employer flexibility than all professions, including policing and nursing (Duxbury \& Higgens, 2013). Duxbury and Higgens (2013) also find that teachers are less committed to their organization, are more likely to leave the profession, and have lower job satisfaction when compared to other professional workers. Seventy percent of Alberta teachers report high levels of stress compared to $57 \%$ of the total of all professionals (Duxbury \& Higgens, 2013); in addition, Alberta teachers were more likely to report depressed mood $(47 \%)$ than other professionals $(36 \%)$ (Duxbury \& Higgens, 2013)

The problem of high levels of teacher stress is not limited only to Canada. For instance, Leung, Wah Mak, Yu Chui, Chiang, \& Lee (2009) found that 38.6\% of high school teachers in Hong Kong report strong maladaptive stress, in addition to $30.3 \%$ suffering from severe to extremely severe anxiety and $12.3 \%$ severe to extremely severe depression. In their study, Bannai, Ukawa, and Tamakoshi (2015) report psychological distress was identified in $47.8 \%$ of male and $57.8 \%$ of female junior high school teachers in Japan.

\section{Impact of Social Supports on Teacher Stress}

Variables such as social support, personality, and self-efficacy have the potential to impact and possibly reduce stress reactivity and strains (Lazarus, 1966; 1999). In regards to social supports, the extant literature affirms that there is a connection between teacher stress and social supports. For instance, Griffith, Steptoe, and Cropely (1999) reported that teachers with high job stress have low social support at work. Richards (2012) found that the most common method of coping with teacher stress is relying on the relationships of friends and family. Leung, Wah Mak, Yu Chui, Chiang, \& Lee (2009) found that teachers with high levels of stress management also reported higher levels of coping resources, including social supports, when compared to their peers with lower levels of stress management. The content of the social support received may also impact stress levels. For instance, Kahn, Schneider, Jenkins-Henkelman, and Moyle, (2006) found positive and negative conversations about the teaching profession effect burnout:

teachers who engaged in more (vs. fewer) communications with positive content with coworkers (i.e., positive emotional social support) experienced lower levels of job burnout, and teachers who engaged in more (vs. fewer) communications with coworkers dealing with negative content (i.e., negative emotional social support) experienced higher levels of job burnout (p. 799).

The hypothesis that social support can mediate the effect of stress has been proposed for decades (House, 1981). Greenglass (1993) states that social supports serve three distinct 
functions for an individual:

First, interpersonal relationships may contribute to health because they are a source of acceptance and intimacy, i.e. emotional support. Second, there is consensus that social support may provide useful information, advice and guidance, i.e. informational support. Third, people may assist with instrumental problems by providing financial assistance, goods, or services, i.e. instrumental support (p. 325).

While the link between social supports and teacher stress is evident in the literature, there are, however, mixed results in regard to social supports actually reducing teacher stress. Some studies report that social supports can influence teacher stress levels, including the extreme manifestation of stress, burnout. For instance, Russell, Altmaier, and Van Velzen (1987) reported that teachers who receive social support from supervisors, particularly with regard to reassurance of worth, were less vulnerable to teacher burnout. Fimian (1986) found that support from school administrators and teaching peers moderated stress among American special education teachers; however, teachers were more likely to receive support during times of stress from their peers than from administrators.

Pierce and Molloy (1990) found that Australian teacher burnout levels were higher among those with lower social supports. In their study of teacher burnout over time, Greenglass, Fiksenbaum, and Burke (1994) found that teacher burnout levels depended both on work stress and on the social support that teachers received from friends and relatives one year earlier. Overall, Greenglass, et al. (1994) found that social support had an overall buffering effect on teacher stress. In a follow up study, Greenglass, Fiksenbaum, and Burke (1996) reported that, of the three sources of social support (supervisor, co-workers, and family and friends), a teacher's co-workers are the most important buffers of the burnout manifestation of emotional exhaustion. Further analysis by Greenglass, Burke and Konarski (1997) revealed that social support, particularly from one's co-workers, predict teacher burnout; in particular, co-worker social support predicted decreased depersonalization and increased feelings of accomplishment. Qin and Zhu (2007) found that support from a teacher's supervisor is the most effective in alleviating stress and feelings of emotional exhaustion, and reduced accomplishment, while support from family and friends is the most effective in mitigating depersonalization.

Other studies report that social supports do not buffer teacher stress levels. Sheffield, Dobbie, and Carroll (1994) found that social supports do not generally predict the psychological health and well-being of teachers. Burke and Greenglass (1994) also found no effect from social supports on teacher job satisfaction, lifestyle behaviors, and self reported physical health. In a different report, Burke and Greenglass (1996) found that social supports do not predict psychological burnout among teachers. Cheuk and Wong (1995) investigated whether social supports have a buffering effect on teacher burnout of teachers in Macau. They found no significant results indicating that the social supports mediate teacher burnout.

There is also an emerging body of research looking at the impact of social media and online communities as a form of social support. For instance, Deryakulu and Olkun (2007) found that an online discussion community for teachers can provide emotional and instrumental support. Leung, Chiang, Chui, Lee, and Mak's (2011) found that novice teachers in Hong Kong reported that online discussion forums acted as a form of stress management.

\section{Gender and its Relationships to Stress and Social Supports}

The CTF (2014) reports that gender impacts aspects teacher stress levels. For instance, 
"Women were more likely than men to report experiencing stress related to having insufficient time to spend with their own children; for caregiving for family and friends; or for recreational pursuits" (p. 7). In addition, women were more likely than men to feel torn between work and home responsibilities (CTF, 2014). Work-life balance is likely more stressful for women as women report having significantly more responsibilities of childcare (Duxbury \& Higgens, 2013). Mäkelä, Hirvensalo, and Whipp, (2014) found that women reported that workload and stress as significantly more influential in their intention to leave the teaching profession when compared to their male colleagues.

The issue of gender and coping with stress is also unclear in the literature. For instance, Greenglass (1993) found that male and female government managers used social supports differently to construct stress coping strategies. Females used social support from their bosses to construct preventative and instrumental coping strategies, while males did not. For both men and women, however, friend and relative support contributed to the use of preventative coping strategies. Interestingly, in another study dealing specifically with teachers, Greenglass, Fiksenbaum, and Burke (1994) reported that support from friends and family had the same impact on work stress and burnout for both males and females. In our previous research (Ferguson et al., 2007), we found that gender was not a significant predictor of overall stress, nor did gender predict the perceived stigma of stress.

\section{Methodology and Methods}

This paper extends the data analysis previously reported by (Ferguson et al., 2007; Ferguson, Frost, \& Hall, 2012). While we have explored the prevalence of stress, the factors that cause stress and the stigma of teacher stress (Ferguson et al., 2007) and which stress factors predict anxiety and depression (Ferguson, Frost, \& Hall, 2012), we have not yet explored the relationship between teacher stress and social supports. Therefore, the instrument and data collection are the same as these prior studies but are reviewed here as well.

\section{Instrument}

Patterning the questionnaire on existing instruments and using response formats and instructions that have already been tested increases the validity and reliability of the questionnaire (Slavin, 1984). Data for this study were collected from a self-report questionnaire that was developed from reviewing the literature on teacher stress. The research of Kyriacou and Sutcliffe (1978), Fimian (1984), Borg and Riding (1991), Manthei and Gilmore (1996), and the British Columbia Teachers' Federation (cited in EdudataCanada, n.d.) were used to develop the questionnaire.

The questionnaire consisted of eight different sections related to teacher stress as well as a demographics section. The sections of the questionnaire that we use in this paper are as follows:

- Participants were asked to rate 46 teaching-related stress factors on a 5-point scale of not at all stressful, mildly stressful, moderately stressful, very stressful, and extremely stressful.

- Participants were asked to indicate how often they discussed stress with other teachers, their principals, their friends, their family, and their doctors on a five-point scale of never, rarely, sometimes, often, and always.

Brock Education Journal, 26(2), 2017 
- Participants were asked if they believed there was a perceived stigma about teacher stress using a 5-point scale of no stigma, mild stigma, moderate stigma, much stigma, and extreme stigma.

- Participants were asked to indicate their job satisfaction using a 5-point scale of very dissatisfied, somewhat dissatisfied, neither satisfied nor dissatisfied, fairly satisfied, and very satisfied.

- Participants rated their career intent (how likely it is that they would be a teacher in 10 years time, provided that they were not within 10 years of retirement) and career commitment (how likely it is that they would choose teaching again as a career if they were to start their working life over again) using a 5-point scale of very unlikely, somewhat unlikely, neither likely nor unlikely, fairly likely, and very likely.

- Participants completed demographics questions, including gender, age, years of experience in teaching, grade level (elementary or secondary), and current teaching assignment.

The questionnaire was reliable with a Cronbach's alpha of .951, significantly above the generally accepted 0.7 cut-off (Kline, 2000).

\section{Participants}

Teachers enrolled in additional qualifications courses through Nipissing University were mailed a questionnaire. The sample for the study focused on teachers living in northern Ontario. To identify teachers in northern Ontario, participants with a postal code beginning with the letter "P" were mailed questionnaires. The "P" postal code region covers a large geographical area (from Honey Harbour in the south to northeastern Ontario to James Bay and the Quebec border in the north, and northwestern Ontario to Manitoba and the US border) and includes 25 school boards (including English public, English Catholic, French public, French Catholic) as well as band-controlled First Nations schools.

Of the 566 questionnaires that were mailed, 274 questionnaires were returned, resulting in a response rate of $48 \%$. For the purpose of our research about social supports, 264 questionnaires were usable for the study. Teachers who completed the survey ranged in age from 25 to 64 , with $220(83.3 \%)$ identifying as female and $44(16.7 \%)$ as male. Years of teaching experience ranged from newly hired teachers to veteran teachers with more than 30 years of experience in the classroom. The grade levels taught covered the range from Junior Kindergarten to the $12^{\text {th }}$ Grade high school level, and while most respondents held permanent full-time appointments, 6 held permanent part-time positions, 24 worked full-time on a limited term contract, and 10 worked as occasional substitute teachers. Similar to representation in the Canadian school systems, a higher proportion of females than males taught at the lower grade levels (Statistics Canada, 2014). Males were more likely to have taught middle and upper grades.

\section{Results}

We used a Principal Components Analysis (PCA) to reduce the 46 stress factors into a smaller number of orthogonal components suitable for inclusion in a regression analysis. We used PCA because we make no assumptions about underlying factors causing stress outcomes or about the a priori interrelationships (if any) between the 46 stressors. Rather, we sought to condense the extensive list of stressors affecting teachers into a manageable and independent list 
of factors. A preliminary PCA using all 46 sources of stress contained in the survey, revealed that nine of the 46 sources either cross-loaded onto multiple components or did not correlate with any components, a result similar to Ferguson, Frost, and Hall (2012). These nine factors were excluded from the subsequent principal components analysis reported in Appendix A (Table 1) as is common practice. From these 37 remaining stressors, we constructed five components using a PCA with varimax rotation. The five components correspond with individual sources of stress related to "Workload," "Student Behaviour," "Professional Relationships" with other teachers and administration, "Societal Attitudes" towards teachers, and "Employment Conditions".

In order to assess the relationship between sources of stress and social support networks, we used ordinal logistic regression to predict the regularity with which a teacher talked to each of the five social support groups about stress: family, friends, other teachers, their principal, and their doctor, because responses were measured under the ordered categories never, rarely, sometimes, often, and always. A teacher's gender; work experience, including years of service, grade level taught, and information regarding the teacher's appointment (full-time, part-time, permanent, contract, temporary, substitute); and beliefs about a stigma associated with experiencing stress as a teacher were included as factors, while the stress component scores were included as covariates. The results for the entire sample of teachers are reported in Appendix B: Table 2 while results for elementary school teachers are reported separately in Appendix C: Table 3. The threshold value at which a teacher is predicted to move from one response category to another is also reported for comparison purposes. For example, when assessing a teacher's frequency of stress discussion with family, if the teacher's overall predicted score was -1.7 , the teacher would be above the threshold to talk rarely to family $(-3.042)$ but below the threshold to talk sometimes (-1.228), so we would predict that the teacher would be most likely to talk rarely to their family about stress. If the overall score increased to 0.6 then the teacher would cross the threshold to talk sometimes to family about stress but would still be below the threshold to talk often $(0.747)$ so we would predict that the teacher would talk sometimes to family about stress.

\section{Research Question \#1: Do certain stressors impact the frequency of utilization of social supports among teachers?}

Overall, teachers who experienced increased workload stress were much more likely to talk to family, friends, and their fellow teachers; however, within the subsample of elementary teachers, the effect of workload stress on frequency of discussion with family and friends was positive but not statistically significant. Workload stress also contributed to an increased frequency of discussion about stress between elementary school teachers and their doctors. Stress from student behaviour, stress from professional relationships, stress from societal attitudes, and stress from employment conditions did not have a statistically significant effect on the frequency of discussion with friends or family. However, increased stress from societal attitudes towards teachers increased the likelihood of talking to other teachers about stress. In contrast, increased stress caused by professional relationships actually reduced the frequency of discussion with one's principal. While increased stress related to student behaviour did not impact the frequency of contact with family, friends, other teachers, or one's principal, it did increase the likelihood that a teacher would talk with his/her doctor about stress. Stress caused by employment conditions did not predict a teacher's frequency of talking to any of their friends, family, teachers, principals, or doctors. 


\section{Research Question \#2: Does teacher gender or other demographic characteristics affect the frequency of utilization of use of social supports?}

Males were much less likely than females to talk to their family, friends, and other teachers about stress. While the coefficients for talking to one's principal and talking to one's doctor are also negative, they are not statistically significant. Nevertheless, it is clear that males reported lower frequency of contacts with social supports when feeling stressed. None of the other demographic characteristics (age, years of experience in teaching, grade level -elementary or secondary- and current teaching assignment) impacted on the frequency of utilization of social supports.

\section{Research Question \#3: Does the perception of a stigma related to teacher stress affect the frequency of utilization of social supports?}

Perceptions of stigma were a significant factor in predicting whether or not a teacher would talk to family or friends about stress. Those who believed that there was no stigma about teacher stress were used as a base reference group. Those who believed that there was extreme stigma were much less likely to talk to their family and friends about stress. Those who believed that there was mild stigma were also less likely to talk to their friends, and, among elementary teachers, those who believed there was mild stigma were also less likely to talk to their principals. Furthermore, those who believed that there was even mild stigma associated with stress were less likely to talk to fellow teachers relative to those who believed that there was no stigma.

\section{Research Question \#4: Does the frequency of utilization of social supports impact teacher job satisfaction, career intent, and career commitment?}

In order to assess the relationship among the frequency of social support use and job satisfaction, career intent, and career commitment, we used an ordinal logistic regression to predict responses to each of the following questions: (a) in general, how satisfied are you with your job as a teacher? (b) in general, how likely is it that you will be a teacher in 10 years time? (only teachers who were more than 10 years from retirement were included in this analysis) and (c) in general, how likely is it that you would choose teaching again as a career if you were to start your working life over again? The results for the full sample are presented in Appendix D: Table 4 while results for elementary teachers are reported separately in Appendix E: Table 5.

Those who talked to their principal less often about stress demonstrated higher job satisfaction compared to those who always talked to their principal about stress. A lower frequency of contact with friends regarding stress also predicted much higher job satisfaction among all teachers; however, among the subsample of elementary teachers the results were not statistically significant. Talking with one's doctor also had a small positive impact on teachers' job satisfaction. A higher frequency of contact with friends about stress predicted lower career commitment among the teachers. Teachers who discussed stress with their friends more often also demonstrated a lower likelihood that they would choose teaching again as a career. 


\section{Discussion}

The purpose of our research was to investigate the relationships among the frequency of utilization of social supports and stress factors, the stigma of teacher stress, job satisfaction, career intent, career commitment, and demographic characteristics. We found that teachers experiencing workload stress were more likely to talk to their friends, family, and fellow teachers. This finding is perhaps not surprising as teachers may not want to talk about workload stress with their principals, as principals may be the cause of some issues surrounding workload. In addition, teachers experiencing professional relationship stress were also less likely to discuss this stress with their principals. Similarly to workload stress, principals may be the cause of professional relationship stress and teachers may not feel comfortable discussing workload stress with them. The power imbalance between teachers and their principals is another possible reason for teachers not talking to their principals about stress. Teachers were also more likely to talk to other teachers about the stress resulting from societal attitudes towards teaching. This makes sense, as teachers can likely to relate to one another's work in ways that friends and family outside the profession may not. It is also possible that friends and family may share negative attitudes about teachers and the teaching profession, and teachers may not be comfortable talking about such attitudes with those who are not teachers themselves.

Our analysis also reveals that those teachers who felt that there is an extreme stigma of teacher stress were less likely to discuss stress with friends and family. Those teachers who felt a strong stigma surrounding teacher stress did not even feel comfortable talking with those close to them in their personal lives. Our findings are similar to Fimian's (1986), who found that during times of stress, teachers are more likely to receive support from colleagues than from administrators. The importance of a teacher's co-workers acting as a buffer to mediate burnout is discussed by Greenglass, Fiksenbaum, and Burke (1996) and Greenglass, Burke and Konarski (1997). Our research affirms that teachers utilize the support of their teaching colleagues with regard to stress from workload and stress from societal attitudes. Teachers tend to use the social supports within their teaching circle, and, like our finding with societal attitudes, it may be that teachers believe that only other teachers can relate to the stress that they experience in their jobs. Our study also indicates that talking to family and friends is related to workload stress among teachers, a finding that complements the work of Greenglass, Fiksenbaum, and Burke (1994) about friends and family being a predictor for teacher burnout.

Among all teachers, stress from student behaviours was the only stress factor linked to talking to their doctors about stress. Teachers do spend the majority of their time at work in the classroom and perhaps stress from student behaviors may be the most pressing for teachers. Among elementary teachers, however, increases in workload stress also increased frequency of discussion with one's doctor. Because of the negative effects of stress on one's health and on worker absenteeism (Naghieh, Montgomery, Bonell, Thompson, \& Aber, 2015), it is concerning that teachers did not seem to utilize their doctors to cope with other sources of stress. Doctors may be able to help with a number of physical and emotional manifestations of stress, such as depression, anxiety, and difficulty sleeping (Duxbury \& Higgens, 2013). Teachers may feel overwhelmed or feel lacking the time to meet with their primary health care provider, particularly considering the increased workload and issues of work-life balance presented in the literature (CTF, 2014; STF. 2013). It is also troubling that, even though student behaviour is a significant source of workload stress that predicts teacher anxiety and depression (Ferguson, 
Frost, \& Hall, 2012), teachers did not utilize the support within their schools to help ease the stress of student behaviour. Teachers could look to their colleagues, and perhaps more importantly to their administrators (who are in a better position to provide support), for help with student behavior. Alternatively, perhaps teachers feel that schools and teachers are being pushed to their limits -with a raise in workplace violence in schools (Gordon, 2017) and seemingly increasing student needs and teachers' feeling they cannot spend time with individual students (CTF, 2014) -the lack of discussion and seeking supports around stress may be an understandable phenomena. As the Saskatchewan Teachers' Federation (2014) found, a majority of teachers believe that stress was just a part of the job. Simply put, teachers may be doing everything they think they can about their stress. In addition, many ways of reducing teacher stress could be done at an organizational level, rather than the onus on individual teachers, which address stress symptoms rather than their cause (Naghieh, Montgomery, Bonell, Thompson, \& Aber, 2015).

The relationship between principals and teacher stress is documented in the literature (Fimian, 1986; Russell, Altmaier, \& Van Velzen, 1987). Teachers in our study, however, clearly did not use the social support from their colleagues nor from their principal to help ease the stress of student behaviours. It is possible that perhaps those teachers who do not talk about stress are able to manage their stress levels at the personal level (Pearlin \& Schooler, 1978). It is also possible that perceived or real stigma of teacher stress could be preventing these conversations about stress from occurring. Teachers may feel judged or inadequate in their roles if they admit to feeling stressed at work to their principals, who are generally teachers' immediate supervisors. In addition because the sample for the study was teachers enrolled in AQ courses, it is possible that teachers may not want to talk to their principals about stress if they had previously consulted with principals about taking an AQ course. Sass, Seal, and Martin (2011) suggested that support from teachers and principals are interrelated, in that support from colleagues would "do little good" if teachers were not supported by principals (p. 211). Again, a perception of a stigma surrounding teacher stress may also explain why teachers might be reluctant to talk to colleagues about stress. We found that those teachers who believed that there is a mild stigma surrounding teacher stress were less likely to talk to fellow teachers about stress. Younghusband, Garlie, and Church (2003) proposed that teachers may not want to discuss stress with administrators as teachers may be perceived as weak or as failures as teachers.

Like Greenglass (1993), we found males and females used social supports differently. Regardless of grade level taught (i.e. elementary or secondary), males in our study are less likely than females to talk to their family, friends, and other teachers about stress. As teacher stress levels vary between men and women (CTF, 2014; Duxbury \& Higgens, 2013), it is plausible that men cope with work stress in different ways from women. We found no significant relationship between gender and talking with one's principal or doctor about stress.

We found that there was higher job satisfaction among those teachers who spoke to their principals and their friends about stress less frequently. Our results also indicate that there was a negative relationship between those teachers who spoke to their friends frequently about stress and teachers' career intent (be a teacher in 10 years time) and career commitment. The findings that teachers who spoke to principals and friends less frequently about stress but had high job satisfaction, and that teachers who frequently talked to their friends about stress but had a lower sense of career intent and career commitment, might be explained by the postulation that those who solve their own problems are more efficacious than those who turn to others for advice and support (Mirowsky \& Ross, 2003; Pearlin \& Schooler, 1978). In addition, speaking to others 
about stress at work could be a sign or an indicator that teachers are quite unhappy with their work and are having difficulty coping. Perhaps those teachers who are able to cope with stress without utilizing social supports have higher job satisfaction and are more committed to the profession. However, opposing this hypothesis, we did find that there was a small positive relationship between teachers speaking to their doctors often about stress and job satisfaction.

\section{Limitations}

Our study is limited in that it was a one-time self-report on teacher stress and the frequency of utilization of social supports. As teachers' jobs can change significantly throughout the year and from year to year, surveying teachers at another date could produce different results. The surveys were mailed to teachers in the middle of the fall term and it is possible that teachers might experience higher levels of stress at other times, such as end of term when report cards are due. While men do constitute a smaller population of elementary school teachers in Ontario, men were underrepresented in the study (only $17.6 \%$ were male). Secondary school teachers were also underrepresented in the study (only $16.1 \%$ were secondary school teachers). It is plausible that, because the job conditions are different between the two levels of schooling, teacher stressors at the high school level could be different from those at the elementary level. We have reported results for elementary school teachers separately, and in many cases the magnitude of the coefficients are similar to those of the entire sample. In several instances they do differ suggesting that there are some differences between elementary school teachers and other teachers; however, due to the limited sample size it was not possible to explore these differences further. The limited sample size also likely contributed to the dearth of statistically significant coefficients in the elementary school teacher subsample compared to the full sample.

Another limitation of the study is that the sample was teachers enrolled in an additional qualification course at Nipissing University. It is possible that teachers experiencing high amounts of stress may be too overwhelmed to be enrolled in a course and thus the sample may underreport the true extent of stress among the population of teachers. It is also possible, however, that participants may be more stressed because of taking a course in addition to their regular teaching jobs. Teachers' reasons and motivations for taking AQ courses could also impact stress levels and different AQ courses could also have different workloads and therefore different stress for teachers taking courses.

\section{Suggestions for Future Research}

Because a one-time questionnaire research design captures a snapshot in time of teachers' stress levels, longitudinal studies that explore the impact of social supports on teacher stress over time, like the work of Greenglass, Fiksenbaum, and Burke (1994), are needed. Teachers' job situations, and therefore their stress levels, can vary as teaching assignments, administrators, and students change. These changes may impact teachers' usage of various social supports. The link between teacher gender and usage of social supports is also an area that warrants further research. Our research found a difference between males and females and their frequency of utilization of social supports to cope with stress while other research has not found a difference among gender, social supports, and burnout (Greenglass, Fiksenbaum, \& Burke, 1994). In addition, our study found that those teachers who spoke to colleagues and principals less frequently about stress had higher levels of job satisfaction. Studying how these individuals 
cope with stress without seeking social support could assist other teachers with providing alternative strategies to deal with work stress. Finally, in our digital age, the possibility of online networks and social media could be another form of social support for teachers. Leung, Chiang, Chui, Lee, and Mak's (2011) study demonstrates the potential of using online forums as a means of social support to reduce teacher stress. The ability to be anonymous in online environments poses an opportunity for teachers to discuss stress without the perceptions of stigma from colleagues and administrators and is an area worthy of more research.

\section{Implications for Practice}

Our study reveals that for teachers in northern Ontario, stress is a significant concern. While teachers may feel overwhelmed with work/life balance and workload demands (Duxbury \& Higgens, 2013), and stress can be very personal and vary from person to person, teachers need to make self-care a priority. For some teachers that may mean using personal stress coping strategies such as mindfulness, exercise, etc., while for others reaching out to friends, family, colleagues, administrators, and their health care providers is necessary and essential. Teachers, however, need to feel safe in talking about stress without fear of stigma, whether perceived or real.

While teachers can take some measures to cope with the symptoms of stress, organization structures (school boards and Ministries of Education) are an avenue to better deal with the causes of teacher stress (Naghieh, Montgomery, Bonell, Thompson, \& Aber, 2015). While further research about organizational changes and teacher stress are needed, some studies have reported social supports such as coaching and mentoring at the organizational level as holding promise in reducing teacher stress (Naghieh, Montgomery, Bonell, Thompson, \& Aber, 2015). At the school level, administrators could provide supports to teachers to reduce stress, particularly with regard to student behaviours, and also work to create an open climate in their schools to acknowledge and discuss teacher stress, as the stigma of teacher stress appears to be a prevailing problem within the teaching profession. Faculties of education can also play a role in teacher stress and wellbeing. Harris (2012), for example, calls for teacher stress management to be a part of formal teacher training in Canada, integrated within pre-service teacher education as well as additional qualification courses. While stress and its manifestations can vary person to person and a course would likely focus on individual teachers' stress rather than organizational changes, courses could include topics such as time management and work/life balance, and students could also discuss stress they experience on practicum. Addressing stress during preservice education could help alleviate some of the stigma of discussing stress in their future careers.

\section{Conclusions}

Our study explored how the frequency of utilization of social supports is related to teacher stress factors, job satisfaction, career intent, career commitment, the perception of a stigma attached to teacher stress, and teacher demographics. Our results show that teachers seldom spoke to their health care providers about and instead utilized family, friends, fellow teachers, and sometimes their principals. Teachers, however, were clearly not always comfortable talking about all stressors with their principals, particularly stress from professional relationships. Males in our study were less likely to talk to their various social supports about stress. There appears to 
be a stigma of teacher stress, as those teachers who felt that there was a mild stigma of teacher stress were less likely to talk to their colleagues about stress. As one teacher said in the open comments section of the survey, "The greatest amount of stigma comes from other teachers. Often when teachers express stress, comments are made such as 'If you can't handle it, leave.' There is not a lot of support within the profession."

We also found that there was a higher level of job satisfaction among teachers who spoke with friends and principals less frequently about stress. In addition, we report that those teachers who frequently talked to their friends about stress have a lower sense of career intent and career commitment. These two results may indicate that teachers with high job satisfaction, career intent, and career commitment likely utilized other stress coping mechanisms other than socials supports. Our findings may also indicate that utilizing social supports may not be enough to combat stress and have an impact on job satisfaction, career intent, and career commitment. As one teacher indicated on the survey, "I feel fortunate because I have a very supportive staff. We share many of our daily challenges. Despite this, I often feel like I am fighting a losing battle."

The results of our study and the extant literature point to teacher stress having a ripple effect, impacting many other aspects of teacher mental health including burnout (Coulter \& Abbey, 2009), absenteeism (Duxbury \& Higgens, 2013), using employee benefits (Duxbury \& Higgens, 2013) and taking leaves of absence (Naylor \& White, 2010), absenteeism (Duxbury \& Higgens, 2013) job satisfaction, intent to stay in the profession (Duxbury \& Higgens, 2013; Ferguson, Frost, \& Hall, 2012), and teacher attrition (Clark \& Antonelli, 2009; McIntyre, 2006). School boards, teachers' unions, and faculties of education need to make workplace health a priority as the impact of employee mental health can be profound (Baumann \& Muijen, 2010). We encourage other researchers to continue to monitor and report on teacher stress, coping strategies, and organizational changes in education that promote workplace wellbeing. 


\section{References}

Bannai, A., Ukawa, S., \& Tamakoshi, A. (2015). Long working hours and psychological distress among school teachers in Japan. Journal of occupational health, 57(1), 20-27.

Baumann, A., \& Muijen, M. (2010). Introduction. In A. Baumann, M. Muijen, \& W. Gaebel (Eds.), Mental health and well-being in the workplace -protection and inclusion during challenging times (pp. 2-5). World Health Organization Europe. Retrieved from http://www.euro.who.int/_data/assets/pdf_file/0018/124047/e94345.pdf

Borg, M. G., \& Riding, R. J. (1991). Occupational stress and satisfaction in teaching. British Educational Research Journal, 17(3), 263-281.

Bowling, N. A., Alarcon, G. M., Bragg, C. B., \& Hartman, M. J. (2015). A meta-analytic examination of the potential correlates and consequences of workload. Work \& Stress, 29(2), 95-113.

Brown, M., Ralph, S., \& Brember, I. (2002). Change-linked work-related stress in British teachers. Research in Education, 67, 1-12.

Burke, R. J., \& Greenglass, E. R. (1994). Towards an understanding of work satisfactions and emotional well-being of school-based educators. Stress Medicine, 10(3), 177-184.

Burke, R. J., \& Greenglass, E. E. (1996). Work stress, social support, psychological burnout and emotional and physical well-being among teachers. Psychology, Health \& Medicine, 1(2), 193-205. doi:10.1080/13548509608400018

Chen, P. Y., \& Spector, P. E. (1992). Relationship of work stressors with aggression, withdrawal, theft and substance use: An exploratory study. Journal of Occupational and Organizational Psychology, 65(3), 177-184.

Cheuk, W., \& Wong, K. (1995). Stress, social support, and teacher burnout in Macau. Current Psychology, 14(1), 42-46.

Clark, R., \& Antonelli, F. (2009). Why teachers leave: Results of an Ontario survey 2006-08. Ontario Teachers' Federation. Retrieved from http://www.otffeo.on.ca/wpcontent/uploads/sites/3/2013/10/why_teachers_leave1.pdf .

Cooper, C. L., Dewe, P. J., \& O’Driscoll, M. P. (2001). Organizational stress: A review and critique of theory, research, and applications. Thousand Oaks, CA: Sage.

Coulter, M., \& Abney, P. C. (2009). A study of burnout in international and country of origin teachers. International Review Of Education, 55(1), 105-121. doi:10.1007/s11159-0089116-X

Deryakulu, D., \& Olkun, S. (2007). Analysis of computer teachers' online discussion forum messages about their occupational problems. Journal Of Educational Technology \& Society, 10(4), 131-142.

Dibbon, D. (2004). It's about time! A report on the impact of workload on teachers and students. Retrieved

from https://www.mun.ca/educ/people/faculty/ddibbon/pdf/teacher\%20workload\%20final\%20 version.pdf

Duxbury, L., \& Higgens, C. (2103). The 2011/2012 national study on balancing work, life and caregiving in Canada: The situation for Alberta teachers. Retrieved from https://www.teachers.ab.ca/SiteCollectionDocuments/ATA/Publications/Research/COOR -94\%20National\%20Study\%20on\%20Balancing\%20Work\%20-Duxbury.pdf 
EdudataCanada. (n.d.). Teacher stress. Retrieved July 2, 2004 from http://www.edudata.educ.ubc.ca/Data_Pages/BCTF/teacher\%20stress.htm .

Elementary Teachers' Federation of Ontario (2012, Nov. 7). Mental stress, workplace violence, harassment top issues for teachers. Retrieved from http://www.etfo.ca/MediaRoom/MediaReleases/Pages/Mental\%20Stress, \%20Workplace \%20Violence, \%20Harassment\%20Top\%20Issues\%20for\%20Teachers.aspx .

Ferguson, K., Frost, L., Kirkwood, K., \& Hall, D. (2007). Teacher stress and stigma in northern Ontario. In LeClair, J. A. \& Foster, L. T. (Eds.) Contemporary Issues in Mental Health: Concepts, Policy \& Practice. Victoria: Western Geographical Press, pp. 211-225.

Ferguson, K., Frost, L., \& Hall, D. (2012). Predicting teacher stress, anxiety, and job satisfaction. Journal of Teaching and Learning, 8(1), 27-42.

Fimian, M. J. (1984). The development of an instrument to measure occupational stress in teachers: The teacher stress inventory. Journal of Occupational Psychology, 57(4), 277293.

Fimian, M. J. (1986). Social support and occupational stress in special education. Exceptional Children, 52(5), 436-442.

Froese-Germain, B. (2014). Work-life balance and the Canadian teaching profession. Canadian Teachers' Federation. Retrieved from http://www.ctf-fce.ca/Research-Library/WorkLifeBalanceandtheCanadianTeachingProfession.pdf

Gordon, A. (2017, Jan 17). Teachers' union raises alarm over rising violence in schools: ETFO calls for more supports for kids with behavioural issues. The Toronto Star. Retrieved from https://www.thestar.com/yourtoronto/education/2017/01/17/teachers-union-raisesalarm-over-rising-violence-in-schools.html

Greenglass, E. R. (1993). The contribution of social support to coping strategies. Applied Psychology: An International Review, 42(4), 323-340. doi:10.1111/j.14640597.1993.tb00748.x

Greenglass, E. R., Burke, R. J., \& Konarski, R. (1997). The impact of social support on the development of burnout in teachers: Examination of a model. Work \& Stress, 11(3), 267278. doi:10.1080/02678379708256840

Greenglass, E. R., Fiksenbaum, L., \& Burke, R. J. (1994). The relationship between social support and burnout over time in teachers. Journal Of Social Behavior \& Personality, 9(2), 219-230.

Greenglass, E., Fiksenbaum, L., \& Burke, R. J. (1996). Components of social support, buffering effects and burnout: Implications for psychological functioning. Anxiety, Stress \& Coping: An International Journal, 9(3), 185-197. doi:10.1080/10615809608249401

Griffith, J., Steptoe, A., \& Cropley, M. (1999). An investigation of coping strategies associated with job stress in teachers. British Journal of Educational Psychology, 69(4), 517-531.

Harris, G. E. (2012). Individual stress management coursework in Canadian teacher preparation programs. Canadian Journal of Education 34(4), 104-117.

Harvey, R. (2004, April 30). Depression haunts teachers. The Toronto Star. Retrieved from http://www.mentalhealthroundtable.ca/apr_2004/TheStar.com_Depr_Apr30.pdf

House, J. S. (1981). Work stress and social support. Reading, MA: Addision-Wesley.

Jamieson, B. (2006). State of the teaching profession 2006: Back in the day... Retrieved from http://professionallyspeaking.oct.ca/september_2006/survey.asp 
Johnston-Gibbens, A. (2014). Workload and volunteerism of educators. Ontario Secondary School Teachers' Federation. Retrieved from https://www.osstf.on.ca/enCA/publications/research-studies/workload-volunteerism-report.aspx

Kahn, J. H., Schneider, K. T., Jenkins-Henkelman, T. M., \& Moyle, L. L. (2006). Emotional social support and job burnout among high-school teachers: Is it all due to dispositional affectivity?. Journal Of Organizational Behavior, 27(6), 793-807. doi:10.1002/job.397

Kline, P. (2000). The handbook of psychological testing ( $2^{\text {nd }}$ ed.). London: Routledge.

Kyriacou, C. (2001). Teacher stress: Directions for future research. Educational Review, 53(1), 27-35.

Kyriacou, C. \& Sutcliffe, J. (1978). Teacher stress: Prevalence, sources, and symptoms. British Journal of Educational Psychology, 48, 159-167.

Lazarus, R. S. (1966). Psychological stress and the coping process. New York, NY: McGraw-Hill.

Lazarus, R.S. (1999). Stress and emotion: A new synthesis. New York, NY: Springer.

Leung, S. K., Chiang, V. L., Chui, Y., Lee, A. K., \& Mak, Y. (2011). Feasibility and potentials of online support for stress management among secondary school teachers. Stress \& Health: Journal of the International Society for the Investigation of Stress, 27(3), 282286.

Leung, S. S., Wah Mak, Y., Yu Chui, Y., Chiang, V. C., \& Lee, A. C. (2009). Occupational stress, mental health status and stress management behaviors among secondary school teachers in Hong Kong. Health Education Journal, 68(4), 328-343.

Mäkelä, K., Hirvensalo, M., \& Whipp, P. R. (2014). Should I stay or should I go? Physical education teachers' career intentions. Research quarterly for exercise and sport, 85(2), 234-244.

Manthei, R., \& Gilmore, A. (1996). Teacher stress in intermediate schools. Educational Research, 28(1), 3-19.

McIntryre, F. (2006). Ontario grads stay with teaching. Professionally Speaking, June, 47-50.

Mirowsky, J., \& Ross, C. E. (2003). Social causes of psychological distress (2 ${ }^{\text {nd }}$ ed.). Hawthorne, NY: Aldine de Gruyther.

Naghieh A, Montgomery P, Bonell CP, Thompson M, Aber JL. (2015). Organisational interventions for improving wellbeing and reducing work-related stress in teachers. Cochrane Database of Systematic Reviews, 4. DOI: 10.1002/14651858.CD010306.pub2.

Naylor, C. \& White, M. (2010). The worklife of BC teachers in 2009: A BCTF study of working and learning conditions. British Columbia Teachers' Federation. Retrieved from http://www.bctf.ca/uploadedfiles/public/issues/WorklifeWorkload/2009/fullreport.pdf

Nixon, A. E., Mazzola, J. J., Bauer, J., Krueger, J. R., \& Spector, P. E. (2011). Can work make you sick? A meta-analysis of the relationships between job stressors and physical symptoms. Work \& Stress, 25(1), 1-22.

Pearlin, L. I., \& Schooler, C. (1978). The structure of coping. Journal of Health and Social Behavior, 2-21.

Pierce, C., \& Molloy, G. (1990). Psychological and biographical differences between secondary school teachers experiencing high and low levels of burnout. The British Journal of Educational Psychology, 60, 37-51.

Qin, Z., \& Weihong, Z. (2007). Teacher Stress, Burnout, and Social Support in Chinese Secondary Education. Human Communication, 10(4), 487-496. 
Richards, J. (2012). Teacher stress and coping strategies: A national snapshot. Educational Forum, 76(3), 299-316.

Russell, D. W., Altmaier, E., \& Van Velzen, D. (1987). Job-related stress, social support, and burnout among classroom teachers. Journal of Applied Psychology, 72(2), 269-274.

Saskatchewan Teachers' Federation. (2013). Teacher time: A study of the challenges of intensification of Saskatchewan teachers' professional time. Retrieved from https://www.stf.sk.ca/sites/default/files/teacher_time.pdf

Sass, D. A., Seal, A. K., \& Martin, N. K. (2011). Predicting teacher retention using stress and support variables. Journal of Educational Administration, 49(2), 200-215.

Sheffield, D., Dobbie, D., \& Carroll, D. (1994). Stress, social support, and psychological and physical wellbeing in secondary school teachers. Work \& Stress, 8(3), 235-243. doi:10.1080/02678379408259995

Slavin, R. E. (1984). Research methods in education: A practical guide. Englewood Cliffs, NJ: Prentice-Hall.

Smethem, L. (2007). Retention and intention in teaching careers: Will the new generation stay?.Teachers And Teaching: Theory And Practice, 13(5), 465-480. doi:10.1080/13540600701561661

Spector, P. E., \& Jex, S. M. (1998). Development of four self-report measures of job stressors and strain: interpersonal conflict at work scale, organizational constraints scale, quantitative workload inventory, and physical symptoms inventory. Journal of Occupational Health Psychology, 3(4), 356-367.

Statistics Canada. (2014). Back to school . . . by the numbers. Retrieved from http://www.statcan.gc.ca/eng/dai/smr08/2014/smr08_190_2014\#a4

Younghusband, L., Garlie, N., \& Church, E. (2003). High school teacher stress in Newfoundland Canada: A work in progress. Paper presented at the Hawaii International Conference on Education, January 7-10, 2003. 


\section{Appendix A: Table 1}

\section{Principal Component Analysis Loadings for Sources of Teacher Stress}

\begin{tabular}{|c|c|c|c|c|c|}
\hline & $\begin{array}{c}\text { Component } \\
1: \\
\text { Workload }\end{array}$ & $\begin{array}{c}\text { Component } \\
\text { 2: } \\
\text { Student } \\
\text { Behaviour } \\
\end{array}$ & $\begin{array}{c}\text { Component } \\
3: \\
\text { Professional } \\
\text { Relationships } \\
\end{array}$ & $\begin{array}{c}\text { Component } \\
4: \\
\text { Societal } \\
\text { Attitude } \\
\end{array}$ & $\begin{array}{c}\text { Component } \\
5: \\
\text { Employment } \\
\text { Conditions } \\
\end{array}$ \\
\hline Too much work to do & .857 & & & & \\
\hline Not enough time to do the work & .847 & & & & \\
\hline Lack of time for marking & .796 & & & & \\
\hline Inadequate preparation time & .750 & & & & \\
\hline $\begin{array}{l}\text { Balancing home and school } \\
\text { responsibilities }\end{array}$ & .732 & & & & \\
\hline Increase in workload & .732 & & & & \\
\hline Administrative paperwork & .601 & & & & \\
\hline $\begin{array}{l}\text { Lack of time to assist individual } \\
\text { students }\end{array}$ & .584 & & & & \\
\hline Taking courses while working full time & .574 & & & & \\
\hline Completing report cards & .496 & & & & \\
\hline Class size & .495 & & & & \\
\hline Split grade classrooms & .416 & & & & \\
\hline Shortages of materials & .413 & & & & \\
\hline $\begin{array}{l}\text { Being accountable for student } \\
\text { achievement }\end{array}$ & .391 & & & & \\
\hline Extra-curricular responsibilities & .352 & & & & \\
\hline Completing IEPs & .270 & & & & \\
\hline Changes in the curriculum & .229 & & & & \\
\hline Poorly motivated students & & .830 & & & \\
\hline Students' attitudes towards work & & .730 & & & \\
\hline Mixed ability of students in classroom & & .661 & & & \\
\hline $\begin{array}{l}\text { Individual students who continually } \\
\text { misbehave }\end{array}$ & & .594 & & & \\
\hline $\begin{array}{l}\text { Impolite and disruptive behaviour of } \\
\text { students in general }\end{array}$ & & .561 & & & \\
\hline Students with difficulties at home & & .249 & & & \\
\hline $\begin{array}{l}\text { Relationship with principal or vice } \\
\text { principal }\end{array}$ & & & .855 & & \\
\hline Attitudes and behaviour of the principal & & & .846 & & \\
\hline $\begin{array}{l}\text { Lack of communication with } \\
\text { administration }\end{array}$ & & & .832 & & \\
\hline $\begin{array}{l}\text { Lack of participation in decision- } \\
\text { making }\end{array}$ & & & .564 & & \\
\hline Relationships with other teachers & & & .238 & & \\
\hline Relationships with support staff & & & .156 & & \\
\hline $\begin{array}{l}\text { Undeserved criticism of teachers and } \\
\text { schools }\end{array}$ & & & & .711 & \\
\hline $\begin{array}{l}\text { Lack of recognition for the } \\
\text { contributions of teachers }\end{array}$ & & & & .694 & \\
\hline $\begin{array}{l}\text { Lack of respect in society for schools } \\
\text { and teachers }\end{array}$ & & & & .677 & \\
\hline Dealing with parents & & & & .247 & \\
\hline Poor opportunities for promotion & & & & & .729 \\
\hline Inadequate salary & & & & & .676 \\
\hline
\end{tabular}


Job security

.581

Lack of training and professional

.510

development

\section{Appendix B: Table 2}

Ordinal Logistic Regression Coefficient Estimates of Effect of Stress Factors on Frequency of Social Contact, Full Sample (Standard Errors in Brackets)

\begin{tabular}{|c|c|c|c|c|c|}
\hline & Family & Friends & Other Teachers & Principal & Doctor \\
\hline Workload Stress & $\begin{array}{c}0.424 * * * \\
(0.130)\end{array}$ & $\begin{array}{c}0.335 * * * \\
(0.130)\end{array}$ & $\begin{array}{c}0.459 * * * \\
(0.131)\end{array}$ & $\begin{array}{c}0.187 \\
(0.127)\end{array}$ & $\begin{array}{c}0.195 \\
(0.132)\end{array}$ \\
\hline Student Behaviour Stress & $\begin{array}{c}0.196 \\
(0.125)\end{array}$ & $\begin{array}{c}0.034 \\
(0.122)\end{array}$ & $\begin{array}{c}0.182 \\
(0.125)\end{array}$ & $\begin{array}{c}0.069 \\
(0.131)\end{array}$ & $\begin{array}{c}0.336 * * * \\
(0.130)\end{array}$ \\
\hline Professional Relationship & 0.037 & 0.111 & -0.079 & $-0.423 * * *$ & 0.101 \\
\hline Stress & $(0.119)$ & $(0.119)$ & $(0.123)$ & $(0.130)$ & $(0.127)$ \\
\hline Societal Attitude Stress & $\begin{array}{c}0.134 \\
(0.125)\end{array}$ & $\begin{array}{c}0.156 \\
(0.124)\end{array}$ & $\begin{array}{c}0.248 * * \\
(0.125)\end{array}$ & $\begin{array}{c}0.106 \\
(0.124)\end{array}$ & $\begin{array}{c}0.019 \\
(0.129)\end{array}$ \\
\hline Employment Conditions & 0.131 & 0.167 & -0.109 & -0.058 & 0.083 \\
\hline $\begin{array}{l}\text { Stress } \\
\text { Female }^{\mathrm{a}}\end{array}$ & $\begin{array}{c}(0.130) \\
--\end{array}$ & $\begin{array}{c}(0.132) \\
--\end{array}$ & $\begin{array}{c}(0.131) \\
--\end{array}$ & $\begin{array}{c}(0.134) \\
--\end{array}$ & $\begin{array}{c}(0.139) \\
--\end{array}$ \\
\hline Male & $\begin{array}{c}-1.516^{* *} \\
(0.342)\end{array}$ & $\begin{array}{c}-1.838^{* * * *} \\
(0.340)\end{array}$ & $\begin{array}{c}-1.237 * * * \\
(0.340)\end{array}$ & $\begin{array}{l}-0.484 \\
(0.335)\end{array}$ & $\begin{array}{l}-0.407 \\
(0.350)\end{array}$ \\
\hline $\begin{array}{l}\text { No Stigma }^{\mathrm{a}} \\
\text { Mild Stigma }\end{array}$ & $\begin{array}{c}-- \\
-0.222 \\
(0.423)\end{array}$ & $\begin{array}{c}-- \\
-0.823 * \\
(0.425)\end{array}$ & $\begin{array}{c}-- \\
-0.768 * \\
(0.445)\end{array}$ & $\begin{array}{c}-- \\
-0.191 \\
(0.433)\end{array}$ & $\begin{array}{c}-- \\
0.051 \\
(0.463)\end{array}$ \\
\hline Moderate Stigma & $\begin{array}{l}-0.010 \\
(0.387)\end{array}$ & $\begin{array}{l}-0.067 \\
(0.392)\end{array}$ & $\begin{array}{l}-0.080 \\
(0.414)\end{array}$ & $\begin{array}{l}-0.093 \\
(0.395)\end{array}$ & $\begin{array}{c}-0.386 \\
(0.433)\end{array}$ \\
\hline Much Stigma & $\begin{array}{c}0.297 \\
(0.421)\end{array}$ & $\begin{array}{l}-0.284 \\
(0.428)\end{array}$ & $\begin{array}{c}0.453 \\
(0.454)\end{array}$ & $\begin{array}{c}0.192 \\
(0.444)\end{array}$ & $\begin{array}{c}0.420 \\
(0.456)\end{array}$ \\
\hline Extreme Stigma & $\begin{array}{c}-1.860 * * \\
(0.830)\end{array}$ & $\begin{array}{c}-1.853 * * \\
(0.837)\end{array}$ & $\begin{array}{c}0.183 \\
(0.872)\end{array}$ & $\begin{array}{l}-0.270 \\
(0.836)\end{array}$ & $\begin{array}{l}-0.113 \\
(0.808)\end{array}$ \\
\hline $\begin{array}{l}\text { Teaching Experience } \\
\text { Grade Level Taught } \\
\text { Type of Teaching } \\
\text { Appointment }\end{array}$ & $\begin{array}{l}\text { Included } \\
\text { Included } \\
\text { Included }\end{array}$ & $\begin{array}{l}\text { Included } \\
\text { Included } \\
\text { Included }\end{array}$ & $\begin{array}{l}\text { Included } \\
\text { Included } \\
\text { Included }\end{array}$ & $\begin{array}{l}\text { Included } \\
\text { Included } \\
\text { Included }\end{array}$ & $\begin{array}{l}\text { Included } \\
\text { Included } \\
\text { Included }\end{array}$ \\
\hline \multicolumn{6}{|c|}{ Frequency of discussion about stress: Threshold value to enter category } \\
\hline Talked Always & $\begin{array}{c}2.823 \\
(0.584)\end{array}$ & $\begin{array}{c}1.639 \\
(0.515)\end{array}$ & $\begin{array}{c}2.319 \\
(0.545)\end{array}$ & $\begin{array}{c}5.829 \\
(1.110)\end{array}$ & $\begin{array}{c}4.868 \\
(0.866)\end{array}$ \\
\hline Talked Often & $\begin{array}{c}0.747 \\
(0.561)\end{array}$ & $\begin{array}{l}-0.577 \\
(0.480)\end{array}$ & $\begin{array}{l}-0.111 \\
(0.506)\end{array}$ & $\begin{array}{c}3.556 \\
(0.588)\end{array}$ & $\begin{array}{l}2.761 \\
(0.566)\end{array}$ \\
\hline Talked Sometimes & $\begin{array}{l}-1.228 \\
(0.564)\end{array}$ & $\begin{array}{l}-2.674 \\
(0.512)\end{array}$ & $\begin{array}{l}-2.533 \\
(0.540)\end{array}$ & $\begin{array}{c}0.815 \\
(0.491)\end{array}$ & $\begin{array}{l}1.305 \\
(0.524)\end{array}$ \\
\hline Talked Rarely & $\begin{array}{l}-3.042 \\
(0.619)\end{array}$ & $\begin{array}{l}-4.796 \\
(0.587)\end{array}$ & $\begin{array}{l}-4.419 \\
(0.615)\end{array}$ & $\begin{array}{c}-0.934 \\
(0.492)\end{array}$ & $\begin{array}{l}-0.439 \\
(0.514)\end{array}$ \\
\hline Talked Never & -- & -- & -- & -- & -- \\
\hline $\begin{array}{l}\text { Number of Observations } \\
\text { Pseudo } \mathrm{R}^{2}\end{array}$ & $\begin{array}{c}264 \\
0.112\end{array}$ & $\begin{array}{c}264 \\
0.116\end{array}$ & $\begin{array}{c}264 \\
0.126\end{array}$ & $\begin{array}{c}264 \\
0.077\end{array}$ & $\begin{array}{c}263 \\
0.056\end{array}$ \\
\hline
\end{tabular}

$* * * \mathrm{p}<0.01, \quad * * \mathrm{p}<0.05, \quad * \mathrm{p}<0.1$

${ }^{\mathrm{a}}$ Included as Base Reference group 
Appendix C: Table 3

Ordinal Logistic Regression Coefficient Estimates of Effect of Stress Factors on Frequency of Social Contact, Elementary School Teachers (Standard Errors in Brackets)

\begin{tabular}{|c|c|c|c|c|c|}
\hline & Family & Friends & Other Teachers & Principal & Doctor \\
\hline \multirow[t]{2}{*}{ Workload Stress } & 0.282 & 0.253 & $0.331 *$ & -0.091 & $0.559 * * *$ \\
\hline & $(0.189)$ & $(0.187)$ & $(0.183)$ & $(0.175)$ & $(0.204)$ \\
\hline \multirow{2}{*}{ Student Behaviour Stress } & 0.132 & -0.113 & 0.119 & 0.198 & $0.385 * *$ \\
\hline & $(0.167)$ & $(0.167)$ & $(0.171)$ & $(0.174)$ & $(0.181)$ \\
\hline Professional Relationship & -0.054 & -0.061 & 0.084 & $-0.480 * * *$ & 0.111 \\
\hline Stress & $(0.163)$ & $(0.164)$ & $(0.164)$ & $(0.169)$ & $(0.177)$ \\
\hline \multirow[t]{2}{*}{ Societal Attitude Stress } & 0.196 & 0.114 & 0.264 & 0.017 & -0.043 \\
\hline & $(0.158)$ & $(0.159)$ & $(0.162)$ & $(0.158)$ & $(0.181)$ \\
\hline Employment Conditions & -0.069 & 0.151 & -0.139 & -0.201 & 0.301 \\
\hline Stress & $(0.167)$ & $(0.168)$ & $(0.170)$ & $(0.177)$ & $(0.184)$ \\
\hline Female $^{\mathrm{a}}$ & - & - & -- & -- & -- \\
\hline \multirow[t]{2}{*}{ Male } & $-1.714 * * *$ & $-2.314 * * *$ & $-2.158 * * *$ & -0.405 & -0.333 \\
\hline & $(0.475)$ & $(0.480)$ & $(0.503)$ & $(0.463)$ & $(0.504)$ \\
\hline No Stigma ${ }^{a}$ & -- & -- & -- & -- & -- \\
\hline \multirow[t]{2}{*}{ Mild Stigma } & -0.392 & -0.765 & $-1.115^{*}$ & $-1.211 * *$ & -0.133 \\
\hline & $(0.578)$ & $(0.574)$ & $(0.612)$ & $(0.602)$ & $(0.634)$ \\
\hline \multirow[t]{2}{*}{ Moderate Stigma } & -0.076 & 0.141 & -0.035 & -0.734 & -0.835 \\
\hline & $(0.511)$ & $(0.522)$ & $(0.544)$ & $(0.536)$ & $(0.563)$ \\
\hline \multirow[t]{2}{*}{ Much Stigma } & 0.007 & -0.025 & 0.128 & -0.551 & 0.060 \\
\hline & $(0.556)$ & $(0.558)$ & $(0.594)$ & $(0.587)$ & $(0.595)$ \\
\hline \multirow[t]{2}{*}{ Extreme Stigma } & $-1.893 *$ & -0.696 & 0.584 & -1.022 & -0.349 \\
\hline & $(1.099)$ & $(1.260)$ & (1.194) & $(1.325)$ & $(1.081)$ \\
\hline Teaching Experience & Included & Included & Included & Included & Included \\
\hline Type of Teaching & Included & Included & Included & Included & Included \\
\hline Appointment & & & & & \\
\hline
\end{tabular}

Frequency of discussions about stress: Threshold value to enter category

\begin{tabular}{|c|c|c|c|c|c|}
\hline Talked Always & $\begin{array}{c}0.958 \\
(0.546)\end{array}$ & $\begin{array}{c}1.953 \\
(0.608)\end{array}$ & $\begin{array}{c}1.739 \\
(0.602)\end{array}$ & -- & $\begin{array}{c}4.948 \\
(1.156)\end{array}$ \\
\hline Talked Often & $\begin{array}{l}-1.045 \\
(0.543)\end{array}$ & $\begin{array}{c}-0.289 \\
(0.548)\end{array}$ & $\begin{array}{c}-0.668 \\
(0.578)\end{array}$ & $\begin{array}{c}2.708 \\
(0.663)\end{array}$ & $\begin{array}{c}2.731 \\
(0.681)\end{array}$ \\
\hline Talked Sometimes & $\begin{array}{l}-2.828 \\
(0.591)\end{array}$ & $\begin{array}{l}-2.409 \\
(0.590)\end{array}$ & $\begin{array}{l}-3.247 \\
(0.657)\end{array}$ & $\begin{array}{c}-0.040 \\
(0.569)\end{array}$ & $\begin{array}{c}1.465 \\
(0.620)\end{array}$ \\
\hline Talked Rarely & $\begin{array}{l}-5.045 \\
(0.815)\end{array}$ & $\begin{array}{l}-4.340 \\
(0.699)\end{array}$ & $\begin{array}{l}-4.851 \\
(0.780)\end{array}$ & $\begin{array}{l}-1.819 \\
(0.585)\end{array}$ & $\begin{array}{l}-0.534 \\
(0.602)\end{array}$ \\
\hline Talked Never & -- & -- & -- & -- & -- \\
\hline $\begin{array}{l}\text { Number of Observations } \\
\text { Pseudo } \mathrm{R}^{2}\end{array}$ & $\begin{array}{c}147 \\
0.080\end{array}$ & $\begin{array}{c}147 \\
0.119\end{array}$ & $\begin{array}{c}147 \\
0.115\end{array}$ & $\begin{array}{c}147 \\
0.057\end{array}$ & $\begin{array}{c}147 \\
0.086\end{array}$ \\
\hline
\end{tabular}

$* * * \mathrm{p}<0.01, \quad * * \mathrm{p}<0.05, \quad * \mathrm{p}<0.1$

${ }^{a}$ Included as Base Reference group 
Appendix D: Table 4

Ordinal Logistic Regression Coefficient Estimates of the Relationship between Social Contact and Job Satisfaction and Career Commitment, Full Sample (Standard Errors in Brackets)

\begin{tabular}{|c|c|c|c|}
\hline & Job Satisfaction & $\begin{array}{c}10 \text { Year } \\
\text { Commitment }\end{array}$ & $\begin{array}{c}\text { Choose Teaching } \\
\text { Again }\end{array}$ \\
\hline Workload Stress & $\begin{array}{c}-0.319 * * \\
(0.153)\end{array}$ & $\begin{array}{l}-0.077 \\
(0.168)\end{array}$ & $\begin{array}{c}-0.306^{* *} \\
(0.142)\end{array}$ \\
\hline Student Behaviour Stress & $\begin{array}{c}-0.454 * * * \\
(0.144)\end{array}$ & $\begin{array}{l}-0.194 \\
(0.153)\end{array}$ & $\begin{array}{c}-0.341 * * * \\
(0.128)\end{array}$ \\
\hline Professional Relationship Stress & $\begin{array}{c}-0.389 * * * \\
(0.145)\end{array}$ & $\begin{array}{l}-0.025 \\
(0.156)\end{array}$ & $\begin{array}{l}-0.228^{*} \\
(0.129)\end{array}$ \\
\hline Societal Attitudes Stress & $\begin{array}{c}0.053 \\
(0.144)\end{array}$ & $\begin{array}{l}-0.095 \\
(0.149)\end{array}$ & $\begin{array}{l}-0.160 \\
(0.130)\end{array}$ \\
\hline Employment Conditions Stress & $\begin{array}{l}-0.163 \\
(0.151)\end{array}$ & $\begin{array}{c}-0.331 * * \\
(0.156)\end{array}$ & $\begin{array}{c}-0.304 * * \\
(0.136)\end{array}$ \\
\hline \multicolumn{4}{|c|}{ Frequency of Discussions about Stress with: } \\
\hline Family Never ${ }^{\mathrm{a}}$ & -- & -- & -- \\
\hline Family Rarely & $\begin{array}{l}-0.733 \\
(0.860)\end{array}$ & $\begin{array}{l}-0.647 \\
(1.047)\end{array}$ & $\begin{array}{l}-0.363 \\
(0.813)\end{array}$ \\
\hline Family Sometimes & $\begin{array}{l}-0.821 \\
(0.811)\end{array}$ & $\begin{array}{l}-1.029 \\
(1.004)\end{array}$ & $\begin{array}{l}-0.533 \\
(0.771)\end{array}$ \\
\hline Family Often & $\begin{array}{l}-1.270 \\
(0.835)\end{array}$ & $\begin{array}{l}-0.544 \\
(1.019)\end{array}$ & $\begin{array}{l}-0.761 \\
(0.783)\end{array}$ \\
\hline Family Always & $\begin{array}{l}-1.076 \\
(0.936)\end{array}$ & $\begin{array}{c}0.917 \\
(1.183)\end{array}$ & $\begin{array}{l}-0.041 \\
(0.885)\end{array}$ \\
\hline Friends Never ${ }^{\mathrm{a}}$ & -- & -- & -- \\
\hline Friends Rarely & $\begin{array}{l}-1.301 * \\
(0.701)\end{array}$ & $\begin{array}{l}-0.627 \\
(0.885)\end{array}$ & $\begin{array}{c}-1.352 * * \\
(0.679)\end{array}$ \\
\hline Friends Sometimes & $\begin{array}{c}-1.411 * \\
(0.739)\end{array}$ & $\begin{array}{l}-1.343 \\
(0.913)\end{array}$ & $\begin{array}{c}-1.612^{* *} \\
(0.713)\end{array}$ \\
\hline Friends Often & $\begin{array}{c}-1.895 * * \\
(0.771)\end{array}$ & $\begin{array}{l}-1.674 * \\
(0.918)\end{array}$ & $\begin{array}{c}-2.110 * * * \\
(0.730)\end{array}$ \\
\hline Friends Always & $\begin{array}{c}-2.130 * * \\
(1.052)\end{array}$ & $\begin{array}{c}-2.593 * * \\
(1.187)\end{array}$ & $\begin{array}{c}-3.086 * * * \\
(0.961)\end{array}$ \\
\hline Teachers Never ${ }^{\mathrm{a}}$ & -- & -- & -- \\
\hline Teachers Rarely & $\begin{array}{c}0.448 \\
(0.801)\end{array}$ & $\begin{array}{l}-0.660 \\
(0.970)\end{array}$ & $\begin{array}{c}0.320 \\
(0.728)\end{array}$ \\
\hline Teachers Sometimes & $\begin{array}{l}-0.333 \\
(0.814)\end{array}$ & $\begin{array}{l}-0.111 \\
(0.938)\end{array}$ & $\begin{array}{c}0.454 \\
(0.721)\end{array}$ \\
\hline Teachers Often & $\begin{array}{c}0.106 \\
(0.831)\end{array}$ & $\begin{array}{l}-0.599 \\
(0.954)\end{array}$ & $\begin{array}{c}0.418 \\
(0.744)\end{array}$ \\
\hline Teachers Always & $\begin{array}{c}0.874 \\
(0.960)\end{array}$ & $\begin{array}{c}-0.069 \\
(1.059)\end{array}$ & $\begin{array}{c}0.647 \\
(0.860)\end{array}$ \\
\hline Principal Never ${ }^{\mathrm{a}}$ & -- & -- & -- \\
\hline Principal Rarely & $\begin{array}{c}0.251 \\
(0.353)\end{array}$ & $\begin{array}{c}0.226 \\
(0.390)\end{array}$ & $\begin{array}{l}-0.055 \\
(0.323)\end{array}$ \\
\hline Principal Sometimes & $\begin{array}{c}0.281 \\
(0.405)\end{array}$ & $\begin{array}{c}-0.448 \\
(0.433)\end{array}$ & $\begin{array}{c}0.222 \\
(0.372)\end{array}$ \\
\hline
\end{tabular}




\begin{tabular}{|c|c|c|c|}
\hline Principal Often & $\begin{array}{c}-.013 \\
(0.824)\end{array}$ & $\begin{array}{l}-0.374 \\
(0.854)\end{array}$ & $\begin{array}{c}0.247 \\
(0.744)\end{array}$ \\
\hline Principal Always & $\begin{array}{c}-5.638 * * * \\
(1.908)\end{array}$ & $\begin{array}{l}-2.561 \\
(1.972)\end{array}$ & -- \\
\hline Doctor Never ${ }^{\mathrm{a}}$ & -- & -- & -- \\
\hline Doctor Rarely & $\begin{array}{c}0.043 \\
(0.321)\end{array}$ & $\begin{array}{c}0.527 \\
(0.351)\end{array}$ & $\begin{array}{l}-0.057 \\
(0.298)\end{array}$ \\
\hline Doctor Sometimes & $\begin{array}{l}-0.142 \\
(0.438)\end{array}$ & $\begin{array}{l}-0.496 \\
(0.493)\end{array}$ & $\begin{array}{c}0.062 \\
(0.397)\end{array}$ \\
\hline Doctor Often & $\begin{array}{l}1.177 * \\
(0.697)\end{array}$ & $\begin{array}{l}1.073 \\
(0.766)\end{array}$ & $\begin{array}{c}0.417 \\
(0.645)\end{array}$ \\
\hline Doctor Always & $\begin{array}{c}0.183 \\
(1.545)\end{array}$ & $\begin{array}{c}0.916 \\
(1.810)\end{array}$ & $\begin{array}{c}1.014 \\
(1.511)\end{array}$ \\
\hline $\begin{array}{l}\text { Gender and Work Experience } \\
\text { Type of Teaching Appointment } \\
\text { Beliefs about Stigma }\end{array}$ & $\begin{array}{l}\text { Included } \\
\text { Included } \\
\text { Included } \\
\end{array}$ & $\begin{array}{l}\text { Included } \\
\text { Included } \\
\text { Included } \\
\end{array}$ & $\begin{array}{l}\text { Included } \\
\text { Included } \\
\text { Included }\end{array}$ \\
\hline \multicolumn{4}{|l|}{ Threshold value to enter category } \\
\hline $\begin{array}{l}\text { Very dissatisfied } \\
\text { Somewhat dissatisfied }\end{array}$ & $\begin{array}{c}-- \\
-6.022 \\
(1.189)\end{array}$ & & \\
\hline Neither satisfied nor dissatisfied & $\begin{array}{l}-4.154 \\
(1.116)\end{array}$ & & \\
\hline Fairly satisfied & $\begin{array}{l}-3.381 \\
(1.107)\end{array}$ & & \\
\hline Very satisfied & $\begin{array}{l}-0.231 \\
(1.089)\end{array}$ & & \\
\hline Very unlikely & & -- & -- \\
\hline Somewhat unlikely & & $\begin{array}{l}-6.098 \\
(1.436)\end{array}$ & $\begin{array}{l}-4.761 \\
(1.079)\end{array}$ \\
\hline Neither likely nor unlikely & & $\begin{array}{l}-4.915 \\
(1.410)\end{array}$ & $\begin{array}{c}-3.454 \\
(1.064)\end{array}$ \\
\hline Fairly likely & & $\begin{array}{l}-4.272 \\
(1.403)\end{array}$ & $\begin{array}{l}-2.802 \\
(1.059)\end{array}$ \\
\hline Very likely & & $\begin{array}{l}-2.339 \\
(1.385)\end{array}$ & $\begin{array}{l}-1.311 \\
(1.047)\end{array}$ \\
\hline Number of Observations & 263 & 231 & 262 \\
\hline Pseudo $\mathrm{R}^{2}$ & 0.136 & 0.132 & 0.084 \\
\hline
\end{tabular}


Appendix E: Table 5

Ordinal Logistic Regression Coefficient Estimates of the Relationship between Social Contact and Job Satisfaction and Career Commitment, Elementary School Teachers (Standard Errors in Brackets)

\begin{tabular}{|c|c|c|c|}
\hline & Job Satisfaction & $\begin{array}{c}10 \text { Year } \\
\text { Commitment }\end{array}$ & $\begin{array}{c}\text { Choose Teaching } \\
\text { Again }\end{array}$ \\
\hline Workload Stress & $\begin{array}{l}-0.404 \\
(0.247)\end{array}$ & $\begin{array}{l}-0.075 \\
(0.257)\end{array}$ & $\begin{array}{c}-0.494 * * \\
(0.229)\end{array}$ \\
\hline Student Behaviour Stress & $\begin{array}{c}-0.702 * * * \\
(0.216)\end{array}$ & $\begin{array}{l}-0.595 * * \\
(0.234)\end{array}$ & $\begin{array}{c}-0.396^{* *} \\
(0.190)\end{array}$ \\
\hline Professional Relationship Stress & $\begin{array}{l}-0.565 * * * \\
(0.213)\end{array}$ & $\begin{array}{l}-0.058 \\
(0.226)\end{array}$ & $\begin{array}{l}-0.274 \\
(0.196)\end{array}$ \\
\hline Societal Attitudes Stress & $\begin{array}{c}0.150 \\
(0.203)\end{array}$ & $(0.212)$ & $\begin{array}{c}0.005 \\
(0.181)\end{array}$ \\
\hline Employment Conditions Stress & $\begin{array}{l}-0.168 \\
(0.213)\end{array}$ & $\begin{array}{l}-0.418^{*} \\
(0.239)\end{array}$ & $\begin{array}{c}-0.511 * * \\
(0.207)\end{array}$ \\
\hline \multicolumn{4}{|c|}{ Frequency of Discussions about Stress with: } \\
\hline Family Never ${ }^{\mathrm{a}}$ & -- & -- & -- \\
\hline Family Rarely & $\begin{array}{c}0.465 \\
(1.700)\end{array}$ & $\begin{array}{l}-0.673 \\
(2.172)\end{array}$ & $\begin{array}{l}1.885 \\
(1.486)\end{array}$ \\
\hline Family Sometimes & $\begin{array}{l}-0.139 \\
(1.698)\end{array}$ & $\begin{array}{l}-1.181 \\
(2.138)\end{array}$ & $\begin{array}{l}1.400 \\
(1.496)\end{array}$ \\
\hline Family Often & $\begin{array}{l}-0.646 \\
(1.652)\end{array}$ & $\begin{array}{l}-1.281 \\
(2.120)\end{array}$ & $\begin{array}{c}0.282 \\
(1.430)\end{array}$ \\
\hline Family Always & $\begin{array}{l}-0.008 \\
(1.757)\end{array}$ & $\begin{array}{l}0.008 \\
(2.238)\end{array}$ & $\begin{array}{l}1.454 \\
(1.547)\end{array}$ \\
\hline Friends Never ${ }^{\mathrm{a}}$ & - & -- & - \\
\hline Friends Rarely & $\begin{array}{c}-0.879 \\
(1.112)\end{array}$ & $\begin{array}{l}-0.780 \\
(1.395)\end{array}$ & $\begin{array}{c}0.322 \\
(1.149)\end{array}$ \\
\hline Friends Sometimes & $\begin{array}{l}-0.955 \\
(1.230)\end{array}$ & $\begin{array}{l}-0.289 \\
(1.514)\end{array}$ & $\begin{array}{c}0.124 \\
(1.309)\end{array}$ \\
\hline Friends Often & $\begin{array}{l}-1.188 \\
(1.242)\end{array}$ & $\begin{array}{l}-0.421 \\
(1.473)\end{array}$ & $\begin{array}{c}0.445 \\
(1.278)\end{array}$ \\
\hline Friends Always & $\begin{array}{l}(1.242) \\
-2.420 \\
(1.570)\end{array}$ & $\begin{array}{l}-0.709 \\
(1.839)\end{array}$ & $\begin{array}{l}-1.949 \\
(1.607)\end{array}$ \\
\hline Teachers Never ${ }^{\mathrm{a}}$ & - & - & - \\
\hline Teachers Rarely & $\begin{array}{c}-1.833 \\
(1.543)\end{array}$ & $\begin{array}{l}-0.783 \\
(2.290)\end{array}$ & $\begin{array}{l}-2.473 \\
(1.662)\end{array}$ \\
\hline Teachers Sometimes & $\begin{array}{l}-2.233 \\
(1.625)\end{array}$ & $\begin{array}{l}-1.842 \\
(2.366)\end{array}$ & $\begin{array}{l}-2.277 \\
(1.822)\end{array}$ \\
\hline Teachers Often & $\begin{array}{l}-1.873 \\
(1.643)\end{array}$ & $\begin{array}{l}-2.415 \\
(2.420)\end{array}$ & $\begin{array}{l}-2.363 \\
(1.860)\end{array}$ \\
\hline Teachers Always & $\begin{array}{l}-1.430 \\
(1.826)\end{array}$ & $\begin{array}{l}-2.271 \\
(2.541)\end{array}$ & $\begin{array}{l}-2.342 \\
(1.988)\end{array}$ \\
\hline $\begin{array}{l}\text { Principal Never } \\
\text { Principal Rarely }\end{array}$ & $\begin{array}{c}-- \\
0.742 \\
(0.536)\end{array}$ & $\begin{array}{c}-- \\
0.655 \\
(0.573)\end{array}$ & $\begin{array}{c}-- \\
-0.377 \\
(0.500)\end{array}$ \\
\hline Principal Sometimes & $\begin{array}{c}0.535 \\
(0.587)\end{array}$ & $\begin{array}{c}-0.023 \\
(0.618)\end{array}$ & $\begin{array}{c}0.593 \\
(0.560)\end{array}$ \\
\hline
\end{tabular}




\begin{tabular}{|c|c|c|c|}
\hline Principal Often & $\begin{array}{l}1.055 \\
(1.098)\end{array}$ & $\begin{array}{l}-0.276 \\
(1.120)\end{array}$ & $\begin{array}{l}-0.772 \\
(1.048)\end{array}$ \\
\hline $\begin{array}{l}\text { Doctor Nevera } \\
\text { Doctor Rarely }\end{array}$ & $\begin{array}{c}-- \\
0.091 \\
(0.458)\end{array}$ & $\begin{array}{c}-- \\
0.273 \\
(0.494)\end{array}$ & $\begin{array}{c}-- \\
-0.179 \\
(0.438)\end{array}$ \\
\hline Doctor Sometimes & $\begin{array}{c}0.656 \\
(0.706)\end{array}$ & $\begin{array}{c}0.193 \\
(0.758)\end{array}$ & $\begin{array}{c}0.302 \\
(0.649)\end{array}$ \\
\hline Doctor Often & $\begin{array}{c}0.535 \\
(1.008)\end{array}$ & $\begin{array}{c}1.901 \\
(1.202)\end{array}$ & $\begin{array}{c}1.100 \\
(0.981)\end{array}$ \\
\hline Doctor Always & $\begin{array}{c}13.924 \\
(789.145)\end{array}$ & -- & $\begin{array}{c}14.343 \\
(668.589)\end{array}$ \\
\hline Gender and Work Experience & Included & Included & Included \\
\hline Type of Teaching Appointment & Included & Included & Included \\
\hline Beliefs about Stigma & Included & Included & Included \\
\hline \multicolumn{4}{|l|}{ Threshold value to enter category } \\
\hline $\begin{array}{l}\text { Very dissatisfied } \\
\text { Somewhat dissatisfied }\end{array}$ & $\begin{array}{c}-- \\
-7.610 \\
(2.278)\end{array}$ & & \\
\hline Neither satisfied nor dissatisfied & $\begin{array}{l}-5.318 \\
(2.183)\end{array}$ & & \\
\hline Fairly satisfied & $\begin{array}{l}-4.611 \\
(2.175)\end{array}$ & & \\
\hline Very satisfied & $\begin{array}{l}-1.439 \\
(2.147)\end{array}$ & & \\
\hline $\begin{array}{l}\text { Very unlikely } \\
\text { Somewhat unlikely }\end{array}$ & & $\begin{array}{c}-- \\
-8.402 \\
(3.093)\end{array}$ & $\begin{array}{c}-- \\
-4.939 \\
(2.117)\end{array}$ \\
\hline Neither likely nor unlikely & & $\begin{array}{l}-6.151 \\
(2.921)\end{array}$ & $\begin{array}{l}-3.630 \\
(2.103)\end{array}$ \\
\hline Fairly likely & & $\begin{array}{l}-5.500 \\
(2.908)\end{array}$ & $\begin{array}{l}-2.816 \\
(2.095)\end{array}$ \\
\hline Very likely & & $\begin{array}{l}-3.112 \\
(2.878)\end{array}$ & $\begin{array}{l}-0.890 \\
(2.082)\end{array}$ \\
\hline Number of Observations & 147 & 137 & 147 \\
\hline Pseudo $\mathrm{R}^{2}$ & 0.154 & 0.197 & 0.158 \\
\hline
\end{tabular}




\title{
The Impact of Use of Manipulatives on the Math Scores of Grade 2 Students
}

\author{
Robert Scott Liggett \\ University of Saskatchewan
}

\begin{abstract}
Today's society places a lot of pressure on schools, teachers, and students to improve test scores. This paper discusses the possibility of using mathematical manipulatives to improve student test scores and students' attitudes towards mathematics. Forty-three Grade 2 students with age ranges between six and eight from a rural town in Saskatchewan were selected. They were divided randomly into two groups: the treatment group $(n=22)$ and the control group $(n=21)$ and their pre-and post-test scores compared. Findings supported the hypothesis that students in the treatment group who received the math intervention obtained higher post-test scores in comparison to their classmates in the control group.
\end{abstract}

Keywords: Mathematic pedagogy, manipulatives, elementary, mathematic skills, assessment

Robert Liggett, Ph.D., is a Sessional Lecturer and a Research Associate in the Department of Education Administration at the University of Saskatchewan. He has worked in rural and urban school systems and is a regular presenter at scholarly conferences in educational leadership. Robert is a bilingual educator with over 20 years of relevant experience who continues to consult and contribute to improving achievement in organization's goals and objectives. His research interests are in the areas of organizational theory, educational leadership, and instructional improvement.

Email: robert.liggett@usask.ca

Brock Education Journal, 26(2), 2017 
The purpose of this study was to determine the effect of manipulatives on improving student performance in mathematics. Education is constantly under the microscope. Within education, we are constantly trying to create the ideal school: one that is driven by a vision that involves an element of dreaming about the very best that can happen. Unfortunately, vision without action is merely a dream. Bringing the vision to reality requires the concerted effort of all education stakeholders, and this belief is certainly relevant as we consider mathematics pedagogy. Understandably, math skills are crucial to functioning in today's world (Burns \& Hamm, 2011; Carbonneau, Marley, \& Selig, 2013). These skills are not just important in school mathematical classes; they are important in our daily lives. Golafshani (2013) stated, "There is no doubt that everyone believes that mathematics is important, however, many students have poor math skills, which indicates that changes are needed in the methodology of teaching mathematics" (p. 140). Golafshani (2013) found that there is a growing consensus around the use of manipulatives in instructional practices.

The ancient Chinese proverb, I hear and I forget, I see and I remember, I do and I understand, suggests important aspects of learning in this area. What is the best method that an educator can use in teaching mathematics? By assumption, the best method is one in which the results will increase not only the achievement of students but also their attitude towards mathematics. How often do we hear a group of 5th Grade students say they like doing math? The chances of this happening may improve with the use of mathematical manipulatives (Burns \& Hamm, 2011; Bjorklund, 2014; Carbonneau et al.; Gauthier et al., 2004).

One may inquire as to just what constitutes a manipulative. Johnson (1993) noted, "Manipulatives are objects used for instruction that vary in shape, size, and color" (p. 10). Ultimately, manipulatives can be any objects that an innovative teacher wishes to use to improve a student's mathematical skills. Gauthier (2004) noted that manipulatives have a place not only at the elementary level but also in the higher grades. From starting with simple beans or buttons to using graphing calculators or computer software, students can explore a vast amount of mathematics that often was incomprehensible in the past. The goals of any math instruction should be to focus on helping students understand concepts. The use of manipulatives allows students to see mathematics as integration by relating procedures used in one question to procedures used in an equivalent question.

Mathematical skills are critical to functioning in today's fast moving and changing world. They are skills that students will use in their daily lives, and thus we should be aware of the importance of keeping an open mind about the use of manipulatives. Education professionals are still learning about the effective use of manipulatives. They would do well to embrace the position that math instruction should focus on helping students understand math concepts. Manipulatives used by teachers have potential when used in such a way that they promote reflection on the part of students. Golafshani (2013) found that mathematical instruction should begin with experiences that are real to students and function as symbols throughout their learning, and, clearly, manipulatives represent important tools in efforts to make mathematics more real. However, as with any tool they should be used with caution and care to optimize results. If used inappropriately, they may result in frustration or confusion, and ultimately disrupt student motivation and overall learning opportunities.

School professionals are constantly looking for methods to improve student learning. Achieving this will require effort and the use of multiple strategies or methods. The goal of this quasi- 
experimental study was to provide information about the value of manipulatives as another tool that is available to assist educators in the endeavor of improving student learning.

\section{Statement of Problem}

A report from the Canadian Broadcast Corporation (2016) noted that Saskatchewan students lag behind all provinces in reading, science and math based on a test from the Organization for Economic Co-operation and Development. Arguably, the general need for Saskatchewan students to perform well on school system and provincial assessment exams becomes increasingly pronounced year after year. This has escalated the levels of pressure on teachers and administrators. Teachers struggle to find adequate time to cover all the material demanded by the curriculum and government; they may not be convinced of the benefits of using manipulatives to aid students with different learning styles and they may believe that manipulatives are merely an additional item increasing their workload with limited promise of success (Golafshani, 2013). Many teachers continue to rely on traditional teaching methods (Mura, 1995). Golfashani (2013) found that the utilization of only one instructional approach results in meeting the learning styles of a few students while those of many other students are ignored. This in turn results in students developing negative self-concept regarding their mathematical abilities, accompanied by a consequent lack of enthusiasm for learning mathematics, which in turn would likely hinder levels of improvement in mathematical skills.

In light of the argument from Golfashani (2013) that traditional approaches are insufficient, the problem requiring investigation is: Does incorporating the use of manipulatives as a teaching method improve student learning of mathematics? Specifically: Are there group differences in the post measure test scores between students who use manipulatives and those who do not, when we control for their pre-test scores, gender and ethnicity? The one-tailed hypothesis $(\alpha=0.05)$ was that Grade 2 students who use manipulatives will perform higher in their post-test scores.

\section{Research Question}

The question becomes, to what extent does the use of mathematical manipulatives improve test scores for Grade 2 students at a school in Saskatchewan? The null hypothesis was that there is no significant difference in test scores between the two groups. This researcher hypothesized that when manipulatives are used with a group of Grade 2 students in one Saskatchewan school, the higher the post-test scores will be.

\section{Related Studies}

Teaching mathematics by using manipulatives has a long history. There has been considerable research completed on the use of manipulatives towards the goal of aiding students to better understand math concepts (Bjorklund, 2014; Burns \& Hamm, 2011; DeLoache, Scudder \& Uttal, 1997; Driscoll, 1983; Freer, 2006; Moyer \& Jones, 2006; Raphael \& Wahlstrom, 1989; Sowell, 1989; Suydam \& Higgins, 1977; Swan \& Marshall, 2010).

Some contradictory research indicated that the use of manipulatives is no more effective than other traditional methods of teaching (Eastman \& Barnett, 1979; Fennema, 1972). One such study completed by Fennema (1972) involved 95 subjects from the age ranges of 7 to 8 years old. They 
were divided into two groups: symbolic and concrete. The concrete group used Cuisenaire rods to answer some math questions and the symbolic group did not. The result was that the children learned better without the manipulative. Fennema (1972) stated, "It does not indicate that the concrete models are not always more effective than symbolic models" (p. 238). Thus, this early study demonstrated that the evidence of the benefits of using manipulatives was far from conclusive.

A study conducted by Eastman and Barnet (1979) resulted in the same conclusion. The study involved 78 university elementary majors. From this educational group, 39 students were placed in an experimental group who could use manipulatives and 39 were placed in a control group without the use of materials. Eastman and Barnett concluded, "In no instance did the experimental (hands on) group perform better than the control group, either on the paper-scored tests or on the tasks where both groups were asked to demonstrate the ability to manipulate the materials" ( $p$. 212). This research seemed to indicate that manipulatives do not aid in improving student learning of mathematics.

However, most of the research points towards the use of manipulatives as a positive tool to improve student learning within mathematics (Parham, 1983; Raphael \& Wahlstrom, 1989; Sowell, 1989; Suydam \& Higgins, 1979). Suydam and Higgins (1977) observed, "the overall point remains, however; far more of the studies favor the use of materials than favor non-use of materials" (p. 18). Much of the literature impacts this current study. This review will provide a chronological perspective regarding the importance of using manipulatives in mathematics.

Some of the earliest research completed in the 1960s and 1970s found mixed results of manipulatives such as concrete or pictorial materials in instruction. The problem with this early research (Kieren, 1971) was that it simply summarized the findings. There was no experimental process utilized as part of this research as there were no classroom observations conducted. As a result, there were no declarations on the belief that manipulatives were beneficial to students. This in turn left the readers to formulate their own conclusions about the effectiveness of manipulatives.

Friedman (1978) conducted an investigative review of 15 studies conducted prior to 1970 that were concerned with elementary school instruction. Friedman's research, dated but still relevant, showed that manipulatives were beneficial for young children but not for older children regarding their learning. In 1977 Suydam and Higgins released the first comprehensive review of over 20 studies involving activity-based learning in mathematical instruction from kindergarten to Grade 8. While this review is notably dated, their review found that using manipulative materials produced greater achievement than not using them at all the levels of elementary school.

Additional research in the 1980s (Parham, 1983) supported the research of Suydam and Higgins regarding the benefits of using manipulatives in mathematics. Further research (Driscoll, 1983; Raphael \& Wahlstrom, 1989; Sowell, 1989) found that students from kindergarten to college age, who use manipulatives in their mathematics class usually outperform those who do not. Furthermore, Sowell (1989) found that attitudes towards mathematics are improved when students have instruction with concrete materials provided by the teachers who are knowledgeable about their use. Further, a study by DeLoache, Scudder and Uttal in 1997 involving young children supported the practice of using manipulatives in mathematics by revealing that concrete objects can help children gain access to concepts and mathematical processes that might otherwise remain a mystery.

Increasingly, educators are coming to understand that manipulative materials are designed to help students at all ages and learning levels. Suydham and Higgins' (1977) investigative review of 
the literature found that the studies support the idea that activity lessons with manipulative materials are important at the elementary school levels, and at the upper elementary school levels. Research conducted by Driscoll (1983) found that results at every grade level support the importance of manipulative activity lessons. Driscoll (1983) argued that manipulatives have a place in the intermediate grades both in developing new mathematical concepts and skills and in providing remedial help to students who may be struggling.

The use of manipulatives in teaching mathematics has developed over time. Golfashani (2013) noted that teaching mathematics have moved from using beans or counters to linking cubes, fractions circles and other technologies. Johnson (1993) stated, "With the increased use of manipulatives, a new attitude is evolving towards mathematics. Mathematics is no longer a set of concrete rules to follow but rather a way of thinking. There are now reasons behind the rules" ( $p$. 11). Through many studies manipulatives have shown to be beneficial in mathematics. Ralphael and Wahlstrom (1989) found that teachers, reporting use of a variety of instructional aids, covered more content, and the use of these aids was found to strongly relate to student achievement in topics such as geometry, ratio, proportion, and percent.

Research conducted by Moyer, 2001 indicated that teachers play an important role in creating mathematical environments that provide students with representatives that enhance their thinking. Vinson (2001) stated, "using appropriate and concrete instruction materials is necessary to ensure that children understand mathematical concepts" (p. 91). Moyer and Jones (2004) completed a study of 10 female middle grades teachers during a summer institute with additional research completed at the schools of the participants. Their study indicated the value of empowering teachers towards the benefits of instruction using manipulatives. This research revealed that the students used manipulatives to aid their learning. These authors noted that "in this study students began to see these materials as one of many tools in their mathematics environment and spontaneously and selectively used the materials effectively to mediate their learning" (Moyer \& Jones, 2004, p.30). It is evident that additional research on the impact of teacher knowledge about the use and benefits of manipulatives as it pertains to instruction is needed.

Swan and Marshall (2010) revisited research on the use of manipulatives in schools. They looked at different ways in which teaching of mathematics and the subsequent learning via the use of manipulatives occurred. Swan and Marshall found that there are potential gains to be made by using mathematics manipulative materials where appropriate and employed in a systematic manner. A further study involving students from Grade 3 and 4 by Burns and Hamm (2011) concluded that manipulatives reinforced math concepts and increased average test scores. More recently, the use of manipulatives has proven to be beneficial to improve learning in preschool children. A study conducted by Björklund (2014) found that manipulatives aided learning in children as young as one and two. Björklund concluded that some manipulative objects seem to encourage certain occupations that emphasise specific learning objects more than others.

Balka (1993) indicated that by using manipulatives, students made mathematical connections that would have otherwise gone unnoticed. More current research studies (Bjorklund, 2014; Burns \& Hamm, 2011; Freer, 2006; Swan \& Marshall, 2010) provided evidence that the use of manipulatives allows students to better understand the abstract concepts of mathematics and to achieve improved results.

In short, within the literature, there appears to be a dichotomy of viewpoints regarding the benefits of using manipulatives to improve mathematic learning. While one group of researchers believes that manipulatives have little effect on improving mathematic learning; another group 
believes this is not the case. Consequently, there remains the unanswered question of whether the use of manipulatives will result in improving learning in mathematics.

\section{Theoretical Framework}

The idea that young children can learn mathematical concepts better through concrete objects comes from the learning theory of Piaget (1970). Piaget's theory of learning is based on his views of constructivism. Driscoll (2005) asserted, "Piaget also called his view constructivism, because he firmly believed that knowledge acquisition is a process of continuous self-construction. That is, knowledge is not out there, external to the child and waiting to be discovered" (p. 191). Driscoll (2005) observed that constructivism is knowledge that is constructed by learners as they attempt to make sense of their experiences. Learners are not just empty vessels waiting to be filled, but rather, they are active organisms seeking meaning.

Golfashani (2013) found that the use of manipulatives can be traced to Piaget's suggestion that children cannot comprehend abstract math through explanations and lectures. Instead, children need experiences with models and instruments in order to grasp the mathematical concepts. Researchers (Driscoll, 2005; Siegler \& Ellis, 1996) summarized Piaget's theory as one in which he argued that children go through four stages of cognitive development. In the first stage or sensorimotor stage, the age range is from birth to two years. In second stage or the preoperational stage, the age range is from two to seven years, and children using symbols and responding to objects characterize this level. The third level, labeled as concrete operational, ranges from seven to eleven years, where children are more capable of thinking logically. At the fourth level of development, the formal operations level at the age range of eleven to twelve, the children are able to demonstrate intelligence through the use of symbols. Kamii and Ewing (1996) argued that Piaget's theory is the only theory in existence that explains children's cognitive development from birth to adolescence. Using Piaget's theory as a framework provides the background for a hypothesis concerning manipulatives as an effective tool for adapting teaching methods to meet the learning styles among children experiencing difficulties with their learning of mathematics.

\section{Methods}

This study took place in a northern Saskatchewan school during the fall of 2016 over a period of two weeks. The first week involved the administration of the pre-test and the second week the post-test. The students came from the town and nearby First Nation's reserve. None of the participants had any learning or physical disabilities.

This study represented a true experimental design because of three factors: manipulation, control and randomization (Creswell, 2009). There is manipulation of a variable by using manipulatives consisting of plastic unifix cubes. Regarding control, the variable is introduced only during the post-test and only to the treatment group. Furthermore, internal validity is increased through random assignment. Random selection was followed, involving Grade 2 students from one elementary school. Random assignment was initiated by selecting the subjects' names out of a hat to be randomly assigned to the two groups. Only one class (treatment group) used manipulatives (plastic unifix cubes) to aid them in their responses to the assessment. This, therefore, was a classic treatment design using a pre-test and post-test to study the cause and effect 
where the independent variable, the use of manipulatives, was examined for its effect on the dependent variable, the test scores. Descriptive statistics were used to summarize the results with respect to the sample data. This included calculating the mean, mode and range of the test results from Grade 2 students within the school.

Inferential statistics were also utilized to look at the difference in comparing an outcome (using manipulatives) across two groups (control and treatment) across a specific time (pre-test to a posttest). Additionally, relationships were considered by focusing on how one variable (using manipulatives) might relate to another (improved tests scores). Specifically, does an increase in one variable co-occur with an increase or decrease in another?

\section{Participants}

There were 20 males and 23 females. The students' ages ranged from six to eight years with the average age range being 6.93 years. The males represented 46.5 percent of the total population whereas the females represented 53.5 percent. There were 22 students in the treatment group consisting of 11 males and 11 females with an ethnicity of 17 First Nations and 5 non-First Nations students. Of the 21 students assigned to the control group, 9 were males and 12 were females with an ethnicity of 8 First Nations and 13 non-First Nations students.

\section{Procedures}

The procedures used in the study included the establishment of a control group (CG) and a treatment group (TG) by random selection of Grade 2 students of two classrooms from the same elementary school. Random assignment was initiated by selecting the subjects' names out of a hat to be randomly assigned to the two groups. The groups were then placed into separate classrooms during the pre- and post-test phases of the study. The treatment group (TG) consisted of 22 students and the control group (CG) consisted of 21 students.

Only one class (TG) used manipulatives (plastic unifix cubes) to aid them in their responses to the post-assessment. The treatment group was given the unifix cubes once, before the post-test with the offer that they could use them if they wanted but no prior practice was given. The pre-test and post-test measures each consisted of 20 addition problems with grouping by tens.

\section{Instrument}

Because no standardized tests could be located for this type of research, assessment tools were created by the researcher and the two Grade 2 teachers whose classrooms were involved in the study. To increase the evidence of validity, the questions were based on a school division-wide math assessment that is given to all Grade 1 students at the end of the mathematical unit on number operations. In addition, the same assessment was used as a diagnostic review tool at the beginning of the Grade 2 mathematical unit on number operations. All grade two teachers taught using the same provincially-approved mathematics textbook and administered the mandated division-wide assessment exams. The manipulative that was used in the study was plastic unifix cubes. Reliability studies utilizing SPSS analytical software were conducted to complete the analysis of the tests. 


\section{Data Analysis}

A one-way ANCOVA analysis was conducted using IBM SPSS version 22, allowing the researcher to look at the effect of one or more factors on the dependent variable (post-test scores), while partialling out or removing the effect of another variable. It is the common analysis for a pre-test and post-test design (Huck \& Mclean, 1975) where the focus is on the dependent variable (post-test) while controlling for the effect of a covariate (pre-test) and for possible confounding factors (gender and ethnicity).

A repeated measures ANOVA, mean gain scores and a multiple regression could also have been other data analysis approaches utilized. However, Huck and McLean (1975) found that a repeated measures ANOVA was shown to provide unclear results, while gain scores analysis was more straightforward, they concluded that a covariance analysis was a more powerful method.

Assumptions for ANCOVA were considered. There was a reasonable correlation (i.e., between .3 and .9) between the covariate (pre-test) and the dependent variable (post-test), [Pearson's correlation $\left.(r)=.81, N=43 ; r=.90, N_{\text {control }}=21 ; r=.38, N_{\text {treatment }}=22\right]$. There was a linear relationship between pre- and post-test scores, as assessed by visual inspection of a scatterplot. There was weak evidence of homogeneity of regression slopes; however, there was no interaction evident. Tests of normality were violated for both the covariate and the dependent variable, as assessed by Shapiro-Wilk's test $(\mathrm{p}<.05)$ whereas a significance level greater than .05 was needed to be normal. While there appeared to be heterocedasticity of variance in a visual inspection of the scatterplot, there was homogeneity of variance as assessed Levene's test of homogeneity of variance $(p=.081)$ including pre-test and post-test variables. We failed to reject the null hypothesis that the variances were different at an alpha of .05. There was one outlier in the data with too low of a score on both the pre- and post-test. However, as the student was part of the class, the student's data was included in the study.

\section{Descriptive Results}

Results

Participants of this study consisted of 43 Grade 2 students at a rural elementary school in northern Saskatchewan. Appendix A: Table 1 provides percentages for participants' demographic categorical variables: gender (male and female) and ethnicity (First Nation and non-First Nation). The gender number within the control group and treatment group was slightly around the midpoint of fifty percent. However, the percentage of First Nations in the treatment group was higher than the control group. Lastly, the average age of the treatment group (6.77) as compared to the control group (6.80) differed in that the control group was on average slightly younger. Descriptive statistics show the mean and standard deviation of the covariate (i.e., pre-test scores) and the dependent continuous ratio variable (i.e., post-test scores) for the treatment group and the control group.

Appendix A: Table 2 provides the descriptive information revealing the pre-test and post-test scores, means and standard deviation by gender and ethnicity. The results appear to show an increase in the mean post-test score. The mean final post-test score of the treatment group $(\mathrm{M}=$ $97 \%, 19.4$ out of 20) was higher than the mean final post-test score of the control group $(\mathrm{M}=79 \%$, 15.8 out of 20$)$. 
Interestingly, the students who were randomly selected for the treatment group achieved higher pre-test scores than the control group. This is noteworthy due to the understanding that it is important to control for pre-test scores that score prior math performance when examining students' differences in performance with and without manipulative (post-test comparison of treatment and control group).

Appendix B: Figure 1 illustrates the pre-test and post-test mean percentage scores between the control group and the treatment group. The post-test mean percentage scores for the treatment group were higher than those of the control group.

As the gender variable did not have significant effect on the outcome, it was removed from subsequent analysis. Thus, the ANCOVA examined the effect of treatment (manipulatives) versus control on post-test scores controlling for ethnicity. The one-way ANCOVA indicates that treatment (use of math manipulatives) had a significant effect on post-test scores $F(1,42=28.33$, $p=<0.001$ ) and explained $42 \%$ of the variance in post-test results (partial eta ${ }^{2}=.42$ ) even when controlling for pre-test and ethnicity (see Appendix A: Table 3). Overall, this model accounted for $84 \%$ of the variance in the post-test scores. This finding supports the hypothesis that Grade 2 students who used manipulatives had higher post-test scores.

Appendix A: Table 2 shows that the mean post-test scores of the treatment group ( $M=97 \%)$ were higher than the mean test scores of the control group $(\mathrm{M}=79 \%)$ when taking into consideration the initial pre-test scores and their ethnicity. Thus, the post-test scores of the students in the treatment group who used manipulatives were 18 percentage points higher than the test scores of the participants in the control group who were not allowed to use manipulatives during the post-test. These results were further validated by an Analysis of Covariance (ANCOVA) test found in Appendix A: Table 3. Appendix A: Table 3 shows an ANCOVA result of $F(1,42=$ 28.33, $p=<0.001$, partial eta ${ }^{2}=.42$ ). This means that significance value of less than 0.001 existed for the post-test between the control and treatment groups. This tells us that the probability of obtaining this value by chance is 1 in 1000. The probability falls well under our alpha cut off range of acceptability that was established earlier at 1 in $20(\alpha=0.05)$. This means that our hypothesis of a group difference with the post-test is indeed supported. Thus, the results of this study did support the hypothesis that the scores in the post-test for the participants in the treatment group would be significantly higher than the scores of the participants in the control group.

\section{Discussion}

To summarize, this study began by asking the question: Are there group differences in the post measure test scores between students who used manipulatives and those students who did not when controlled for their pre-test scores, gender and ethnicity? This study provided support for the belief that manipulatives had a positive effect on Grade 2 mathematical achievement in addition tests while controlling for gender, ethnicity and pre-test scores. Consequently, manipulatives do offer benefits to students. This study provides evidence that those students who used mathematical manipulatives performed better on the post-test than those who did not use manipulatives.

\section{Additional Contributions Of This Research}

The results of the study do complement the findings of other research on using mathematical manipulatives, particularly the research conducted by Balka (1993), Björklund (2014), Burns and 
Hamm (2011), DeLoach, Sudder and Uttal (1997), Driscoll (1983), Freer (2006), Gauthier et al., (2004), Raphael and Wahlstrom (1989), Sowell (1989), and Swan \& Marshall (2010). These studies focused on research where using manipulatives with elementary and middle school students resulted in an increase in student achievement. This study is unique in that the intervention was minimal but still revealed strong results. A study such as this supports the belief that if students use mathematical manipulatives, not only does it increase their mathematical achievement scores, but it also provides them with additional methods or strategies that are critical to building problem solving skills.

The results of this study suggest that the use of mathematical manipulatives in answering mathematical problems would be an asset to improving the students' learning and development. Golafshani (2013) stated, "The fact that every classroom consists of students with different levels of ability to understand mathematical concepts means that teachers should focus on using multiple teaching strategies so that all students can benefit" (p. 139). This is something that all educators should consider with their mathematical programs in assisting students to achieve higher academic success. Eventually students will not only be more prepared to handle the demands at school, but also the later requirements of university, jobs and life. Ultimately, this study further supports the broader claim that students who are allowed to use manipulatives to answer mathematical problems will achieve better test scores than those who do not use manipulatives.

\section{Limitations}

This study revealed three limitations. Firstly, tests of normality of the sample were violated which is an important assumption of the ANCOVA analysis. The lack of a formal and recognized standardized test that could be used and repeated in the study posed a hindrance. One was created based on division wide assessment exams. Future research could consider the development of a test that was more difficult and more items to attain a greater distribution of scores.

Secondly, the size of the population in the treatment and control group was small. Only 43 Grade 2 students and only one elementary school were utilized for this study. Thus, one is limited in its ability to generalize to greater populations. Furthermore, the population and thus the sample contained no students with disabilities. The potential effects of manipulatives on mathematic learning for the population deserve to be looked at in the future. A positive finding provides some motivation to develop and further this research. The intervention provided students only the manipulative during the post-test. Future research can further examine the relative benefit of such an intervention compared to larger changes in teaching strategies.

Additional research into the effects of using manipulatives with specific genders remains unclear. This study was unable to analyze gender due to non-normality in the data, and did not include a measure of students' preferred learning styles. Future research is required to shed light upon the degree to which manipulatives differentially improve the instruction and learning of mathematics within education for specific gender and learning styles. These insights would prove beneficial to the instruction and learning of mathematics in the long term.

\section{Conclusion}

In an era when the demands for better schools, higher student learning, and school accountability are intense, any factor that directly affects an increase in student learning must be 
taken seriously. A primary goal of education is to improve and extend student learning. Ultimately, a study such as this supports the belief that when students use mathematical manipulatives, not only does it increase their mathematical achievement scores, but it may also provide them with additional methods or strategies that are critical to building problem solving skills. The results of this study suggest that the use of mathematical manipulatives in answering mathematical problems would be an asset to improving the students' learning and development. The goal is for students to be able to handle the demands at school, but also the later requirements of university, jobs and life. 


\section{References}

Balka, D. (1993). Making the connections in mathematics via manipulatives. Contemporary Education, 65(1), 19-23.

Björklund, C. (2014). Less is more - mathematical manipulatives in early childhood education. Early Child Development and Care, 184(3), 469-485.

Burns, B. A., \& Hamm, E. M. (2011). A comparison of concrete and virtual manipulative use in third-and fourth-grade mathematics. School Science and Mathematics, 111(6), 256-261.

Carbonneau, K. M., Marley, S., \& Selig, J. (2013). A meta-analysis of the efficacy of teaching mathematics with concrete manipulatives. Journal of Educational Psychology, 105(2), 380-400. doi:10.1037/a0031084

CBC News, (2016). Saskatchewan students lag behind all provinces in reading, science, math. Retrieved from http://www.cbc.ca/news/canada/saskatchewan/sask-studentsinternational-test-poor-performance-1.3885549

Creswell, J. (2009). Research design: Qualitative, quantitative and mixed methods approaches. Thousand Oakes, CA: Sage.

DeLoache, J., Schudder, K., \& Uttal, D. (1997). Manipulatives as symbols: A new perspective in the use of concrete objects to teach mathematics. Journal of Applied Developmental Psychology, 18(1), 37-54.

Driscoll, M. (1983). The role of manipulatives in elementarty school mathematics. In M. Driscoll (Ed.), Reserach within reach: Elementary school mathemathematics (pp. 21-28). Reston, Virgina: National Council of Teachers on Mathematics.

Driscoll, M. P. (2005). Psychology of learning for instruction ( $3^{\text {rd }}$ ed). Toronto: Allyn and Bacon.

Eastman, P. E., \& Barnett, J. (1979). Further study of the use of manipulatives with prospective teachers. Journal for Research in Mathematics Education, 10(3), 211-213.

Fennema, E. (1972). The realtive effectiveness of a symbolic and a concrete model in learning a selected mathematics principle. Journal for Research in Mathematics Education, 3(4), 233-238.

Freer, D. (2006). Keeping it real: The rationale for using math manipulatives in the middle grades. Mathematics teaching in the middle school, 11(5), 238-242.

Friedman, M. (1978). The manipulative materials strategy: The latest Pied Piper? Journal for Research in Mathematics Education, 9(1), 78-80.

Gauthier, R., Lawson, A., Connelly, R., Dawson, R., Enns, E., Gagnon, A., ...Smith, L. (2004). Teaching and learning mathematics. The report of the expert panel on mathematics in grades 4 to 6 in Ontario. Ontario, Canada: Ontario Ministry of Education. Retrieved from http://www.edu.gov.on.ca/eng/document/reports/numeracy/panel/numeracy.pdf

Golafshani, N. (2013) Teachers' beliefs and teaching mathematics with manipulatives. Canadian Journal for Education, 36(3), 137-159.

Huck, S., \& McLean, R. (1975). Using a repeated measures ANOVA to analyze the data from a pre-test-post-test design: A Potentially confusing task. Psychological Bulletin, 82(4), 511518.

Johnson, K. (1993). Manipulatives allow everyone to learn mathematics. Contemporary Education, 65(1), 10-11.

Kamii, C., \& Ewing, J. (1996). Basic teaching on Piaget's constructivism. Childhood Education, $72(5), 260$.

Kieren, T. (1969). Activity Learning. Review of Educational Research, 39(4), 509-522. 
Levin, B. (2001). Reforming education: From origins to outcomes. London: Routledge Falmer. Moyer, P. S. (2001). Are we having fun yet? How teachers use manipulatives to teach mathematics. Educational Studies in Mathematics, 47(2), 175-197.

Moyer, S., \& Jones, G. (2004). Controlling choice: Teachers, students, and manipulatives in mathematics classrooms. School Science and Mathematics, 104(1), 16-31.

Mura, R. (1995). Images of mathematics held by university teachers of mathematics education. Educational Studies in Mathematics, 28(4), 385-399.

Parham, J. L. (1983). A meta-analysis of the use of manipulative materials and student achievement in elementary school mathematics. Dissertation Abstracts International, 44A(96), 1-63. (UMI No. 83124771)

Piaget, J. (1970). The science of education and the psychology of the child. New York: Grossman.

Raphael, D., \& Wahlstrom, M. (1989). The influence of instructional aids on mathematics achievement. Journal for Research in Mathematics Education, 20(2), 173-190.

Siegler, R., \& Ellis, S. (1996). Piaget on childhood. Psychological Science, 7(4), 211-215.

Schmoker, M. (2004). Tipping point: From freckless reform to substantive instructional improvement. Phi Delta Kappan, 85(6), 424-432.

Schwahn, C., \& Spady, W. (1998). Why change doesn't happen and how to make sure it does. Educational Leadership, 55(7), 45-47.

Sowell, E. (1989). Effects of manipulative materials in mathematics instruction. Journal for Research in Mathematics Education, 20(5), 498-505.

Suydam, M., \& Higgins, J. (1977). Activity based recommendations from research. Columbus, Ohio: ERIC Center for Science, Mathematics, and Environmental Education.

Swan, P. \&. Marshall, L. (2010). Revisiting mathematics manipulative materials. Australian Primary Mathematics Classroom, 15(2), 13-19.

Vinson, B. (2001). A comparison of pre-service teachers' mathematics anxiety before and after a methods class emphasizing manipulatives. Early Childhood Education Journal, 29(2), 8994.

Weiss, D. (2006). Keeping it real: The rationale for using math manipulatives in the middle grades. Mathematics teaching in the middle school, 11(5), 238-242. 
Table 1

$$
\text { Appendix A: Tables 1, 2, \& } 3
$$

Descriptive Statistics

\begin{tabular}{|c|c|c|c|c|c|c|c|}
\hline & \multirow{2}{*}{$\begin{array}{l}\text { Gender } \\
\text { Male }\end{array}$} & \multicolumn{2}{|c|}{ Ethnicity } & \multicolumn{4}{|c|}{ Age } \\
\hline & & Female & $\begin{array}{l}\text { First } \\
\text { Nations }\end{array}$ & $\begin{array}{l}\text { Non-First } \\
\text { Nations }\end{array}$ & 6 & 7 & 8 \\
\hline Control Group & $45 \%$ & $52 \%$ & $32 \%$ & $72 \%$ & $75 \%$ & $43 \%$ & $40 \%$ \\
\hline $\begin{array}{l}\text { Treatment } \\
\text { Group }\end{array}$ & $55 \%$ & $48 \%$ & $68 \%$ & $28 \%$ & $25 \%$ & $57 \%$ & $60 \%$ \\
\hline
\end{tabular}

Table 2

Descriptive Statistics of Test Means by Gender and by Ethnicity

\begin{tabular}{|c|c|c|c|c|c|c|c|}
\hline & & Pre-Test & & & Post-Test & & \\
\hline & & $\begin{array}{l}\text { Percentage } \\
\text { Score }\end{array}$ & Mean & $S D$ & $\begin{array}{l}\text { Percentage } \\
\text { Score }\end{array}$ & Mean & $S D$ \\
\hline \multirow{5}{*}{$\begin{array}{l}\text { Control Group } \\
N=21\end{array}$} & All & $77.5 \%$ & 15.5 & 4.18 & $79.0 \%$ & 15.8 & 3.12 \\
\hline & Female & $76.7 \%$ & 15.3 & 4.81 & $78.3 \%$ & 15.7 & 3.39 \\
\hline & Male & $78.3 \%$ & 15.7 & 3.43 & $80.0 \%$ & 16.0 & 2.92 \\
\hline & First Nations & $78.8 \%$ & 15.8 & 3.06 & $82.5 \%$ & 16.5 & 1.60 \\
\hline & $\begin{array}{l}\text { Non-First } \\
\text { Nations } \\
\end{array}$ & $76.5 \%$ & 15.3 & 4.85 & $76.9 \%$ & 15.4 & 3.78 \\
\hline \multirow{5}{*}{$\begin{array}{l}\text { Treatme } \\
N=22\end{array}$} & All & $86.5 \%$ & 17.3 & 1.62 & $97.0 \%$ & 19.4 & 0.73 \\
\hline & Female & $88.6 \%$ & 17.7 & 1.27 & $95.9 \%$ & 19.2 & 0.87 \\
\hline & Male & $84.5 \%$ & 16.9 & 1.87 & $97.7 \%$ & 19.5 & 0.52 \\
\hline & First Nations & $85.6 \%$ & 17.1 & 1.69 & $97.1 \%$ & 19.4 & 0.71 \\
\hline & $\begin{array}{l}\text { Non-First } \\
\text { Nations }\end{array}$ & $90.0 \%$ & 18.0 & 1.22 & $96.0 \%$ & 19.2 & 0.84 \\
\hline
\end{tabular}

Table 3

Inferential Statistics Results from an ANCOVA Analysis

\begin{tabular}{lllllll}
\hline Source & $\begin{array}{l}\text { Type III Sum of } \\
\text { Squares }\end{array}$ & $D f$ & Mean Square & $F$ & Sig. & $\begin{array}{l}\text { Partial } \\
\text { Squared }\end{array}$ \\
\hline $\begin{array}{l}\text { Corrected } \\
\text { Model }\end{array}$ & $290.42^{\mathrm{a}}$ & 3 & 96.81 & 73.13 & $<.001$ & .85 \\
\hline Intercept & 84.46 & 1 & 84.46 & 63.80 & $<.001$ & .62 \\
\hline Pre-test & 150.14 & 1 & 150.14 & 113.41 & $<.001$ & .74 \\
\hline Ethnicity & 5.69 & 1 & 5.69 & 4.30 & .045 & .10 \\
\hline CGTG & 37.51 & 1 & 37.51 & 28.33 & $<.001$ & .42 \\
\hline Error & 51.63 & 39 & 1.32 & & & \\
\hline Total & 13704.00 & 43 & & & & \\
\hline $\begin{array}{l}\text { Corrected } \\
\text { Total }\end{array}$ & 342.05 & 42 & & & & \\
\hline
\end{tabular}

Brock Education Journal, 26(2), 2017 


\section{Appendix B: Figure 1}

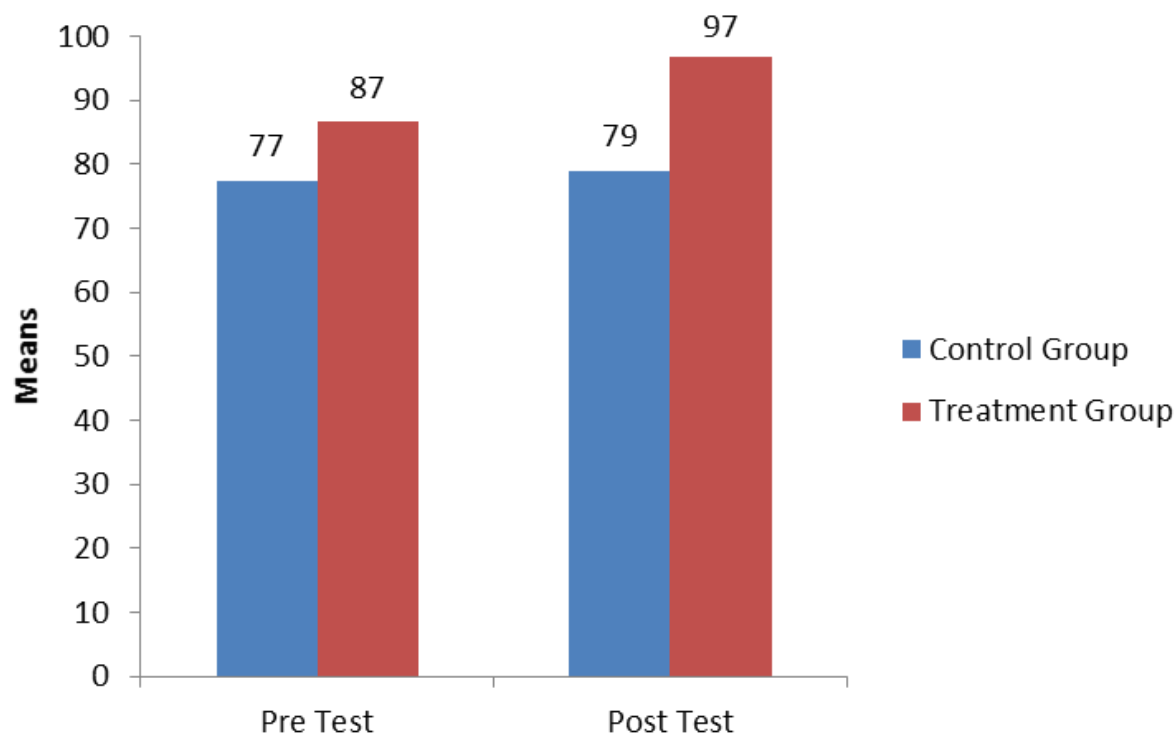

Figure 1. Pre-and post percentage means between control group and treatment group. 
Kotsopoulos, et al. The diagnosis dilemma: Dyslexia and visual-spatial ability

\title{
THE DIAGNOSIS DILEMMA: DYSLEXIA AND VISUAL-SPATIAL ABILITY
}

\author{
Donna Kotsopoulos \\ Huron University College \\ Joanna Zambrzycka \\ University of Toronto \\ Samantha Makosz \\ Wilfrid Laurier University \\ Emma Asdrubolini \\ Jovana Babic \\ Olivia Best \\ Tara Bines \\ Samantha Cook \\ Natalie Farrell \\ Victoria Gisondi \\ Meghan Scott \\ Christina Siderius \\ Dyoni Smith \\ Wilfrid Laurier University
}

\begin{abstract}
Visual-spatial ability is important for mathematics learning but also for future STEM participation. Some studies report children with dyslexia have superior visual-spatial skills and other studies report a deficit. We sought to further explore the relationship between children formally identified as having dyslexia and visual-spatial ability. Despite our best efforts, and despite recruiting from a large potential sample population, we were unable to secure a sufficient amount of participants for statistical power. Thus, our findings consider the ethical dilemma of diagnosis; namely, (1) how do children come to be tested for disabilities? And, (2) what are the potential implications, mathematical or otherwise, for children who have disabilities but are not formally identified? This report has important implications for children with disabilities and for educators.
\end{abstract}

Key words: Dyslexia, formal identification, visual-spatial ability

Contact Author: Donna Kotsopoulos, Ph.D., Provost and Dean, Faculty of Arts and Social Science, Huron University College. Email: dkotsopo@ huron.uwo.ca

Donna Kotsopoulos is the Provost and Dean, Faculty of Arts and Social Science, Huron University College, London, Ontario. Her research explores mathematical cognition across the lifespan and organizational change, leadership and resource allocation in post-secondary institutions. This research is funded by the Natural Sciences and Engineering Research Council of Canada (NSERC) and the Social Sciences and Humanities Research Council of Canada (SSHRC). 
Visual-spatial ability is comprised of the following subcomponents: spatial visualization, mental rotation, and spatial perception (Linn \& Peterson, 1985). It involves the ability to perform movements of various two- or three-dimensional figures and to mentally combine, transform, and move these figures to produce a new design (Casey et al., 2008; Clements, 2004). The research demonstrating the importance of visual-spatial ability in children is compelling. Numerous studies support the notion that visual-spatial ability promotes and is linked to mathematics learning and enhances the possibility of an individual participating in science, technology, engineering, and mathematics (STEM) careers (Lubinski, 2010; Newcombe, 2010; Tolar, Lederberg, \& Fletcher, 2009; Wai, Lubinski, \& Benbow, 2009). Noteworthy in this growing body of research is the finding that visual-spatial ability is malleable; that is, it can be taught and children can show improvement over time (Uttal et al., 2013).

Our initial aim in this research was to explore the relationship between visual-spatial ability and children formally identified with "dyslexia." Approximately 4 to $10 \%$ of the population is estimated to have dyslexia (Aleci, Piana, Piccoli, \& Bertolini, 2010; Osisanya, Lazarus, \& Adewunmi, 2013; Snowling \& Melby-Lervåg, 2016). Dyslexia is defined as "a pattern of learning difficulties characterized by problems with accurate or fluent word recognition, poor decoding, and poor spelling abilities" (American Psychiatric Association, 2013, p. 67). Aleci and colleagues (2010) have proposed that individuals with dyslexia may also have a general impairment of spatial perception whereby a crowding effect occurs in the reading of texts. However, some studies report that individuals with dyslexia have superior visual-spatial ability (Wang \& Yang, 2011) while others suggest that no significant differences exist (Duranovic, Dedeic, \& Gavrić, 2015). The research is also rather scant with younger elementary students (age 8 to 10), which was the intended foci age of this research.

Our interest in exploring the relationship between visual-spatial ability and dyslexia was motivated by the conflicting research, the proposed importance of visual-spatial ability to STEM participation, and the highly malleable nature of visual-spatial ability. As we explain shortly, despite our best efforts, we were unable to secure a sufficient amount of participants to create a statistically reliable sample, despite our research-based estimates of a potential sample population. Consequently, our findings had less to do with dyslexia and visual-spatial reasoning and more to do with the dilemma of diagnosis; namely, (1) how do children come to be tested for disabilities? And, (2) what are the potential implications, mathematical or otherwise, for children who have disabilities but are not formally identified?

We state up front that we do not take the opportunity to challenge constructions of disability. This was not our intention and nor the focus of the unintended shift in foci. Given the importance of mathematics education to a child's future, ensuring that all children have access to mathematics education, or access to additional supports if a disability is identified, should be a common global concern for teachers, educators, and policy makers. Consequently, reflecting on the outcomes of our recruitment efforts we believe is an important commentary that may serve to advance discussions of equity and school-based processes.

\section{Dyslexia and Visual-spatial Ability}

Wang and Yang (2011) looked at visual-spatial abilities in Chinese and Taiwanese students aged 10-12 with dyslexia against a control from both countries. Participants were asked to rotate a computer 3D model of a field of columns hiding a ball and were then asked to pick the correct location of the ball from the plan. Their results showed no significant difference between the groups with dyslexia and the control on accuracy. They did find a significant difference in answering speed with the participants with dyslexia answering more 
quickly than the controls. This suggests that individuals with dyslexia have improved visualspatial abilities based on faster response times without an increase in error rates.

Brunswick, Martin, and Marzano (2010) found no task in which university-aged students with dyslexia outperformed a control group when using a virtual reality test and a paper-and-pencil test. A sex effect was noted, however. Males with dyslexia outperformed females with dyslexia and unimpaired individuals on a variety of measures. This finding further suggests that superior visual-spatial ability in those with dyslexia may be sex-specific.

Testing the hypothesis that children with dyslexia have enhanced visual-spatial abilities, Duranovic, Dedeic, and Gavrić (2015) used multiple visual-spatial tasks, including the Vandenberg Test of Mental Rotation (1978), and found no significant differences between groups, which suggests that children with dyslexia have similar visual spatial abilities to unimpaired children. In contrast, Winner et al. (2011) found that high school students with dyslexia compared to a non-dyslexic group did not have enhanced visual-spatial skills but rather deficits on many visuospatial tasks. This contradicts results from Duranovic, et al. who found equivalent scores on similar tasks.

Russeler, Scholz, Jordan, and Quaiser-Pohl (2005) aimed to determine the significance of mental rotation ability in children with developmental dyslexia. These researchers compared the mental rotation abilities among children with dyslexia to children without dyslexia. They compared the results from three tests in which letters, three-dimensional figures, and coloured pictures tested the children's mental rotation abilities. Results suggested that children with dyslexia, when compared to the control group, showed a deficient in mental rotation and spatial abilities.

Jones, Branigan, and Kelly (2008) tested dyslexic and non-dyslexic university-level readers' visual attention through a visual-search task and letter position encoding through a symbols task and found significant differences in dyslexic and non-dyslexic readers, in favor of those without dyslexia. These findings support the connection between developmental dyslexia and decreased visual attention ability. Similarly, Facoetti, Corradi, Ruffino, Gori, and Zorzi (2010) tested the phonological, rapid automatized, and visual spatial attention skills in children with familial risk of developmental dyslexia to a group of children without familial risk of developmental dyslexia. Results from a comparison of the two groups suggest that children at risk show a deficit in visual-spatial attention.

Given the importance of spatial ability to mathematics and to future STEM participation, we sought to explore the relationship between children formally identified as having dyslexia and visual-spatial ability and we sought to contribute to the understudied population of school-aged children in grades three to eight. This was the preliminary phase of a sequence of studies that would then ultimately consider the malleability of spatial ability in children with dyslexia.

\section{Participants}

\section{Intended Study}

Students were recruited from 10 elementary schools from a mid-sized urban center. Only students "formally" identified with dyslexia were invited to participate in our research. The list of potential participants was first established by each of the school's special education teacher who oversees education plans provided to students with exceptionalities, and who would have knowledge of those students formally identified.

In our own jurisdiction, there is a distinction between students whose exceptionalities have been identified either formally or informally - and this may also be common in other school boards. A formal identification, as we explain shortly, would have involved psychometric assessments and would be more reliable in our view than informal and perhaps inconsistent identification of students by teachers. For this research, the psychometric 
assessments may have overtly stated "dyslexia" as a diagnosis or would have indicated "difficulties characterized by problems with accurate or fluent word recognition, poor decoding, and poor spelling abilities" (American Psychiatric Association, 2013, p. 67).

In our jurisdiction, parents or the school principal can initiate the formal identification of a student and this occurs through a review and recommendation by the Identification, Placement and Review Committee (IPRC). This committee is legislated to identify exceptional students and to determine an action plan for meeting the needs of the student. The IPRC includes numerous education professionals and formal identification usually involves significant psychometric assessment, usually at the expense of the school board. All psychoeducational assessments of children aged 18 and younger require informed consent from parents. Long delays for school board funded testing of children are often reported by parents and teachers (Blackstock, 2016); consequently, some parents pay for private psychometric assessment to expedite the formal identification (Dunn, 2006).

A student who has been reviewed by the IPRC is considered to be formally identified. An individual education plan (IEP), which outlines the special education program and learning goals for the student, must be completed within 30 school days of a student's formal identification by the IPRC (OME, 2002). The formal identification ensures services and supports for the student because there is an explicit and legal obligation on behalf of the school board to be accountable to the recommendations of the IPRC. This is not to say that those students who have been informally identified are not receiving appropriate services. These students may also have IEPs. However, there is no formal accountability to the IPRC. We surmise that there are advantages for a formal identification or otherwise such a process would not exist. Formal identification creates an obligation by the school to accommodate or modify services and supports based on the needs of the student, and these obligations are not subject to constraints that may arise in terms of budget cutbacks for teaching support, resources, and so forth.

We take the time to explain this process of formal identification in our jurisdiction because our results are directly impacted because of this process. Using conservative population estimates of the prevalence of dyslexia (approximately 4\%), based on the population of students $(n=4138)$ at the 10 elementary schools participating in the study, we anticipated approximately 165 potential participants. Instead, only 25 students were formally identified across the 10 schools, of which 13 parents agreed to allow their child to participate in the study (boys $n=8$, girls $n=5$ ). Participants ranged from the third to eighth grade. Therefore, less than $1 \%$ of the students at these 10 schools were formally identified as having dyslexia and thus officially receiving the supports and services necessary to develop their reading and/or their writing.

\section{Measures and Procedures}

A variety of measures were collected for the students that agreed to participate. These included official school-level achievement data, psychometric assessment, and a demographic questionnaire completed by the parents. The children were then tested individually on different days and in different locations as they were tested at their respective schools. Students were tested on spatial transformations (Levine, Huttenlocher, Taylor, \& Langrock, 1999), the Piagetian Water-Level-Task (Quaiser-Pohl, Lehmann, \& Eid, 2004), the Rod-and-Frame Test (Quaiser-Pohl et al., 2004), and the Vandenberg Mental Rotations Task (MRT) (Quaiser-Pohl et al., 2004; Shepard \& Metzler, 1971; Vandenberg \& Kuse, 1978). The tasks were selected because they were either previously used or had similar properties to in other studies to explore visual-spatial ability and thus the results would enable us to consistently contribute to prior research findings. These tests were also selected because they were easily administered by 
classroom teachers and thus could be used in the future to assist with identifying students if our results should a robust pattern.

Given the very limited amount of participants, and the wide range in ages and grades, we do not report the full results of this testing in this paper given the lack of statistical power in the small sample $(n=11)$. As outlined, our focus shifted to consider why so few students were formally identified and the implications of this unexpected and corollary finding for children with exceptionalities.

\section{Educational Implications}

From the early on during the recruitment period of the research, it became apparent that there were not going to be enough students to compose an adequate sample. However, this led to what may be an even more important question regarding identification of students with learning disabilities and potential equity issues in special education. To make clear, at each of the schools there were students who were informally identified as having reading and/or writing challenges. These students were receiving some level of supports and services if informally identified and we make no judgement on the quality of what is provided for these students. Nevertheless, given our criteria for inclusion in this research, these students were not invited to participate because their diagnosis was not independently confirmed through psychometric assessments and formalized through the IPRC.

It may be that there were, by chance, few students with dyslexia compared to what might be expected. Or, it may be that some parents have declined to have their child formally identified for various reasons, such as fear of stigma. Parents have the right to refuse sharing the psychometric assessments with the school, including any diagnoses (Ontario Psychological Association, 2013). This concern may have contributed partially to the low number of possible participants for our study but, in our view, not sufficiently enough to account fully for the very low number of formally identified students.

In each of the participating schools, we were told consistently and clearly by the special education teachers that quotas existed on the number of students that were funded annually for psychometric assessment. As a result, a plausible explanation is that students who may need to be tested and identified formally are not because of limited funding. Our results raise important ethical questions about who gets tested, who gets identified formally, and to what extent are instances of comorbidity of other learning challenges missed because formal testing and IPRC review is not occurring?

The discrepancy between how many students actually struggle with reading and the number who are formally identified is problematic. Firstly, identification is important because many students have difficulties that extend beyond reading. Dyslexia tends to "co-occur with other disorders, including specific language impairment, speech sound disorder, and attentiondeficit/hyperactivity disorder" (Snowling \& Melby-Lervåg, 2016). Students who are not identified are not only going to continue to struggle with reading, but with potentially other comorbid disorders that are perhaps less obvious, and may impede cognitive and social development in other ways. Consequently, a lack of formal identification may also prevent learning about other challenges that might otherwise go undetected.

For example, a comorbid diagnosis of dyslexia and dyscalculia (i.e., problems processing numerical information, learning arithmetic facts, and performing accurate or fluent calculations) occurs in approximately $40 \%$ to $65 \%$ of identified cases (Barbaresi, Katusic, Colligan, Weaver, \& Jacobsen, 2005; Osisanya et al., 2013; Wilson et al., 2015), despite the fact that they are proposed to have different cognitive profiles (Landerl, Fussenegger, Moll, \& Willburger, 2009). We would assert that children are more likely to be tested for dyslexia than dyscalculia, although no research was found to indicate the prevalence of one over the other.

Brock Education Journal, 26(2), 2017 
Secondly, identification can lead to early intervention, which ensures that the student receives support before they get too far behind their peers. Knivsberg, Reichelt and Nødland (1999) suggest that symptoms become apparent during the pre-school years, meaning that intervention can begin before students have a chance to fall too far behind. Reading skills are crucial in most school disciplines, raising the concern that students with poor reading skills will fall behind in multiple subjects. For example, Beringer et al. (2008) found that students with dyslexia also had problems with both handwriting and written composition, again going back to the comorbidity of disorders. Therefore, early identification ensures that support is available for not only reading, but also all compounding academic difficulties.

Finally, in the absence of formal identification, accountability and the full range of services and supports may not be accessible to a student, or potentially even scaled back in instances where resources are limited. According to Dunn (2006), teacher's observations are not given equal weight to psychoeducational assessments in terms of support recommendations. In fact:

In order for a student to be classified, the standardized assessment scores completed by the school psychologist or speech and language pathologist had to render a profile commensurate with an exceptionality category (e.g., learning disability). If this was not the case, the student would be considered as a slow learner and denied the services he/she needed (Dunn, 2006 ,p. 129).

When recruiting participants for this study, many special education teachers suggested that the sample size could be increased by including those students with IEPs for reading difficulties, despite not being formally diagnosed. While it may be viewed that our inclusion criteria was a limitation of this research, depending on teacher judgment only of learning challenges would have opened up greater concerns over the validity of our participant sample and thus was not considered at any time.

The observation by the special education teachers that more students could be included based on identifications done by teachers, demonstrates that there are students who are informally identified and receiving some level of support. However, the validity of the identification, the extent of the support, and whether the support adequately addresses all the learning challenges of the student would be uncertain without the psychometric assessments and the IPRC review. Moreover, the extent to which the support and services might continue consistently through a child's education and whether these supports and services are scaled back in times of fiscal constraint are unknown. To be clear, we make no rehabilitation judgement; that is, we are not suggesting that formal diagnosis results in beneficial outcomes for the student or more beneficial outcomes than that of an informally identified student. Rather, formal identification results in consistent and sustained learning support services and may also yield comorbid diagnoses.

Perhaps one of the most important reasons that so few formal identifications are occurring is due to the high costs of psychometric assessments, approximately $\$ 1,500$ to $\$ 2,500$ in Ontario (Blackstock, 2016). As a result, many of the schools report that there are restrictions placed on how many students they can recommend for these assessments. For low socioeconomic status (SES) schools in particular, which tend to have higher levels of students with special education needs (People for Education, 2013), sending every student for testing is just not practical. Regardless, parents who can afford the assessments can expedite the process.

Parents of our student participants were also asked in which grade they noticed their child had a reading difficulty and also the grade their child was formally diagnosed. The number of years between the onset of reading difficulties and formal diagnosis was as follows: $15 \% 0$ years, $8 \% 1$ year, $23 \% 2$ years, $38 \% 3$ years, $8 \% 4$ years, and $8 \% 5$ years. Therefore, the majority of children had to wait three years for a formal diagnosis. Evidence from our own small sample of students supports an SES advantage for formal identification. We found that 
$61.5 \%$ of the mothers of participants had some form of post-secondary education, which is said to be a predictor of high SES (Mistry, Biesanz, Chien, Howes, \& Benner, 2008). This means that diagnosis and support goes to perhaps to those who can afford it rather than those who are most in need. Alternatively, parents from higher socioeconomic backgrounds tend to advocate more for their children (Lareau, 1987), and this may offer a partial explanation for the higher SES amongst those children formally identified in the small sample.

Our intent in this research was to examine the visual-spatial abilities of elementary students with dyslexia. Given the mixed research in this area, the importance of visual-spatial reasoning, and its highly malleable nature, this goal is still laudable - and more research is still needed. Our unexpected results of low formal identification suggest that research that comparative research that explores learning and longitudinal socio-economic implications for learners who are formally versus informally identified as having exceptionalities is also, and perhaps urgently, needed. Research of this nature would also investigate the extent to which teacher judgements are sufficient for developing plans of action for special education, in the absence of specialized professional support and recommendations (i.e., educational psychologist). Whether a student is truly marginalized over the long-term by receiving only an "informal" identification is unknown. From an equity perspective, research of this nature should be a priority for all stakeholders, including researchers, parent groups, and also schools.

\section{Acknowledgement}

Sincere thanks to Dr. Kristiina Montero and Dr. Steve Sider, Wilfrid Laurier University, who provided guidance and input to the authors during the research. 
Kotsopoulos, et al. The diagnosis dilemma: Dyslexia and visual-spatial ability

\section{References}

Aleci, C., Piana, G., Piccoli, M., \& Bertolini, M. (2010). Developmental dyslexia and spatial relationship perception. Cortex, 48(4), 466-476.

American Psychiatric Association. (2013). The Diagnostic and Statistical Manual of Mental Disorders, DSM-V (Fourth ed.). Washington: Author.

Barbaresi, W. J., Katusic, S. K., Colligan, R. C., Weaver, A. L., \& Jacobsen, S. J. (2005). Math learning disorder: Incidence in a population-based birth cohort, 1976-82. Ambulatory Pediatrics, 5(5), 281-289.

Berninger, V. W., Nielsen, K. H., Abbott, R. D., Wijsman, E., \& Raskind, W. (2008). Writing problems in developmental dyslexia: Under-recognized and under-treated. Journal of School Psychology, 46(2008), 1-21.

Blackstock, E. (2016). Waitlists for Psychoeducational Assessment in Ontario, http://www.vbpsychology.com/waiting-lists-for-psychoeducational-assessments-inontario: Valetin \& Blackstock Psychology.

Brunswick, N., Martin, G. N., \& Marzano, L. (2010). Visuospatial superiority in developmental dyslexia: Myth or reality? Learning and Individual Differences, 20(5), 421-426.

Casey, B. M., Andrews, N., Schindler, H., Kersh, J. E., Samper, A., \& Copley, J. (2008). The development of spatial skills through interventions involving block building activities. Cognition and Instruction, 26(3), 269-309.

Clements, D. H. (2004). Geometric and spatial thinking in early childhood education. In D. H. Clements, J. Sarama \& A.-M. Di Biase (Eds.), Engaging young children in mathematics: Standards for early childhood mathematics education (pp. 267-298). Mahwah, NJ: Lawrence Earlbaum Associates, Inc.

Dunn, M. W. (2006). It was written all over him: Classroom teachers' referral criteria for special education services. International Journal of Special Education., 21(2), 124139.

Duranovic, M., Dedeic, M., \& Gavrić, M. (2015). Dyslexia and visual-spatial talents. Current Psychology, 34(2), 207-222.

Facoetti, A., Corradi, N., Ruffino, M., Gori, S., \& Zorzi, M. (2010). Visual spatial attention and speech segmentation are both impaired in preschoolers at familial risk for developmental dyslexia. Dyslexia. , 16(3), 226-239.

Jones, M. W., Branigan, H. P., \& Kelly, M. L. (2008). Visual deficits in developmental dyslexia: relationships between non-linguistic visual tasks and their contribution to components of reading. Dyslexia, 14(2), 95-115.

Knivsberg, A., Reichelt, K., \& Nødland, M. (1999). Comorbidity, or coexistence, between dyslexia and attention deficit hyperactivity disorder. British Journal of Special Education, 26(1), 42-47.

Landerl, K., Fussenegger, B., Moll, K., \& Willburger, E. (2009). Dyslexia and dyscalculia: Two learning disorders with different cognitive profiles. Journal of Experimental Child Psychology, 103(3), 309-324.

Lareau, A. (1987). Social class differences in family-cchool relationships: The importance of cultural capital. Sociology of Education, 60(2), 73-85.

Levine, S. C., Huttenlocher, J., Taylor, A., \& Langrock, A. (1999). Early sex differences in spatial skill. Developmental psychology, 35(4), 940.

Linn, M. C., \& Peterson, A. C. (1985). Emergence and characterization of sex differences in spatial ability: A metaanalysis. Child Development, 56, 1479-1498.

Lubinski, D. (2010). Spatial ability and STEM: A sleeping giant for talent identification and development. Personality and Individual Differences, 49, 344-351. 
Kotsopoulos, et al. The diagnosis dilemma: Dyslexia and visual-spatial ability

Mistry, R. S., Biesanz, J. C., Chien, N., Howes, C., \& Benner, A. D. (2008). Socioeconomic status, parental investments, and the cognitive and behavioral outcomes of lowincome children from immigrant and native households. Early Childhood Research Quarterly, 23(2), 193-212.

Newcombe, N. S. (2010). Picture this: Increasing math and science learning by improving spatial thinking. American Educator, 34(2), 29-43.

OME. (2002). The Individual Education Plan (IEP): A Resource Guide. Toronto, ON.

Ontario Psychological Association. (2013). Professional practice guidelines for school psychologists in Ontario [Electronic Version]. Retrieved August 16, 2016, from http://psych.on.ca/OPA/media/Public/OPA\%20Guidelines\%20and\%20Reviews/profe ssional-practice-guidelines-for-school-psychologists-in-ontario-2013.pdf

Osisanya, A., Lazarus, K., \& Adewunmi, A. (2013). Manifestations of dyslexia and dyscalculia. Journal of International Special Needs Education, 16(1), 40-52.

People for Education. (2013). Mind the Gap: Inequality in Ontario's Schools. from http://www.peopleforeducation.ca/wp-content/uploads/2013/05/annual-report-2013WEB.pdf

Quaiser-Pohl, C., Lehmann, W., \& Eid, M. (2004). The relationship between spatial abilities and representations of large-scale space in children--a structural equation modeling analysis. Personality and Individual Differences, 36(1), 95-107.

Rüsseler, J., Scholz, J., Jordan, K., \& Quaiser-Pohl, C. (2005). Mental rotation of letters, pictures, and three-dimensional objects in German dyslexic children. Child Neuropsychology, 11(6), 497-512.

Shepard, R. N., \& Metzler, J. (1971). Mental rotation of three-dimensional objects. Science, $171,701-703$.

Snowling, M. J., \& Melby-Lervåg, M. (2016). Oral language deficits in familial dyslexia: A meta-analysis and review. Psychological Bulletin, 1-48.

Tolar, T. D., Lederberg, A. R., \& Fletcher, J. M. (2009). A structural model of algebra achievement: Computational fluency and spatial visualisation as mediators of the effect of working memory on algebra achievement. Educational Psychology, 29(2), 239-266.

Uttal, D. H., Meadow, N. G., Tipton, E., Hand, L. L., Alden, A. R., Warren, C., et al. (2013). The malleability of spatial skills: A meta-analysis of training studies. Psychological Bulletin, 139(2), 352-402.

Vandenberg, S. G., \& Kuse, A. R. (1978). Mental rotations. A group test of threedimensional spatial visualization. Perceptual and Motor Skills, 47, 599-604.

Wai, J., Lubinski, D., \& Benbow, C. P. (2009). Spatial ability for STEM domains: Aligning over 50 years of cumulative psychological knowledge solidifies its importance. Journal for Educational Psychology, 101(4), 817-835.

Wang, L., \& Yang, H. (2011). The comparison of the visuo-spatial abilities of dyslexic and normal students in Taiwan and Hong Kong. Research in developmental disabilities, 32(3), 1052-1057.

Wilson, A. J., Andrewes, S. G., Struthers, H., Rowe, V. M., Bogdanovic, R., \& Waldie, K. E. (2015). Dyscalculia and dyslexia in adults: Cognitive bases of comorbidity. Learning and Individual Differences, 37(0), 118-132.

Winner, E., von Karolyi, C., Malinsky, D., French, L., Seliger, C., \& Ross, E. (2011). Dyslexia and visual-spatial talents: Compensation vs deficit model. Brain and Language, 76(2), 81-110. 


\section{BOOK REVIEW}

Title:

Author:

Publisher:

Year of Publication:

Reviewed by:
Ipsative Assessment:

Motivation Through Marking Progress
Gwyneth Hughes

London UK: Palgrave Macmillan.

In this book, Hughes makes a case for the use of ipsative (self-referenced) assessment, either in place of or in addition to the current regimen of norm-referenced and criterion-referenced assessment predominant in higher education. Hughes offers insights into the current practice of competitive assessment and social selection that characterizes assessment across higher education. In her book, Hughes demonstrates the linkages among ipsative assessment, student feedback, and formative assessment. Hughes has worked extensively in the area of ipsative assessment and clearly has a broad understanding of the topic.

The book comprises two parts: The first six chapters present Hughes's argument for ipsative assessment, while the last five chapters offer some limited evidence of ipsative assessment practices, and a discussion of the obstacles to initiating and inculcating educational innovation and change, particularly changes in assessment practices.

Hughes defines ipsative assessment as involving comparisons between past and current work to identify a learner's growth over time, rather than progress toward an external set of criteria. Therefore, ipsative assessment is an internal or self-referenced assessment. The use of ipsative assessment requires knowledge of a learner's prior accomplishments to make a comparison with current work. In practice, such comparisons may be difficult, because the assessor needs access to a student's work history. Hughes points out that ipsative assessment is compatible with selfassessment as students have the most knowledge about their respective prior levels of knowledge. However, the author argues that accurate self-assessment requires the student to be trained in assessment. Hughes recognizes that a lack of training in this area may entail reduced reliability, which is an issue for institutional assessment policies.

Hughes points out that the current competitive assessment regimen values reliability and objectivity, as the primary perceived function of education is social selection, i.e. a major role for higher education is to identify those who, based on merit, should benefit from the scarce resources of the academy and the better employment opportunities that follow. Education is utilized for certification and credentialing, therefore educational benchmarks for success must possess a functionality recognized by society as being universally accepted and replicable.

Ipsative assessment occurs in other venues outside education. Hughes gives the example personal best which is common in sports, where a competitor strives to improve against his/her previous best effort. Sports combines all three assessment regimens: Winning is clearly normreferenced; attaining a qualifying standard is criterion-referenced; and attaining a personal best is 
ipsative, and by far the most common attainment in sports. This is a rare example of harmony across the three assessment regimens, although not all three are equally valued by society.

Hughes states that there is confusion and conflict in the current education system She points out that the current system emphasizes a deficit rather than attribute model (Hughes, 2014a). Under the deficit model, attention is focused on what students lack or cannot do rather than the attribute model, which identifies what students know or can do. Competitive assessment also: conflicts with research demonstrating the effectiveness of assessment for learning; is often demotivating, especially for low-achieving students; tends to focus on summative assessments, thus limiting feedback's usefulness to students; usually involves one-off snapshots of student achievement, rather than viewing assessment as longitudinal and progressive; and promotes an entity rather than fixed theory of intelligence (Dweck, 1999, 2006). Hughes claims that ipsative assessment models address all the issues discussed above.

A major strength of Hughes' book is her argument that ipsative assessment is more congruent with assessment for learning, as well as congruent with giving and utilizing quality feedback, compared to other assessment regimens.

Assessment for learning is based on the theory of social constructivism, whereby learners engage with others to construct and refine their knowledge. Hughes notes that "Assessment for learning ... draws on the discourse of learner empowerment, self-respect, self-reliance and lifelong learning that challenge the ideology of meritocracy" (p. 31). She argues that ipsative assessment supports all the above dimensions. Hughes supports her argument with a summary of research by Nicol and Macfarlane-Dick (2006) as well as Hughes' own previous work. Assessment for learning is an important strategy. In a synthesis of more than 8,000 metaanalyses, Hattie (2009) found that assessment for learning (formative assessment) has a very significant effect size of 0.90 with respect to student achievement.

Hughes also makes a persuasive case for the relationship between ipsative assessment and the provision of feedback. In the same study cited above, Hattie (2009) found an effect size of 0.73 for feedback with respect to student achievement, without differentiating for the quality of the feedback. Hughes comments that feedback is often seen as a gift that instructors give to students, as part of a one-way transmission of information. Research shows that this method of providing feedback is of limited value (Hattie \& Timperley, 2007). Rather, Hughes indicates that feedback should be a dialogue between student and assessor, and that ipsative assessment is very well suited to this dialogue. She states that feedback involves recognition of a baseline starting point for students' knowledge, progress in their understanding, and discussion concerning next steps.

A particular strength of Hughes' book is her discussion of three dimensions to assessor's responses: feed up, which allows students to answer questions about goals; feed back, which lets students respond based on their current level of knowledge; and feed forward, which provides students with the ability to answer questions about where they need to or wish to go next (Hattie \& Timperley, 2007; Hughes, 2011, 2014a). Hughes argues for a model for effective feedback by Hattie and Timperley (2007) that identifies four levels of feedback: task level, process level, selfregulation level, and self level. Hughes describes the Hattie and Timperley hierarchy of effective feedback, with the most effective levels being task and process and argues convincingly that these levels are particularly addressed in ipsative feedback.

Hughes provides an interesting example of ipsative assessment in the second section of her book. In discussing the possibility of a dual assessment regimen — whereby formative assessment 
is ipsative but summative assessment is criterion-referenced-she describes a typical doctoral program. In most doctoral programs, candidates first develop their skills and knowledge. This portion of the doctorate is typically ipsative, with supervisors identifying areas of strength (and gains), areas requiring further development, and progress toward $\mathrm{PhD}$ candidates' goal of beginning their doctoral research. The dissertation and defense are criterion-referenced, with objective standards that must be met to attain the degree. Since this is a common assessment format in many doctoral programs, Hughes cites doctoral programs as an example of an assessment regimen in which ipsative assessment is already in place.

Hughes limits evidence supporting ipsative assessment in practice to her own research. She provides two small case studies of fully ipsative assessment regimens, both structured and investigated by Hughes herself. The book would have benefited from the inclusion of studies of ipsative assessment by other researchers. Hughes is pragmatic when discussing the potential for fully ipsative assessment regimens in higher education. She recognizes that the goals of education are typically at odds with completely ipsative assessment, since this violates the requirements for reliability and replicability necessary for the goal of social selection and credentialing.

Additionally, Hughes' claim that ipsative assessment promotes a holistic rather than fragmented view of curriculum is questionable. While this claim may have merit, Hughes offers insufficient supporting evidence or argument for the claim. Hughes also claims that ipsative assessment is low stakes relative to the high stakes competitive assessments that dominate higher education. This point needs more justification and seems at odds with her description of ipsative assessment as part of assessment in a doctoral program. Finally, Hughes discussion of whether ipsative assessment might in fact cause other assessment issues to arise is relegated to a brief half page near the end of the book. This point should be explored more fully.

The major attribute of ipsative feedback is the view of assessment as a longitudinal process that involves a dialogue between assessor and assessed. This stance is based on a social constructivism theory of learning coherent with assessment for learning, Moreover, such an attitude towards assessment has positive implications for learners' intrinsic motivation, selfregulation, incremental theory of intelligence, and propensity to view learning as a life-long process. Hughes's book offers an excellent discussion of the attributes of ipsative assessment, while recognizing the limitations of a fully ipsative assessment paradigm. Substantial additional research is needed to more fully investigate how ipsative assessment might be implemented in education. Nonetheless, Hughes's book identifies a potentially beneficial strategy for assessment, and raises awareness of a concept that certainly belongs in the assessment discussion. 


\section{References}

Dweck, C. (1999). Self-theories: Their role in motivation, personality, and development. Philadelphia, PA: Psychology Press.

Dweck, C. (2006). Mindset: The new psychology of success. New York, NY: Ballantine Books.

Hattie, J. (2009). Visible learning: A synthesis of over 800 meta-analyses relating to achievement. London, UK: Routledge.

Hattie, J., \& Timperley, H. (2007). The power of feedback. Review of Educational Research, 77(1), 81-112. http://dx.doi:10.3102/003465430298487

Hughes, G. (2011). Towards a personal best: A case for introducing ipsative assessment in higher education. Studies in Higher Education, 36(3), 353-367. http://dx.doi:10.1080/03075079.2010.486859

Hughes, G. (2014a). Ipsative assessment: Motivation through marking progress. London UK: Palgrave Macmillan.

Hughes, G. (2014b). Use of self-referential (ipsative) feedback to motivate and guide distance learners. Open Learning, 29(1), 31-44. http://dx.doi:10.1080/02680513.2014.921612

Nicol, D., \& Macfarlane-Dick, D. (2006). Formative assessment and self-regulated learning: A model and seven principles of good feedback practice. Studies in Higher Education, 31(2), 199-218. http://dx.doi:10.1080/03075070600572090 